\title{
Beyond Visualization: Spatial Presence and Virtual Heritage
}

\author{
by
}

\section{Nicole Howell, Dip.Tech, B.Arch.Sc.}

A thesis submitted to the Faculty of Graduate and Postdoctoral Affairs in partial fulfillment of the requirements for the degree of

Master of Architecture

Carleton University

Ottawa, Ontario

(C) 2017, Nicole Howell 


\begin{abstract}
Beginning with the hypothesis that cultural heritage embodies both tangible and intangible values in its definition; this thesis proposes that if we are to truly experience heritage through virtual means, both sets of values must be incorporated into the experience. The project presented in this paper exists in the intersection of three fields of study: cultural heritage, virtual reality, and video games.
\end{abstract}

Virtual reality technology has allowed us the opportunity to accurately visualize the physical characteristics of a space around us, with the emphasis residing primarily on the visual and sensory experience. Immersive video games place emphasis on a user's cognitive or emotional experience in virtual space by creating relationships and building value systems within the game worlds. Through the sensory stimuli of the former, and the cognitive and emotional stimuli of the latter, a combined methodology is proposed to create a fully immersive virtual environment that allows a user the opportunity to experience the intangible emotional and cognitive values of architectural heritage in addition to the already well-established tangible spatial experiences achieved by virtual reality.

This thesis begins with establishing a definition of cultural heritage and a critical analysis of existing technologies and methodologies used in its representation through virtual heritage. It is then followed by a discussion of the video game industry, and how it addresses the elements lacking in the previous analysis, with emphasis on intangible cognitive experiences. Finally, a characteristic framework that merges the successes of both industry methodologies is proposed to demonstrate the possibilities of experiencing 
the intangible values of heritage, using the Carbide Willson Mill ruins site in Gatineau Park as a project example. 


\section{Acknowledgements}

I would like to thank my advisor, Dr. Stephen Fai, for his invaluable support and guidance, not only throughout this project but also through my educational career at Carleton University. I would also like to extend my thanks to the Carleton Immersive Media Studio Lab. 


\section{Table of Contents}

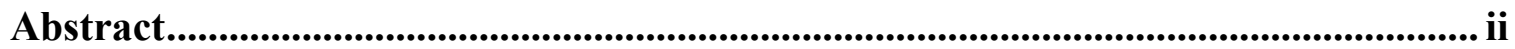

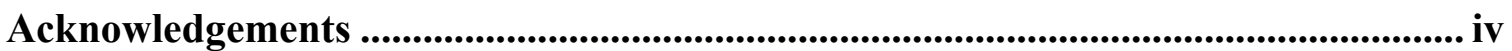

Table of Contents ...................................................................................................................... v

List of Illustrations...................................................................................................................... vii

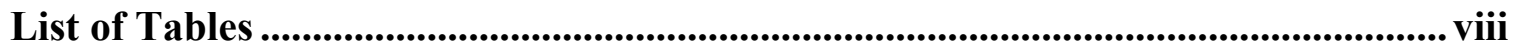

1 Chapter: Introduction ........................................................................................... 1

2 Chapter: Cultural Heritage ............................................................................................. 6

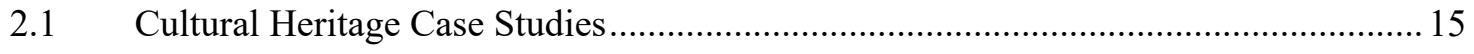

2.1.1 Ise Jingu Grand Shrine .................................................................................... 16

2.1.2 Anne Frank House......................................................................................... 17

3 Chapter: Virtual Heritage........................................................................................ 19

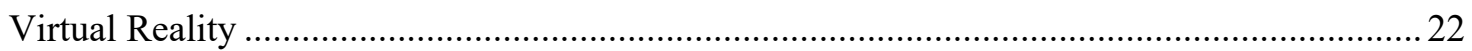

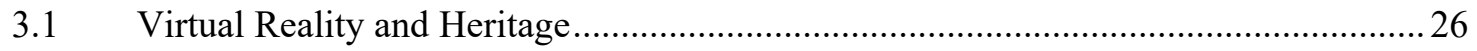

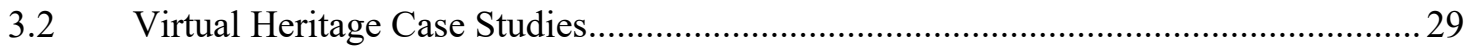

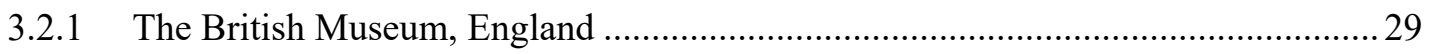

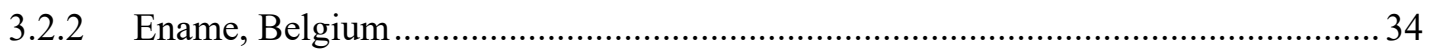

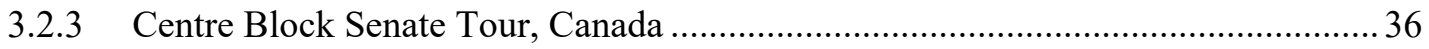

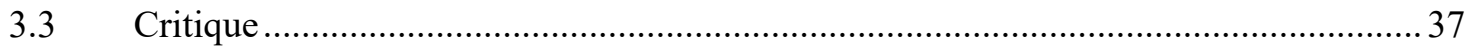

4 Chapter: Intangible Values Unlocked in Video Games ............................................. 39

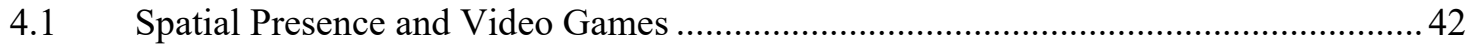

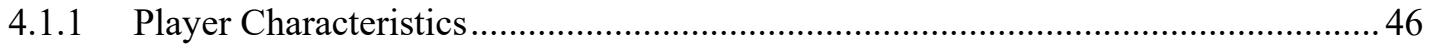

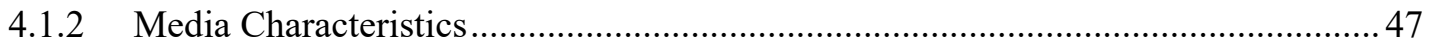

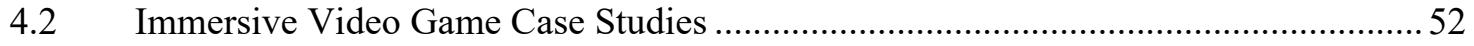




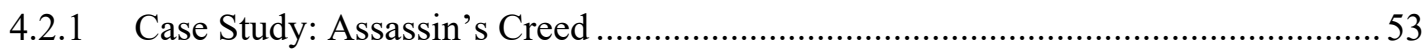

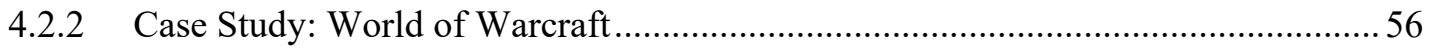

5 Chapter: Spatial Presence in Virtual Heritage .......................................................... 60

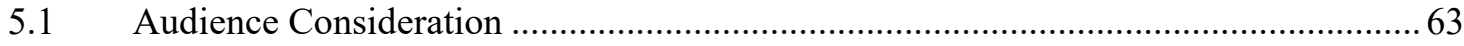

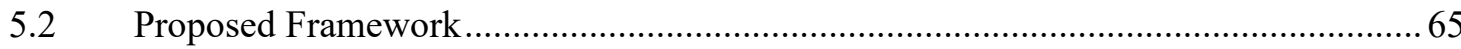

5.2.1 Step 1: Define heritage Values and Character-defining Elements .......................... 65

5.2.2 Step 2: Establish target goals and purpose of virtual heritage experience. ................66

5.2.3 Step 3: Represent tangible space through documentation, representation, or interpretation.

5.2.4 Step 4: Represent intangible values through cognitively immersive experiences. .. 70

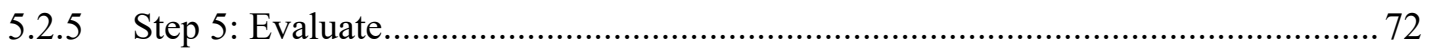

6 Chapter: Project Example .............................................................................................. 73

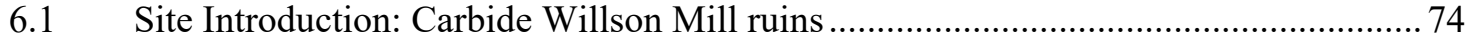

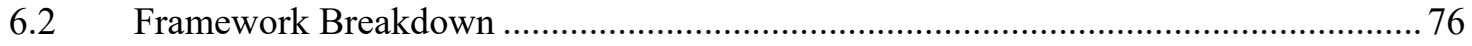

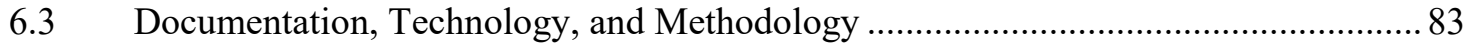

7 Chapter: Conclusion ........................................................................................................ 89

Bibliography ............................................................................................................................... 93

APPENDIX 


\section{List of Illustrations}

Illustration 1 Archival photograph of Carbide Willson Mill, Gatineau Park. 1917. http://www.biographi.ca/en/bio/willson_thomas_leopold_14E.html

Illustration 2 Ise Jingu Shrine, Japan. http://www.isejingu.or.jp/en/ritual/index.html

Illustration 3 Hands Omni Glove. Rice University. http://news.rice.edu/2015/04/22/gamers-feel-the-glove-from-riceengineers-2/

Illustration 4 Silchester Roman Town model and scent vials. University of Reading. Oct 2016. https://www.reading.ac.uk/news-andevents/releases/PR703427.aspx

Illustration 5 British Museum. Google Street View. http://www.britishmuseum.org/with_google.aspx

Illustration 6 4D visualization of evolution of the Ename Abbey site (1150). Pletinckx et al., "Virtual-Reality Heritage Presentation at Ename." http://dl.acm.org/citation.cfm?id=614970

Illustration 7 Visualization of the two-level model of Spatial Presence. Wirth, Werner et al., "A Process Model of the Formation of Spatial Presence Experiences," Media Psychology 9 (2007).

Illustration 8 Assassin's Creed II, Ubisoft Montreal. http://www.archdaily.com/774210/maria-elisa-navarro-thearchitectural-consultant-for-assassins-creed-ii

Illustration 9 World of Warcraft gameplay user interface. http://justrpg.com/reviews/world-of-warcraft

Illustration 10 Carbide Willson Mill ruins virtual reality experience. Archival sourced from Capital Gems, edited by Author.

Illustration 11 Location of Carbide Willson Mill ruins, Gatineau Park. Google, altered by Author.

Illustration 12 Sensory recreation of tangible elements. Author.

Illustration 13 Pointcloud, Carbide Willson Ruins. Author.

Illustration 14 Photogrammetry, Carbide Willson Ruins. Author.

Illustration 15 Photosphere, Carbide Willson Ruins. Author. 


\section{List of Tables}

Table 1 Spatial presence characteristic assessment of Assassin's Creed.

Table 2 Spatial presence characteristic assessment of World of Warcraft. 


\section{Chapter: Introduction}

This thesis proposes a framework that can be applied to virtual reality representations of cultural heritage, as defined in the following chapter, to intrinsically combine both tangible and intangible heritage value. When discussing cultural heritage in the context of this thesis, the focus is primarily on the architectural remnants of our cultural history. The proposed methodology will allow a user the opportunity to experience both sets of values in virtual space, drawing from methods and technologies existent in the virtual technology and gaming industries. The proposed framework suggests we should no longer be limited to our five senses when experiencing virtual environments, but rather, offered an experience that addresses both sensory and cognitive stimuli thus allowing for full mental immersion in virtual reality. Through such an experience, users are given the tools to experience and build psychological and emotional ties, values, and relationships within the virtual environment, in addition to the material characteristics of the space around them. ${ }^{1}$ By experiencing both tangible and intangible characteristics and values of an historic site, a user is able to experience heritage in the full sense of the definition.

Virtual reality, or VR, has become a tool commonly used in the architectural and heritage industries, allowing users to experience space through virtual means, whether via computer screen, or, immersively, through the use of an immersive

1 Wirth, Werner et al., "A Process Model of the Formation of Spatial Presence Experiences," Media Psychology 9 (2007) 
headset and 360-degree imagery. In the architectural industry, VR is primarily used as a marketing tool to demonstrate proposed designs and allow clients the opportunity to visualize constructed digital environments. In the heritage industry, VR is primarily used as a documentation and educational tool for displaying digital records of existing buildings. The primary differences between both uses lie in the fabrication methods of the digital environments themselves and the purpose for which the models are created. The former is constructed through digital modelling software and creates the opportunity for a user to experience an un-built space, most often for the purpose of selling a design idea to a client or often used as a marketing tool. The latter is retrieved through digital recording, allowing the user to experience a heritage environment while not being physically present at the historic site, or as an additional layer of information and experience to visitors of a particular site. In both instances, virtual reality is used as a means to visualize the environments, allowing the user to experience the space at a 1-to-1 scale via digital tools.

While these tools provide an exciting way to visualize space, it is often solely the material elements of a place or design that are digitized and experienced in virtual reality. While enabling users the opportunity to experience material space in a virtual environment, these tools often lack elements of interaction and human connectivity.

Cultural heritage embodies both tangible and intangible heritage values ${ }^{2}$ that are crucial in understanding the full significance of a building or place and its historical

2 Jukka Jokilehto, “Definition of Cultural Heritage," ICCROM Working Group 'Heritage and Society.' 13-45. 
or cultural significance — values that ultimately create an empathetic relationship between a user and his or her environment. Technology used in the field of heritage has ultimately focused on the visual representation of a material object, and the study of intangible values in virtual space has not yet been thoroughly explored. As we continue to represent cultural heritage through digital means, and if we are to claim an accurate representation of said heritage via these tools, it is crucial for a complete representation that addresses all aspects, tangible and intangible, of the cultural heritage in question.

An investigation into techniques and methodologies utilized to experience the intangible in virtual space led this research to the video game industry. The idea of building emotional relationships and empathetic connections between a person and a virtual environment is prevalent in the video game industry, as the industry recognizes that in order for a user to become attached or immersed in a virtual world, ultimately enabling them to grow an emotional appreciation or understanding of a certain environment, the digital world must encompass far more than simply advanced visualization techniques. This paper seeks to explore ways in which virtual reality, drawing from existing methodologies applied in the cultural heritage and video game industries, can create the opportunity for a user to experience such intangible values in particular relation to cultural heritage in a virtual environment.

An international study on spatial presence theory has proposed a set of parameters required for a game or virtual environment to become fully immersive, allowing the user to become spatially present. Spatial presence provides the user with the opportunity to build a value system in a virtual space, thus enabling them to 
experience intangible values in a virtual world. The parameters described to achieve spatial presence will be utilized to assess two well-known immersive video games, Assassin's Creed and World of Warcraft. The study suggests spatial presence is not unique to virtual reality, but "can also occur in users of conventional media, such as books or television." This enables us to look critically at the existing game worlds independently of media.

This paper will then explore ways in which these methods can be applied to a virtual representation of an historic site and thus allow a user to experience the intangible values of heritage in a virtual environment. The Carbide Willson Ruins will be used as a project example, as its complex industrial and character histories and unique physical fabric make it an ideal candidate for a game-like environment. A new framework for achieving spatial presence in an historic virtual environment will be proposed, and the parameters will be applied as a means to explore ways in which we can create emotionally engaging and interactive immersive virtual environments that allow the user to experience the intangible values of cultural heritage.

The final project will include an in-depth story-board proposal of the proposed Carbide Willson Ruins game-world, addressing each characteristic outlined in the framework to achieve spatial presence as it relates to the site. Finally, a critique of the methods applied will be discussed, and further research and investigation into spatial presence and virtual heritage will be proposed. A set of questions will then be

\footnotetext{
${ }^{3}$ Wirth, Werner et al., "A Process Model of the Formation of Spatial Presence Experiences," Media Psychology 9 (2007): 495.
} 
proposed to assess the results, which can be applied to future projects of this kind, to determine whether or not the methodologies proposed have been successful in allowing a user the opportunity to experience intangible values in virtual space. An in-depth conclusion will summarize the research and proposed project, and conclude this thesis.

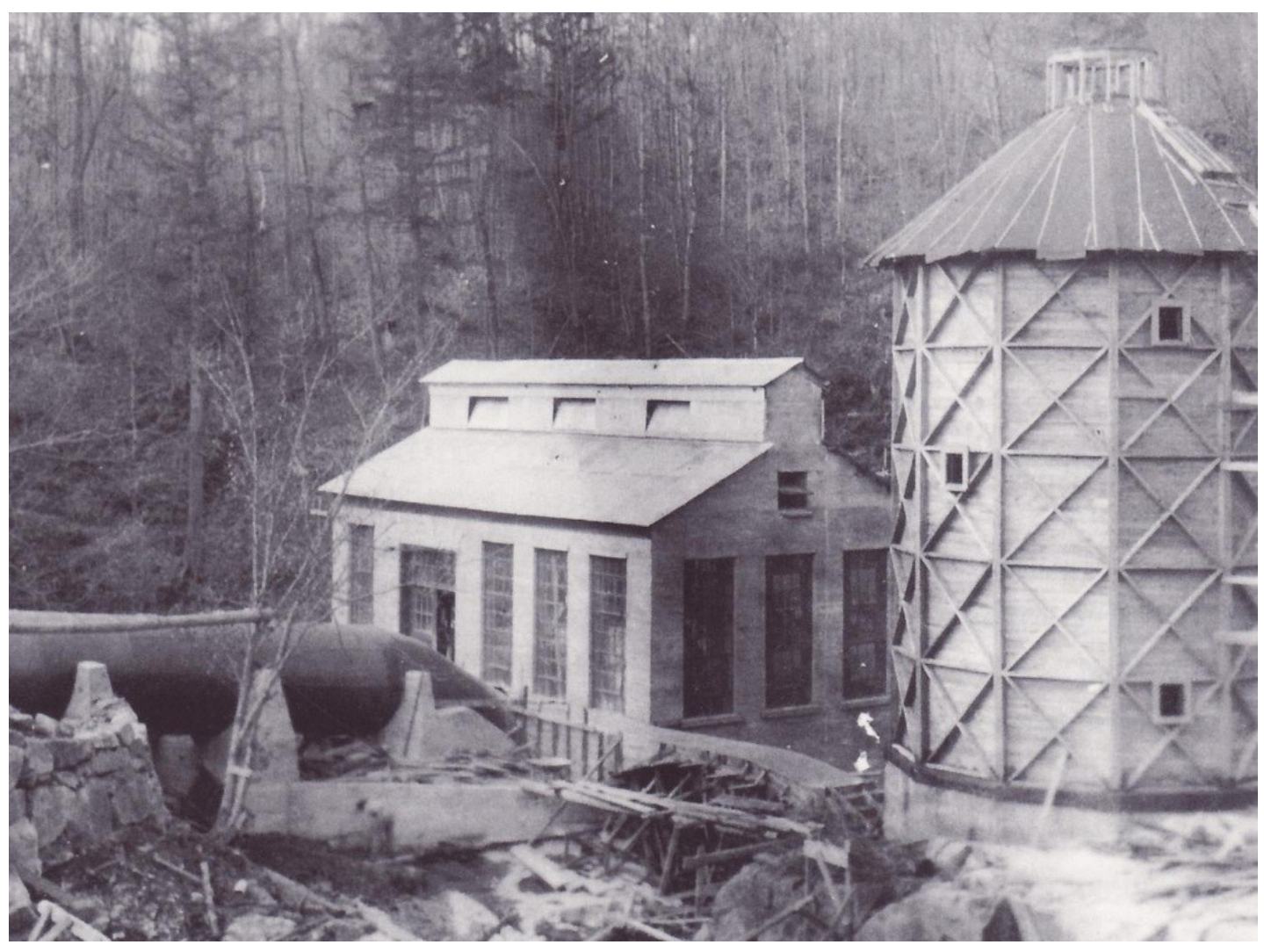

Illustration 1 Archival photograph of Carbide Willson Mill, Gatineau Park. 1917. 


\section{Chapter: Cultural Heritage}

Nationwide, more than twenty-percent of Canada's historic buildings have been demolished, ${ }^{4}$ with more are at risk daily. While the efforts of historians, conservationists, governments, and other industry professionals have contributed greatly towards a thriving heritage industry in our country, it is crucial for the importance of preserving our cultural and architectural heritage that we spread this awareness to a broader audience.

Nearly seven-hundred thousand images and four million cultural objects are contained in the Artefacts Canada database, ${ }^{5}$ and the numbers grow as more objects are documented. As of the 2016, there were 976 registered National Historic Sites in Canada, ${ }^{6}$ and more than thirteen thousand registered historic places represented on the Canadian Register of Historic Places. ${ }^{7}$ As large as this number is, it fails to account for the thousands of registered historic places across the country that have yet to be added to the online register. ${ }^{8}$ The number of properties covered by this

\footnotetext{
4 “The Canadian Register," accessed February 11, 2017. http://www.historicplaces.ca/en/pages/register-repertoire.aspx

5 “The Canadian Heritage Information Network," Accessed February 13, 2017. http://www.rcipchin.gc.ca/index-eng.jsp

6 "Parks Canada's Departmental Performance Report 2013-14," http://www.pc.gc.ca/eng/docs/pc/rpts/rmr-dpr/index.aspx.

7 "The Canadian Register."

8 "The Canadian Register."
} 
register will continue to increases as property owners and conservationists apply for heritage status.

Standards and guidelines for heritage conservation have been created by participating government and private organizations; and the preservation, rehabilitation, and restoration of our architectural heritage has become common practice in the architectural and construction industry across the country. Through an appreciation for our cultural heritage, we have reduced the risk of losing our historic landmarks and ensured the protection of our cultural identities. The vastness and complexity of Canada's heritage industry demonstrates our appreciation as a country for our own cultural heritage, and there is no doubt that these sites are a valuable resource. It is vital to ensuring these resources are accurately represented that we explore new ways to document, experience, and share this heritage through virtual means.

Prior to looking further into virtual representation of heritage, it is essential to establish a clear definition of culture and cultural heritage. With a clear understanding of cultural heritage and the heritage values that surround it, we can then begin to dissect individual historic sites to discover both tangible and intangible values that are intrinsic in their definition. Jukka Jokilehto, a staff member at the International Centre for the Study of the Preservation and Restoration of Cultural Property (ICCROM) — an intergovernmental organisation with a mandate to promote 
the conservation of cultural heritage ${ }^{9}$ — collected a series of definitions of cultural heritage ranging from the 6th $\mathrm{AD}$ Antiquity writings of Theoderic the Great to the 2004 ICOMOS UK cultural landscapes document.. The following are a sample of the definitions acquired that provide an in-depth understanding of cultural heritage throughout history, taken directly from Jokilehto's Definition of Cultural Heritage document, 1990, revised 2005. Descriptions that are most significant to this thesis have been underlines in the following texts.

\section{7, England, SPAB Manifesto}

'Manifesto' of the Society for the Protection of Ancient Buildings (SPAB founded by Morris on 23 March, 1877)

** For what is left we plead before our architects themselves, before the official guardians of buildings, and before the public generally, and we pray them to remember how much is gone of the religion, thought and manners of time past, never by almost universal consent, to be Restored; and to consider whether it be possible to Restore those buildings, the living spirit of which, it cannot be too often repeated, was an inseparable part of that religion and thought, and those past manners. For our part we assure them fearlessly, that of all the Restorations yet undertaken the worst have meant the reckless stripping a building of some of its most interesting material features; whilst the best have their

\footnotetext{
9 Jukka Jokilehto, "Definition of Cultural Heritage," ICCROM Working Group 'Heritage and Society.' 13-45.
} 
exact analogy in the Restoration of an old picture, where the partlyperished work of the ancient craftsmaster has been neat and smooth by the tricky hand of some unoriginal and thoughtless hack of today. If, for the rest, it be asked us to specify what kind of amount of art, style, or other interest in a building, makes it worth protecting, we answer, anything which can be looked on as artistic, picturesque, historical, antique, or substantial: any work, in short, over which educated, artistic people would think it worthwhile to argue at all. [...]

\section{4, UNESCO Convention (The Hague)}

Convention for the Protection of Cultural Property in the Event of Armed Conflict, The Hague Convention, adopted by UNESCO at The Hague, 14 May 1954 (§ 1)

For the purposes of the present Convention, the term 'cultural property' shall cover, irrespective of origin or ownership:

Movable or immovable property of great importance to the cultural heritage of every people, such as monuments of architecture, art or history, whether religious or secular; archaeological sites; groups of buildings which, as a whole, are of historical or artistic interest; works of art; manuscripts, books and other objects of artistic, historical or archaeological interest; as well as scientific collections and important collections of books or archives or of reproductions of the property defined above; 
buildings whose main and effective purpose is to preserve or exhibit the movable cultural property defined in sub-paragraph (a) such as museums, large libraries and depositories of archives, and refuges intended to shelter, in the event of armed conflict, the movable cultural property defined in subparagraph (a); centres containing a large amount of cultural property as defined in subparagraphs (a) and (b), to be known as 'centres containing monuments.'

\section{2, UNESCO Convention (World Heritage)}

Convention concerning the protection of the World Cultural and Natural Heritage, adopted in Paris, 16 November $1972(\S 1,4,5)$

For the purposes of this Convention, the following shall be considered as 'cultural heritage': Monuments: architectural works, works of monumental sculpture and painting, elements or structures of an archaeological nature, inscriptions, cave dwellings and combinations of features, which are of outstanding universal value from the point of view of history, art or science; groups of buildings; groups of separate or connected buildings which, because of their architecture, their homogeneity or their place in the landscape, are of outstanding universal value from the point of view of history, art or science; sites: works of man or the combined works of nature and of man, and areas including archaeological sites which are of outstanding universal value from the historical, aesthetic, ethnological or anthropological points of view. 
1981, ICOMOS Australia (Burra)

Burra Charter (Australia)

\section{Definitions}

For the purpose of this Charter:

Place means site, area, building or other work, group of buildings or other works together with pertinent contents and surroundings.

Cultural significance means aesthetic, historic, scientific or social value for past, present or future generations.

Fabric means all the physical material of the place.

Conservation means all the processes of looking after a place so as to retain its cultural significance. It includes maintenance and may according to circumstance include preservation, restoration, reconstruction and adaptation and will be commonly a combination of more than one of those.

\section{4, Nara Document on Authenticity}

Cultural diversity and heritage diversity.

5. The diversity of cultures and heritage in our world is an irreplaceable source of spiritual and intellectual richness for all humankind. The protection and enhancement of cultural and heritage diversity in our world should be actively promoted as an essential aspect of human development.

6. Cultural heritage diversity exists in time and space and demands respect for other cultures and all aspects of their belief systems. In cases 
where cultural values appear to be in conflict, respect for cultural diversity demands acknowledgement of the legitimacy of the cultural values of all parties.

7. All cultures and societies are rooted in the particular forms and means of tangibles and intangible expression which constitute their heritage, and these should be respected.

\section{4, ICOMOS UK (Cultural landscapes)}

\section{Cultural Qualities in Cultural Landscapes}

\section{DEFINITIONS}

This paper adopts the following definitions of key terms:

Cultural Landscapes: Cultural landscapes are particular landscapes that reflect interaction over time between people and their surroundings Cultural Qualities: Cultural qualities are attributes of cultural landscapes that reflect human value systems

Value: Value is the value people give, either individually or collectively, and at local, national or international level, to cultural qualities in landscape.

Significance: Significance reflects the assessment of total value we ascribe to cultural and natural qualities in cultural landscapes, and thus how we evaluate their overall worth to society, to a nation or to local communities. Significance may relate to one particular quality or to a collection of several particular qualities. 
The terms and descriptions listed above suggest that the definition of cultural heritage is evolving. Early texts describe the value of cultural heritage as material and quantifiable, yet as time progressed, we begin to see an acknowledgement of cultural significance and intangible values. Today, our definition of heritage relies strongly on the intangible heritage values tied to cultural heritage, and it is these values that are the driving force of this paper. Gustavo Araoz, the current President of ICOMOS, the International Council on Monuments and Sites-a nongovernmental organization that is dedicated to the conservation and protection of monuments and sites across the globe - explains that the values of our traditional and cultural heritage "no longer reside exclusively on its physical fabric and form, but on intangible concepts that by their very nature are in constant flux. ${ }^{10}$ " While the material nature of a particular site is no doubt both significant and intrinsic in the value recognized in a particular site, it is the intangible and everchanging values imposed on the place that define it as heritage. Deducting from the above definitions, we can understand cultural heritage comprises two primary components: the physical or material fabric of the site or artefact itself-as without the site there is no basis for analysis and the site becomes no longer heritage, but, rather, history — as well as the intangible cultural and heritage values imposed

${ }^{10}$ Gustavo Araoz, "Protecting Heritage Places under the New Heritage Paradigm \& Defining its Tolerance for Change," (2009): 4. 
on it. Prior to delving deeper into the study of intangible cultural heritage and how it relates to virtual representation, however, we must first establish a clear definition of heritage value. Once established, this thesis will then continue with an analysis of virtual representation of said heritage, followed by a proposal for how to address both tangible and intangible values in the representation.

Parks Canada has outlined key definitions in The Standards and Guidelines for the Conservation of Historic Places in Canada, a benchmark publication for the practice of heritage conservation in our country. Their definition of heritage value is as follows:

Heritage value (valeur patrimoniale): The aesthetic, historic, scientific, cultural, social or spiritual importance or significance for past, present or future generations. The heritage value of an historic place is embodied in its character-defining materials, forms, location, spatial configurations, uses and cultural associations or meanings.

As per the above definition, it clearly states that heritage value comprises both tangible values, such as materials, forms, location, and spatial configurations, and intangible values, such as uses and cultural associations or meanings. Both are intrinsic in the definition. We can appreciate the value of a site's tangible material nature, the physical elements that comprise the site in question. However, it is the intangible values - the cultural associations and meanings - that allow us to connect 
with the site and ultimately construct an empathetic relationship between ourselves and cultural heritage.

Empathy plays an essential role in the experience of cultural values, as cultural values are what ultimately make a person care about heritage. It is the cognitive condition that ties the physical site to our human values and emotions. ${ }^{11}$

As the site chosen as demonstration of the project proposal in chapter 6 is in Canada, the Parks Canada definition of heritage value will be utilized in the formation of the proposed framework.

\subsection{Cultural Heritage Case Studies}

Acknowledging the definition of "heritage value" as defined by Parks Canada in the previous chapter, we can begin to analyze existing sites to gain a firmer understanding of the tangible and intangible values that determine cultural heritage. As we will see from the following examples, the intangible values associated with the sites are as valuable as their tangible counterparts. If we strip away the intangible heritage values of each site, the values that hold significance to the site's cultural history and context, we are left with simply an architectural landmark that would no longer be defined as heritage. This chapter demonstrates the importance of the

\footnotetext{
${ }^{11}$ Barbara Kirshenblatt-Gimblett, "Theorizing Heritage," Ethnomusicology, Vol. 39, No. 3. (1995): 367-380.
} 
intangible heritage value of each site, and that it is intrinsic in each site's definition of heritage.

\subsubsection{Ise Jingu Grand Shrine}

One example that strongly communicates the modern definition of heritage is the Ise Jingu grand shine in Mie Prefecture, Japan. Known as Japan's most sacred shrine, the site dates back to the $3^{\text {rd }}$ Century, and is dedicated to the sun goddess, Amaterasu. Every twenty years, the shrine is torn down and rebuilt using new materials. The reconstruction involves thirty rituals and ceremonies, including one surrounding the cutting of the first trees for the new space. The process takes approximately eight years to complete. ${ }^{12}$ The shrine holds great cultural value to the community. However, the physical material that constructs the shrine is not what holds the cultural value, rather the preservation of the local craftsmanship and the ceremony that accompanies the dismantling and reconstruction of the site that goes with it that ensures the site's identity as cultural heritage.

12 “Ise Jingu, Rituals and Ceremonies,” Accessed February 10, 2017, 


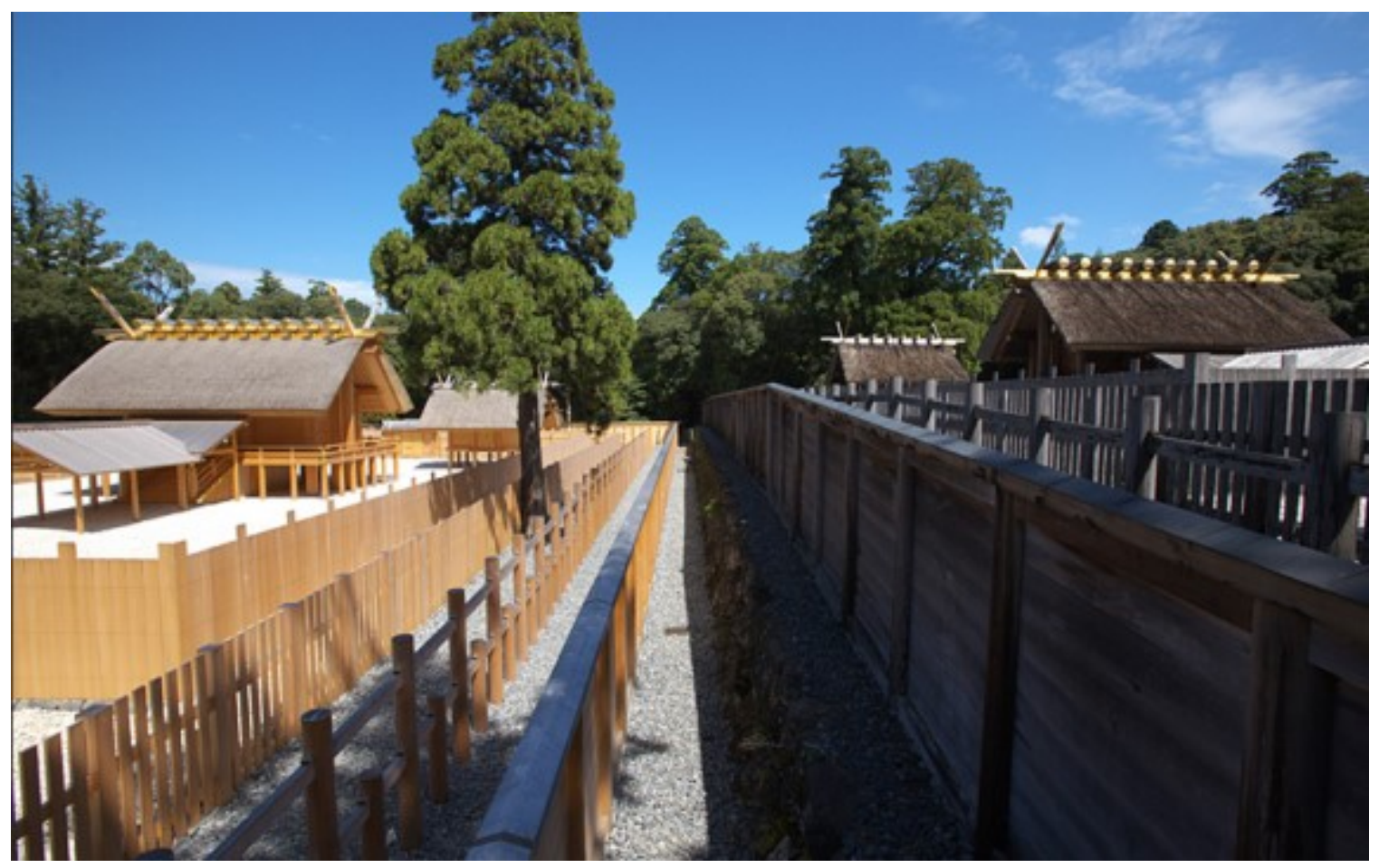

Illustration 2 Ise Jingu Shrine, Japan

\subsubsection{Anne Frank House}

The Anne Frank House in Amsterdam, Netherlands, now a museum, is a prime example of intangible heritage. The apartment, an unassuming unit that would otherwise hold no greater heritage value than its neighbour, architecturally speaking, is a prominent historical landmark in the city of Amsterdam due to its association with the Frank family. This is where Anne Frank wrote her diary while hiding from the Nazi's between 1942-1944 — before her tragic capture in $1944 .{ }^{13}$ The site's cultural association to the family and the devastating events of the war are what define this site as cultural heritage. In 2009, the writings from Anne Frank's diary

\footnotetext{
13 “Anne Frank House Museum,” Accessed March 1, 2017. http://www.annefrank.org
} 
were officially included in the UNESCO Memory of the World Register, the World Heritage List for documents. ${ }^{14}$

14 "Diary of Anne Frank on UNESCO documentary heritage list," (2009) Accessed March 1, 2017. 


\section{Chapter: Virtual Heritage}

Virtual heritage is the use of electronic media to recreate or interpret culture and cultural artefacts as they are today or as they might have been in the past. ${ }^{15}$ More comprehensively, it is defined as "the use of computer-based interactive technologies to record, preserve, or recreate artefacts, sites and actors of historic, artistic, religious, of cultural significance and to deliver the results openly to a global audience in such a way as to provide formative educational experiences through electronic manipulations of time and space." ${ }^{" 16}$ Evident in both definitions is the recreation of cultural sites or artefacts for the purpose of educational or explorative interpretation. These experiences are meant as interpretive tools intended to educate. This suggests that there is much more to these experiences than simply the visual reconstruction of the material space. As technologies advance, we have begun to explore new and innovative ways to communicate heritage through virtual means.

The London Charter establishes a set of guidelines for "the use of technology in the creation of virtual heritage." ${ }^{17}$ Conceived in 2006, The London Charter for the Computer-based Visualisation of Cultural Heritage was created as a "means of ensuring the methodological rigour of computer-based visualization as a means of

${ }^{15}$ D.B. Roehl, "Virtual Archeology. Bring New Life to Ancient Worlds," Innovation 28 (1997): 35.

${ }^{16}$ R. Stone and T. Ojika, “Virtual Heritage: What Next?” IEEE Multimedia 7(2) (2000): 73-74.

${ }^{17}$ Laia Pujol and Erik Champion, "Evaluating Presence in Cultural Heritage Projects," International Journal of Heritage Studies 18-1 (2012): 83-102. 
researching and communicating cultural heritage." 18 The following quote is taken from the document $A$ New Introduction to the London Charter $^{19}$ :

The London Charter was born out of an anxiety that serious heritage visualization was suffering, in prestige and perceived integrity, by its superficial similarities to computer-generated imagery seen in ahistorical popular games and films. We now find ourselves, however, gravitating towards a, perhaps wiser, recognition of interconnectedness: an observation that computer-based visualizations are valuable in part precisely because they collapse boundaries between the mysteries of rarefied academic research and popular understanding.

The London Charter outlines six principles for the use of computer-based visualisation methods in relation to "intellectual integrity, reliability, documentation, sustainability, and access," 20 and is concerned with, "research and dissemination of cultural heritage across academic, educational, curatorial and commercial domains." 21

The following are the six principles outlined in The London Charter:

\footnotetext{
18 Hugh Denard, “A New Introduction to The London Charter,” Accessed March 1, 2017.

19 Hugh Denard, “A New Introduction to The London Charter,” Accessed March 1, 2017.

20 “The London Charter,” Accessed February 6, 2017. http://www.londoncharter.org

21 “The London Charter,” Accessed February 6, 2017. http://www.londoncharter.org/
} 
Principle 1: Implementation The principles of the London Charter are valid wherever computerbased visualisation is applied to the research or dissemination of cultural heritage.

Principle 2: Aims and Methods A computer-based visualisation method should normally be used only when it is the most appropriate available method for that purpose.

Principle 3: Research Sources In order to ensure the intellectual integrity of computer-based visualisation methods and outcomes, relevant research sources should be identified and evaluated in a structured and documented way.

Principle 4: Documentation Sufficient information should be documented and disseminated to allow computer-based visualisation methods and outcomes to be understood and evaluated in relation to the contexts and purposes for which they are deployed.

Principle 5: Sustainability Strategies should be planned and implemented to ensure the long-term sustainability of cultural heritage-related computerbased visualisation outcomes and documentation, in order to avoid loss of this growing part of human intellectual, social, economic and cultural heritage.

Principle 6: Access The creation and dissemination of computer-based visualisation should be planned in such a way as to ensure that maximum possible benefits are achieved for the study, understanding, interpretation, preservation and management of cultural heritage. 
What is not addressed in the London Charter are the intangible experiences and educational functions of virtual reality for understanding and appreciating heritage values. I would argue that a more comprehensive framework must be set in place to ensure a complete and authentic experience of tangible heritage and intangible heritage values in the context of virtual heritage.

\section{Virtual Reality}

Virtual Reality is commonly used in the cultural and architectural heritage fields due to its immersive properties. It allows a user the opportunity to visualize a space or artefact three-dimensionally using immersive, 3D digital technologies. Virtual reality has opened tremendous possibility in our ability to share elements of heritage with a broader — both intellectually and geographically — audience. There are many variations of virtual space, ranging from three-dimensional displays on a computer, to fully immersive virtual experiences requiring the use of specialized threedimensional head-set technology such as the Oculus Rift or PlayStation VR. It is well-used in the heritage industry as it allows for accessible spatial experiences, and in the gaming industry as it "promotes active participation."22

Technological advancements in the field of virtual reality have come far in the past few decades, particularly in the realm of visualization. However, new advancements

${ }^{22}$ Stone and Ojika, "Virtual Heritage: What Next?" 
of old technologies are making addressing all five senses in virtual reality possible. ${ }^{23}$ Sound has successfully been integrated into many virtual reality experiences through narration, environmental noise, and music. ${ }^{24}$ Smell, taste, and touch, however, are less frequently integrated into virtual reality, as they require the use of less readily available technologies. However, the following examples demonstrate the possibilities of integrating all five senses through newly proposed products.

The FEELREAL headset is a proposed product that works together with existing virtual reality headsets, such as the Oculist Rift, and promises a virtual reality mask and that provides "new sensations through smells and senses of wind, heat, water mist and vibration present in virtual worlds. ${ }^{25}$

Another new technology that addresses the lack of touch in VR environments is the Hands Omni glove, an experimental product designed by students at Rice University's George R. Brown School of Engineering in Houston Texas. The glove simulates touch through small bladders in the glove that "can be filled with air to activate pressure that simulates touch." 26 The prototypes use an open-source

\footnotetext{
${ }^{23}$ Grigore C. Burdea and Philippe Coiffet, Virtual Reality Technology, $2^{\text {nd }}$ Edition [New Jersey: WileyIEEE Press, 2003], 84-102.

24 Stefania Serafin and Giovanni Serafin, "Sound Design to Enhance Presence in Photorealistic Virtual Reality," International Conference on Auditory Display, Sydney (2004): 2.

25 "FEELREAL: The Virtual Reality Mask," 2015.

${ }^{26}$ Lucy Ingham, "VR Feedback Glove to Bring Back Sense of Touch to Virtual Reality," Factor (2015) Accessed February 15, 2017.
} 
electrical prototyping platform called Arduino and are designed to be easily integrated into gaming systems of the future.

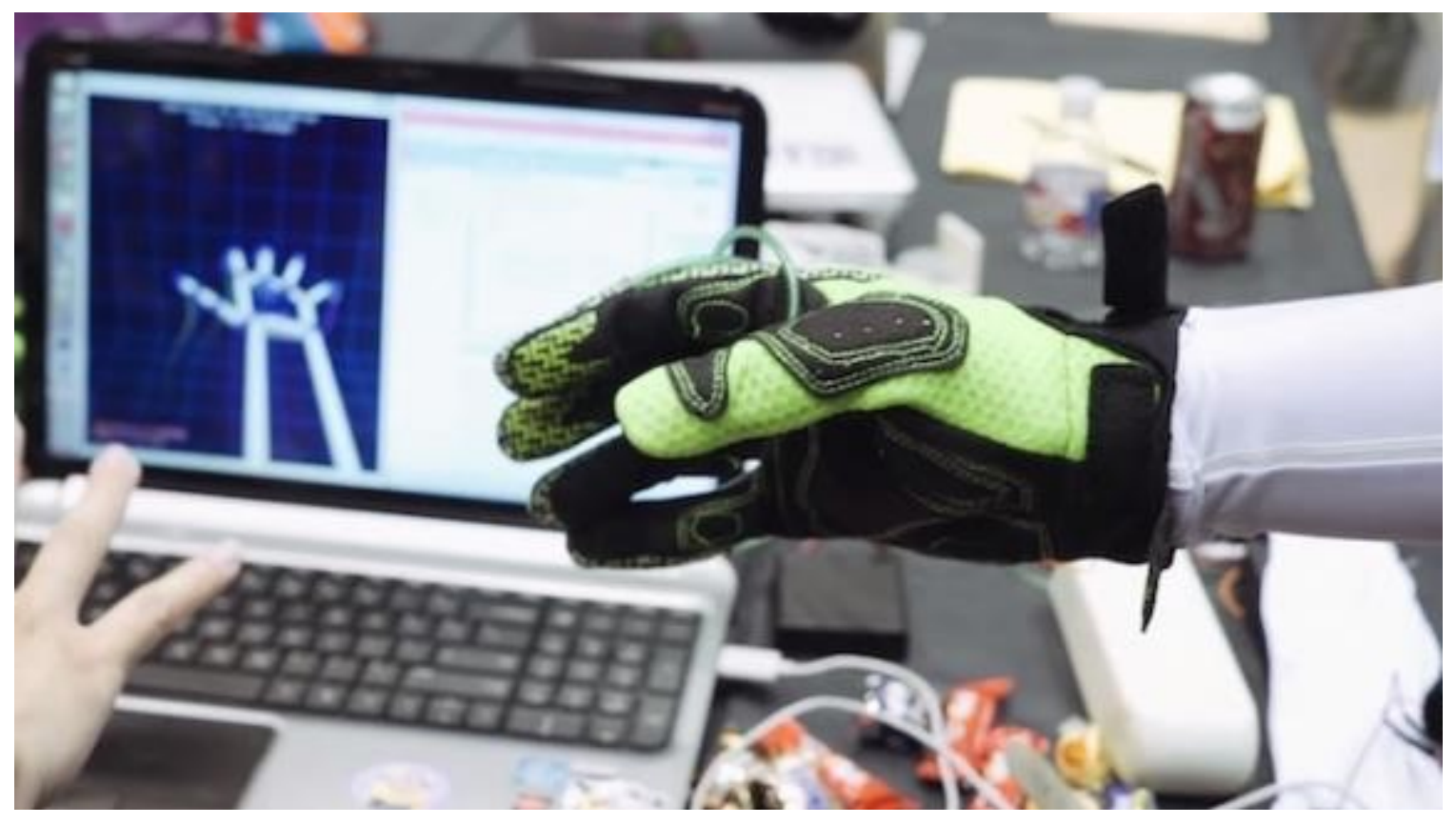

Illustration 3 Hands Omni Glove, Rice University.

These principles of full-sensory virtual experience are being explored in recent archaeological projects, allowing the user to experience the scent and sounds of a recreated historic environment.

Using records created by archaeologists working at the site, Dr. Ian Ewart, an anthropologist at the University of Reading's School of the Built Environment, recreated the experience of travelling through Silchester, an ancient roman town that existed in what is now Great Britain. The goal was to create an accurate and immersive recreation of an ancient town long-lost to history.

Recognizing scent as a significant sensory experience, Dr. Ewart investigated new methods of integrating smell into one's experience of a virtual space. Not only do 
different smells trigger memory and enrich the perception of our environments, but scent can actually alter emotional state. ${ }^{27}$

The town was digitally recreated using modelling software based on the archaeological findings, and the sounds and smells of the past were incorporated into the virtual reality experience. The sensory experiences tied to the virtual environment include "dogs barking, tools banging and flies buzzing, and the smell of animals, the herb garden, and even the cess pit." ${ }^{28}$

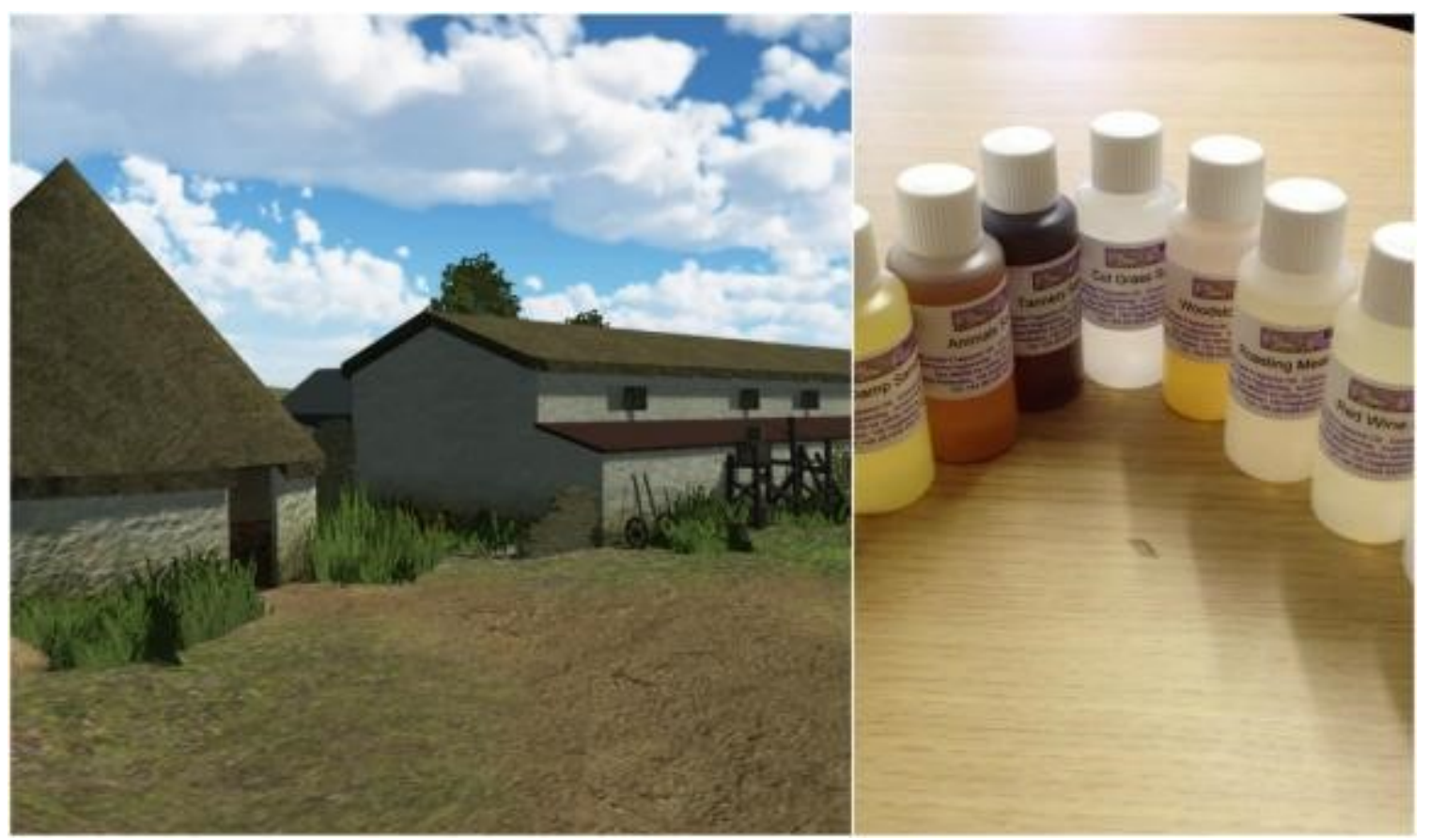

Illustration 4 Silchester Roman Town model and scent vials.

${ }^{27}$ S. Chu and J. Downes, “Odour-evoked autobiographical memories,” Chemical Senses 25 (2000): $111-116$

28 "Virtual Reality Experience Allows You to Walk Around and Even Smell this Roman Town," Accessed March 1, 2017. 
These technologies have rendered virtual reality an incredible tool for replicating real-world experiences by stimulating the senses. However, simply addressing the five senses is only one part of creating fully immersive experiences, which lack cognitive stimulation. In order to achieve a fully immersive virtual reality experience, both sensory and cognitive stimuli must be addressed.

\subsection{Virtual Reality and Heritage}

Before exploring how we can truly experience heritage in virtual reality, we must first ask why. One of the most obvious benefits of creating virtual experiences of architectural and cultural heritage is accessibility. VR allows people from all over the world the opportunity to experience a site they otherwise would not be able to visit in person due to geographical, monetary, or various level of physical disability.

Creating a means of virtual visitation also contributes to a site's continued preservation, maintenance, and sustainability. Archaeological sites, in particular, are susceptible to environmental and human degradation. The more visitors travel through the site, the higher the risk of damage and wear.

Machu Picchu, Peru, for example, is a highly sought-after tourism destination. Approximately 900,000 tourists visit the region annually, and the archaeological zone- which is spread over 31,000 hectares - reports devastating effects from the high-level of foot traffic moving through the site each day. ${ }^{29}$ Tourism not only

29 Lincoln R. Larson and Neelam C. Poudyal, "Developing sustainable tourism through adaptive resource management: a case study of Machu Picchu, Peru," Journal of Sustainable Tourism 20-7 (2012): 917-938. Accessed February 5, 2017. 
greatly increases pollution and puts the region's biodiversity at risk, but is also directly attributed to landslides on the mountainside. ${ }^{30}$ Offering a fully-immersive virtual reality tour of Machu Picchu and the Inca trail that leads to the city may offer potential visitors an alternate way to experience the cultural destination without imposing on the tourist footprint.

Virtual reality also provides an entirely new way of experiencing space. It allows for enhancement of information and creates new ways for users to interact with information and digital artefacts. ${ }^{31}$ These new methods are more than simply an alternative to the original, but an enhancement offering new layers of information to be experienced.

There are also psychological benefits to utilizing virtual reality technologies in experiencing heritage as it relates to empathy. Empathy, as mentioned in Chapter 2, is what allows us to care or add meaning to a material site or object. It is the intangible values associated with cultural heritage that allow us to empathize with the site in question, and virtual reality can facilitate similar empathetic reactions with the user.

Jeremy Bailenson, professor of communication at Stanford University, explains how virtual reality has the ability to give "everyone, regardless of where they live, the

\footnotetext{
30 "Historic Sanctuary of Machu Picchu," Accessed March 1, 2017. http://whc.unesco.org/en/soc/1094

${ }^{31}$ Stone and Ojika, "Virtual Heritage: What Next?"
} 
kind of experience needed to generate the urgency required to prevent environmental calamity." 32 The Virtual Human Interaction Lab, headed by Bailenson at Stanford University, released an interactive virtual documentary on the topic of ocean acidification. The intention was that by allowing users the opportunity to experience the effects of acid erosion in the ocean first-hand through virtual reality, they would gain a newfound appreciation for the situation, and as a result, be more likely to get involved in corrective action.

Bailenson is optimistic about the possibilities of VR in spreading awareness of global warming, and says, "with the proper software, video feed, and VR headset, just about anyone might be able to experience environmental change in the Amazon, the Arctic, or even under the ocean." ${ }^{33}$

In summary, studies suggest that immersive virtual reality can be used successfully to promote compassion and empathy. Immersive virtual experiences have proven more effective than video or other demonstrative educational efforts. This offers great potential for projects that deal with cultural heritage. Virtual reality-can be used as a tool to create an empathetic reaction from a user through the experience of intangible. This hypothesis is the driving force of this thesis, and the final chapters propose a specific methodology to achieve exactly this. First, however, we will

\footnotetext{
${ }^{32}$ Heather Millar, “Can Virtual Reality Emerge As a Tool for Conservation?” YaleEnvironment360, June 27, 2016, Accessed February 15, 2017

${ }^{33}$ Millar, "Can Virtual Reality Emerge As a Tool for Conservation?"
} 
consider three case studies that demonstrate how virtual reality and virtual tools are currently being used in heritage projects.

\subsection{Virtual Heritage Case Studies}

Three examples of virtual heritage are studied in the following sections:-the British Museum, England; the archaeological site at Ename, Belgium; and the Centre Block of the Parliamentary Precinct National Historic Site, Ottawa. Each virtual heritage experience features unique characteristics and educational intentions, but demonstrate common methodologies and technologies applied to virtual heritage today.

\subsubsection{The British Museum, England}

The British Museum, established in 1753, is one of the most prominent examples of how virtual technologies can be used to make cultural heritage accessible to the public through digital means. With a permanent collection of around 8 million works, with artefacts ranging from ancient civilizations to modern cultures around

the world, it is one of the most comprehensive museums in existence. ${ }^{34}$ In 2015, the British Museum embarked on a partnership with Google, allowing over 5,000

\footnotetext{
34 “The British Museum,” Accessed February 5, 2017.
} 
cultural objects from the museum's collection to be digitized and displayed in a free, online virtual museum environment. ${ }^{35}$

The Google Cultural Institute, a not-for-profit initiative founded in 2011, utilized Google Street View technology to create virtual tours of cultural destinations allowing their collections to be "more widely accessible to a global audience." 36 According to their website, The Institute has already helped over 800 other cultural institutions digitize their collections to be accessible by the public online.

Many of the British Museum's artefacts have been digitally catalogued and displayed in a digital replica of the museum that users can virtually walk through on their computers to view the items on display in a similar way that they would if they were visiting the museum itself. Not only are the artefacts themselves documented, but the museum space and display rooms have also been digitally recreated to ensure the museum-going experience is preserved, allowing digital and physical users the ability to access the same experience through different means. The intention behind the project, according to Amit Sood, director of the Google Cultural Institute, is to "bridge the gap between high culture and popular culture," allowing users the opportunity to experience the exhibits in their own way.

35 Mark Brown, "British Museum exhibits viewable online thanks to Google partnership," The Guardian, November 12, 2016. Accessed February 5, 2017.

36 “Google Cultural Institute,” Accessed February 5, 2017. 
The technical and organizational requirements of embarking upon such a large-scale project are complex. The documentation of the museum's interior architectural spaces for the interior Street View footage took 15 months to record, as documentation could only take place during the closing hours of the museum. Physically, the museum is massive, comprising over 807,000 Square feet spread out over 94 galleries. The scale often prohibits visitors from being able to see all exhibit spaces during a visit to the museum. What the virtual exhibits does is allow visitors a chance to see other parts of the museum they may have missed, despite having physically travelled to the museum in London. For those that are unable to travel on site in the first place, it allows the exhibits to be shared with an audience who otherwise would never get a chance to see it. Not only does this allow for a more global audience, but it contributes to global education by ensuring the knowledge of the historical artefacts is accessible world-wide.

There are two key experiential components to the virtual tour: the visual walkthrough of the museum's interior rooms, and an interactive digital map with a collection of images, text, and audio samples that relate to particular artefacts in the museum's collections. The Google Street View museum walk-through allows the user the chance to move through the interior rooms and exhibits of the museum, visually experiencing the space in a similar manner to which you would walk through in person. By clicking on points on the ground, you are virtually transported to that location and can look around the room and zoom in to view certain artefacts more closely. One of the main successes of the project is that the virtual experience of the museum is also partially interactive through the digital map on their website; a 
program entitled The Museum of the World. The virtual tour is predominantly visual, allowing the user to move through the interior rooms of the museum with a click of the mouse; each room visually accessible by rotating the view around set points on the floor. The virtual point map has additional integrated interactive elements that allow a broader and more intellectually rich learning experience. For example, by clicking on certain objects, you can hear an auditory recount of an artefact's history read by the museum curators who share their thoughts as you progress through the space. In addition to images of related objects, a Google map shows you where the artefact is originally from. We can also find information on the values that an artefact embodies, such as its relationship to a particular culture or moment in history, or the importance of an architectural space as it relates to a particular historical figure or ceremony. These intangible values are communicated through text, images, and sound, and would otherwise not be able to be communicated simply through visualization.

While the Google Street View tour allows a user the ability to visualize the interior of the building and its exhibits, the interactive digital point map allows users the ability to learn more about the intangible values of items in the collection through their curated digital library. 


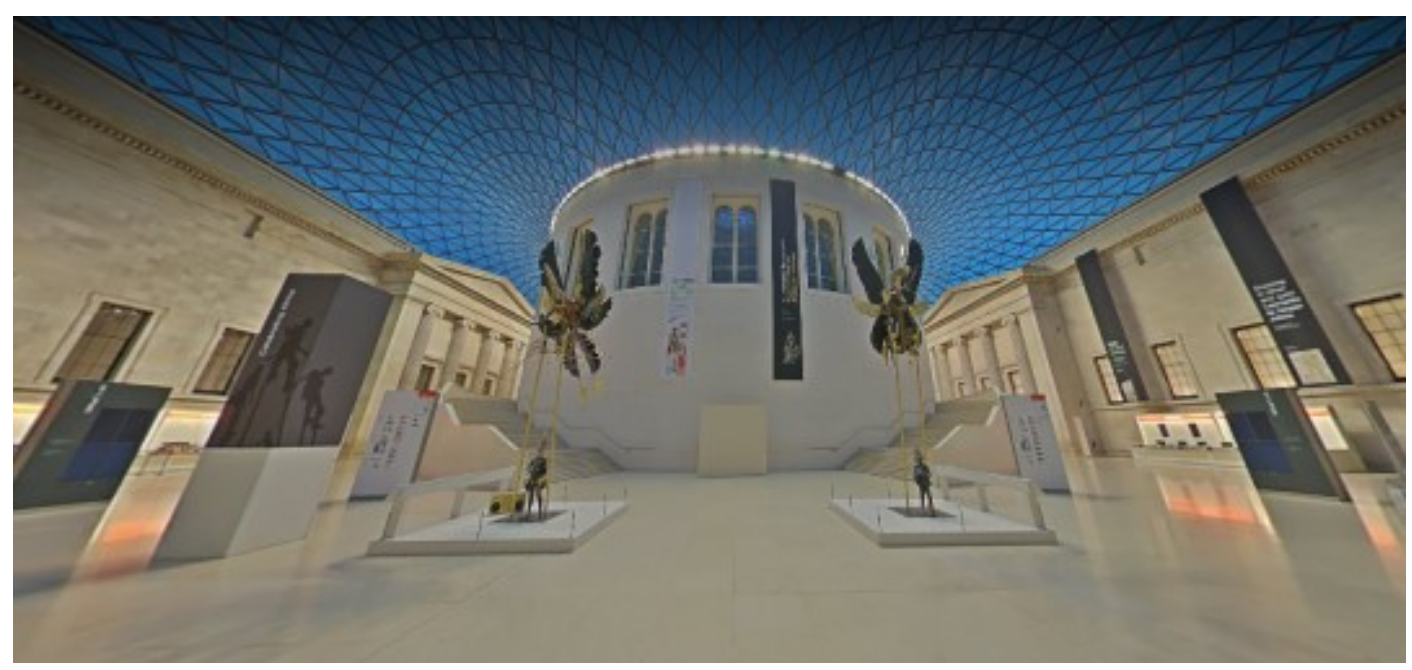

\section{Illustration 5 British Museum. Google Street View.}

The primary drawback to the British Museum's virtual programs is that both the Google Street View virtual tour and Museum of the World interactive experience are not integrated. Rather, they are two unrelated programs accessed through different parts of the website. The problem with not having both systems integrated is that it creates a lack of interactive experience in the virtual tour, resulting in the tour being solely a tool for visualization. In addition, the tour is only accessible through a computer screen and is not available to experience through an immersive virtual reality headset.

The tour, while being 3-dimensional through the use of the Google Street View technology, does not offer much more in terms of experience than what a series of carefully selected photographs can offer. This creates a disconnect between the user and the virtual space, as their only interaction is expressly visual, and all other aspects of interaction are removed, offered only through the separate interactive point map through the Museum of the World. 


\subsubsection{Ename, Belgium}

The archaeological site of Ename is located in the province of East Flanders, Belgium. An extensive excavation effort has been underway since 1982, revealing rich archaeological heritage in the region. Amidst the ruins, researchers have found evidence of three important classes in medieval Flanders; the religious class, the working class, and the fighting class. The archaeological site has been developed into an open-air archaeology museum accessible to the public. The purpose of the project, named Ename 974 — after the year of the first medieval settlement in the region — is to communicate "new insights about archaeology, history, and conservation to the general public with great attention to scholarly accuracy and by means of multimedia technologies." 37

Virtual reality is a tool used as part of the Ename 974 conservation and education plan. The techniques utilized are designed to assist the user in understanding and experiencing the results of extensive archaeological and historic research. ${ }^{38}$ The virtual exhibits bring to life the archaeological remains on the site, including monuments and surrounding historical landscape. The intent of the virtual recreations used in the virtual reality displays is to help visitors understand the original context of the sites.

\footnotetext{
${ }^{37}$ Pletinckx et al., "Virtual-Reality Heritage Presentation at Ename," IEEE MultiMedia V7-2 (2000): 45-48. Accessed February 1, 2017.

${ }^{38}$ Pletinckx et al., "Virtual-Reality Heritage Presentation at Ename,” Accessed February 1, 2017.
} 
Ruins, while appealing in their own way, are often difficult for a visitor to interpret. The virtual recreations of these ancient ruins are among the most important technologies on-site, allowing the remains to be brought to life, and to develop new technologies and standards for heritage valorization. ${ }^{39}$

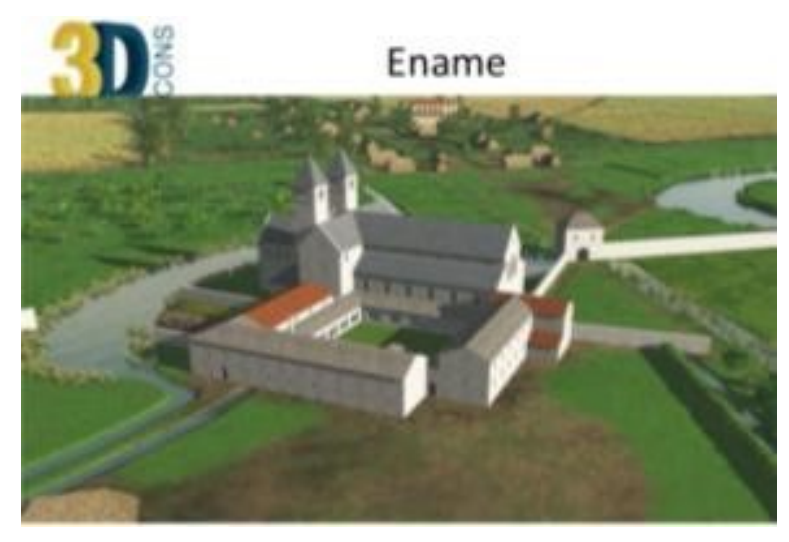

\section{Illustration 6 4D visualization of evolution of the Ename Abbey site (1150)}

While the site uses virtual reality as a tool to demonstrate the recreation of the sites, the question remains if the users are in fact experiencing the full extent of the site's heritage through the headsets. The virtual tools and methods implemented allow visitors to visualize the ancient structures as they likely appeared, but again, these tools are simply methods of visualization. Do they offer more than simply demonstrative images or video? There is no doubt that the virtual reality experience is educational and demonstrative of a time long passed, but the experience itself is not complete in the sense that only the visual nature of the ancient structures are recreated and experienced. The intangible values surrounding the particular sites are

\footnotetext{
${ }^{39}$ Pletinckx et al., "Virtual-Reality Heritage Presentation at Ename," Accessed February 1, 2017.
} 
not tied to the virtual experience; rather users are left to discover these elements on their own through outside text or other educational materials.

The success of the Ename virtual demonstrations lies in its ability to translate the visual recreations of the ancient site to a public audience, but a critical look at the recreations suggest that only a small part of the site's heritage has been addressed.

\subsubsection{Centre Block Senate Tour, Canada}

The most recent of the three projects, the Senate Virtual Tour, is a collaboration among Senate Communications, Public Services and Procurement Canada (PSPC), and the Carleton Immersive Media Studio (CIMS). ${ }^{40}$ It is comprised of a virtual tour of the Senate foyer, antechamber, and chamber. Three-dimensional photographic spheres were captured using a DSLR Camera with fisheye lens and a Nodal Ninja- a tripod attachment and were linked together to create an interactive digital tour, accessible to the public through their own home computers. Clickable elements that comprise gifs of photogrammetric models, photography, and animations of the poincloud and Revit model, have been integrated into the tour, allowing users the chance to click on various objects and learn information about their history. One of the great successes of the Centre Block virtual tour lies in its beautifully accurate visual representation of the interior Centre Block spaces, and it is difficult to discern the virtual representation from a real-life visual experience in Centre Block in terms of the visual presentation.

40 “Senate Tour,” Accessed March 14, 2017. http://tour-ext.sencanada.ca/tour/index.html 


\subsection{Critique}

Technology is fast advancing, and soon virtual reality will encompass more than just the visual nature of an environment. Through the stimulus of all five senses, we are getting closer to re-creating accurate and fully-immersive recreations of our surrounding environments. However, while these senses contribute to the human experience of a place, experience is not limited to merely sensory.

In considering architectural and cultural heritage there exists intangible values that remain intrinsic the site's heritage. These values may include the significance of a place in relation to an historic event, or perhaps its relation to a significant person in history. It may be the site of an historic breakthrough or the last remaining example of a particular type of structure or artefact. These are values that we cannot necessarily see, smell, feel, hear, or taste, yet they are integral to the place's identity.

While addressing all five senses in a virtual experience augments a user's appreciation and understanding of space, we are still only addressing the material nature of a place, not the cultural identity or values surrounding it. This leads to the conclusion that, although virtual reality technology has become so advanced that virtual recreations can nearly rival the real-world experience of a physical place, the fully contextual experience has not yet been achieved. To fully experience a site's heritage through virtual reality, as described in previous chapters, we must target both tangible and intangible values and experiences in our virtual recreations if we are to claim an accurate representation of heritage. 
Can we experience something we can't see, taste, hear, touch, or smell in a virtual environment? How can we build value systems and intangible relationships in a virtual recreation of an historic site? The answers to these questions lie in the immersive worlds of the video gaming industry. 


\section{Chapter: Intangible Values Unlocked in Video Games}

Since the inception of early online role playing games in the mid 1970s, the video game industry has created virtual environments that capitalize on human emotion. Through cognitively demanding tasks and experiences, visually stimulating environments, and progressive storylines, games draw users into their worlds and create relationships between the user and game space. The effects and successes of video games is currently a wide-spread subject area, as video games in some form or another have become main stream across the globe. In fact, 97\% of American adolescents are reported to play at least one hour of video games per day. ${ }^{41}$ Numerous studies have been conducted on the psychological and educational effects of gaming, and how they relate to human interaction, growth, intelligence, and emotional capacity. ${ }^{42}$ Though the range of types and genres of games is vast, there are consistent elements in all immersive games that can be studied to discover the underlying methods utilized in these virtual environments to create relationships between the real and the virtual.

Gaming experiences vary by genre and media, but one consistency throughout the videogame industry is the ability of most games to create a relationship and emotionally connected experience to a virtual place through immersive experiences.

\footnotetext{
${ }^{41}$ Isabela Granic, Adam Lobel, Rutger C.M.E. Engels, "The Benefits of Playing VideogamesAmerican Psychologist, Vol 69-1 (2014): 66-78.

${ }^{42}$ Mark Griffiths, "The educational Benefits of video games," Education and Health Vol. 20 No.3 (2002): 47-51.
} 
These immersive experiences allow the user to create their own value systems within the game, ultimately resulting in the user caring about the game world. Gamers feel emotionally connect to the game worlds and characters as evidenced by the continual return to the game. Moreover, that built emotional connection remains even when they are not actively in the game space, resulting in a change in their emotional status and an eagerness to return to the virtual world.

The user experiences the game on a cognitive level in addition to merely a sensory level. These relationships and cognitive connections between the user and the virtual game world enable the user to create value systems, feel empathetic attachment to places and characters, and actually care about the virtual space. It is these connections that drew me towards the gaming industry for this thesis.

I will analyze the methods by which the video game industry builds an empathetic relationship between user and a virtual environment as a potential way for the intangible qualities of architectural and cultural heritage to be experienced in virtual reality.

People form empathetic relationships with an artefact or a place, resulting in a value imposed on the heritage that recognizes more than simply the material value of the physical space. The value imposed on an historic site by a user goes far beyond the monetary value that exists in the material composition of the place, as is it the heritage value of a cultural heritage site that contributes greatly to its value for the community, which may include value placed upon its historic significance in relation to a place, a person, or an event in history. 
Ultimately, we feel an empathetic connection to the site, and as a result feel a need to protect and preserve said historic value. We have imposed our own value systems on an historic site, and it is these values that ultimately define the site's heritage. It is also these values, these empathetic relationships, which parallel a user's experience in certain virtual game environments. These games have managed to recreate more than simply the physical and sensory experiences of the real world, they have allowed users the opportunity to mentally place themselves in the game world and experience the virtual worlds in a manner similar to how they experience real life by building relationships, growing attachments between characters, plot lines, and places, and ultimately caring about the virtual environment around them.

What intrigues me about these occurrences is that we can draw significant parallels between these human experiences in the game worlds, and the way we experience heritage. In addition to merely placing value on the physical material of a piece of architectural heritage, we, as a culture or community, take great care in protecting the intangible values of the place as well. In essence, we care about heritage, because we place value on the cultural, environmental, political, and social relationships and characteristics that the heritage represents. The way we respond to heritage is similar to the way users respond to immersive game worlds. In both instances, we are given the opportunity to build our own value systems and place our own unique values on a place.

This fascinating parallel between game experience and heritage experience offers an exciting clue to how we can effectively and completely experience a site's heritage in the virtual world. If video games manage to create these paralleled relationships 
with a fictional gamer world, the opportunity exists where we could potentially create these same intangible experiences of heritage in virtual space. Through an analysis of these games and a study of what they have done to achieve this level of immersion that allows for these values to be built, we may be able to withdraw the same characteristics and apply them to a virtual representation of an historic place and create the opportunity for a user to experience more than simply the sensory recreation of the material place, but rather the intangible values that are inherent in its heritage.

\subsection{Spatial Presence and Video Games}

Presence, derived from the word 'telepresence' was first widely established by computer scientist Marvin Minsky in his 1980 paper entitled Telepresence, ${ }^{43}$ is not a new concept, nor is the study of how it relates to culture and cultural heritage. This concept of presence allows users the ability to "experience a sense of 'being there' across the gap of cultural difference," 44 suggesting, and in fact proven through documented reports of numerous user groups, ${ }^{45}$ we are able to reach out and experience new cultures and participate in unique cultural activities through the experience of cultural presence. Further, researchers have tied this concept to cultural heritage, and how the previously mentioned concept of cultural presence

\footnotetext{
43 Marvin Minsky, “Telepresence,” OMNI Magazine (1980), Accessed February 2, 2017.

${ }^{44}$ M.T. Jones, "The Impact of Cultural Transmission through Bishoujo Games," Psychology Journal 3, no. 3 (2005): 292-311.

${ }^{45}$ G. Fontaine, "The experience of a sense of presence in intercultural and international encounters," Accessed February 1, 2017.
} 
allows us to understand cultural heritage and the cultures and cultural values that surround it ${ }^{46}$.

In order to understand how these games achieve the level of immersion necessary for its users to build these value systems, we must look closely at the games themselves to determine what characteristics and methods are applied that allow for the desired level of mental connection to occur. The immersive phenomenon in question is known as Spatial Presence; a term that defines a state of cognitive immersion in an environment other than the one in which you physically exist. Spatial presence, also commonly referred to as cognitive immersion, is what allows a user to be fully immersed in a virtual game environment, and forget that he or she is in a world alternate to reality. It can be further understood as a state of being mentally present somewhere else when a person's perception, whether complete or in part, "fails to accurately acknowledge the role of technology that makes it appear that $\mathrm{s} / \mathrm{he}$ is in a physical location and environment different from her/his actual location and environment in the physical world." ${ }^{\text {47 }}$ Spatial Presence, unlike telepresence, a nearly identical term when discussing spatial immersion, does not reference a specific technology such as virtual reality or two-dimensional computer game worlds; rather it is independent of media and is a general concept that can be applied to all aspects and variations of virtual space.

\footnotetext{
${ }^{46}$ M.T. Jones, "The Impact of Cultural Transmission through Bishoujo Games."

47 "The Concept of Presence: Explication Statement," International Society for Presence Research (2000), Accessed February 20, 2017.
} 
In 2007, a team of 16 scientists, headed by Werner Wirth proposed a theoretical model for the formation of Spatial Presence. They studied and tested various video games and media technologies to understand what characteristics and parameters are required for a user to become spatially present within a game world. The framework laid out by Wirth et al. is useful in that it "integrates a range of existing theories from psychology, communication, and virtual reality into a clear and unified structure."${ }^{\circ 4}$ Spatial Presence is defined as "media contents [being] perceived as 'real' in the sense that media users experience a sensation of being spatially located in the mediated environment." ${ }^{, 49}$ This method will be used as a tool to analyze three conceptually different video games, to determine precisely what tools and strategies are successful in drawing the user in and building that human-to-virtual relationship that comes from being fully immersed in a game. These methods will then be applied to a virtual recreation of a particular site, to explore how we can experience the intangible qualities of heritage through a fully-immersive virtual environment.

${ }^{48}$ Miguel Mera, "Towards 3-D Sound: Spatial Presence and the Space Vacuum," The Palgrave Handbook of Sound Design and Music in Screen Media (Palgrave Macmillan UK: 2016): 94.

${ }^{49}$ B. Wissmath, D. Weibel, and R. Groner, "Dubbing or Subtitling? Effects on Spatial Presence, Transportation, Flow, and Enjoyment," Journal of Media Psychology 21-2 (2009): 114-125. 


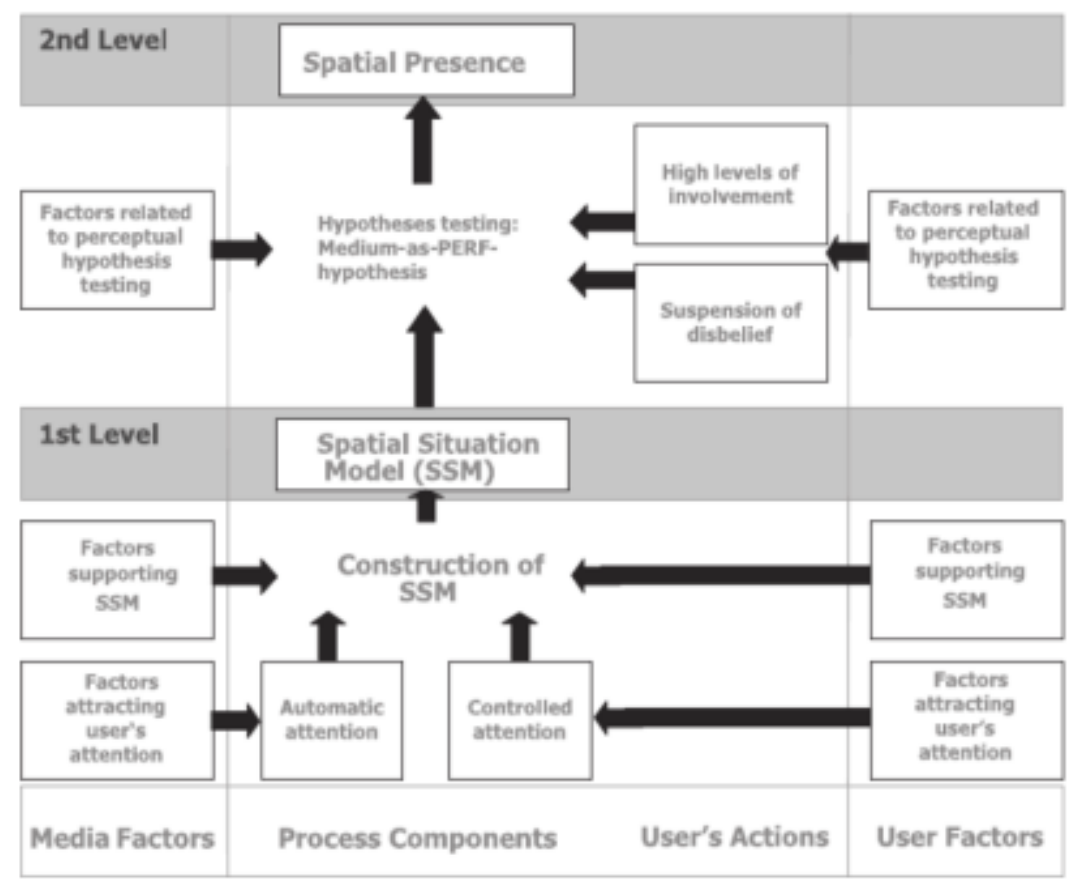

Illustration 7 Visualization of the two-level model of Spatial Presence

Dr. Jamie Madigan, author of The Psychology of Games website and related books, breaks down the theory of spatial presence as originally proposed by Dr. Wirth and his associates in his 2010 article entitled The Psychology of Immersion in Video Games. ${ }^{50}$ The article outlines the three steps that spatial presence occurs in:

1. Players form a representation in their minds of the space or world with which the game is presenting them.

2. Players begin to favor the media-based space (i.e., the game world) as their point of reference for where they "are."

3. Profit!

50 Jamie Madigan, “The Psychology of Immersion in Video Games,” Accessed February 2, 2017. 
There exist two major divisions of characteristics that contribute to spatial presence: player characteristics and media characteristics. While it is evident there are requirements media must possess in order to promote cognitive immersion, there are also certain characteristics required from the user. Combined, these characteristics lay out a very basic framework that outlines the requirements to achieve spatial presence through virtual means.

\subsubsection{Player Characteristics}

A user's mental state, personality, and desire for immersion are all factors that come into play in consideration of their ability to achieve spatial presence. Essentially, users who pay attention are rewarded with cognitive immersion experiences, whereas users who are disinterested or whose attentions aren't directed towards the media in question are unable to achieve the state necessary to achieve spatial presence.

There are two primary reasons why a user's attention may be directed towards the desired media. ${ }^{51}$ The first is when the media triggers one's attention through involuntary methods, where the sensory output or content of the media draws a user's intention through a high-level of intrigue or interest. In this case, it is essential that the media output is continuous and uninterrupted to ensure the sensory stimuli continues to hold the user's attention. For example, a television program with

\footnotetext{
${ }^{51}$ Wirth, et al. "A Process Model."
} 
exceptional visual display and sensory vividness_- or richness_- ${ }^{52}$ or dramatic contextual action may hold a user's involuntary attention in passing. In the event that the stimuli are interrupted, the user is pulled out of the involuntary immersion.

The second is when a user voluntarily offers his or her attention to the media in question because they understand it to be enjoyable or relevant to them. In this case, a user is predisposed to becoming immersed in a particular media due to a mental want or need to learn more or experience the media content. Motivational resources are not required to pique the user's interest, as the interest or motivation already exists. These users are naturally more likely to become spatially present or immersed in a media that related to their interests and addresses their motivations.

\subsubsection{Media Characteristics}

Media characteristics required in order to offer an opportunity for spatial presence are more easily quantifiable than player characteristics, as they rely on methods and characteristics of a particular media that can be assessed through a basic analysis of the virtual environments. Dr. Madigan breaks down two main categories of characteristics that promote spatial presence into those that "create a rich mental model of the game environment and those that create consistency between the things in that environment." ${ }^{, 53}$ In theory, by achieving states of both mental richness and consistency a game space or virtual environment has the potential to stimulate spatial

52 Jonathan Steuer, "Defining Virtual Reality: Dimensions Determining Telepresence," Social Responses to Communication Technologies, Stanford University (1993): 10.

53 Jamie Madigan, “The Psychology of Immersion in Video Games,” Accessed February 2, 2017. 
presence of its user. A detailed framework and breakdown of steps required to achieve both states, as broken down by Madigan in response to the framework outlined by Wirth et al. in their research, allows us to study virtual game worlds and dissect their characteristics as they relate to the formulation of spatial presence. The following sections discuss each step and characteristic as laid out in the previously mentioned research.

\section{Mental Richness}

Mental richness is loosely defined as a state of containing high quantities of something desirable, pleasing, deep, and/or strong. There are four primary characteristics a game space needs to achieve this state. They are multiple channels of sensory information, completeness of sensory information, cognitively demanding environments, and a strong and interesting narrative, plot, or story.

\section{Multiple channels of sensory information}

Straight forward in its title requirements, multiple channels of sensory information relate to the methods used to appeal to a user's five senses; sight, sound, touch, taste, and smell. Sight and sound are perhaps the two most common senses stimulated while playing video games, as visual and audio technologies are commonplace in most user's technological set up. Visually, modern games have reached a level of accuracy and vividness that rivals or exceeds the real world. Audio accompanies essentially any game on the current market, as music, talking, and background noise is translated through speakers or headphones. Touch has been addressed to a lesser degree, as many game consoles feature controllers that vibrate and move according to elements of the game. Smell and taste have yet to be addressed in mainstream 
games, but new technologies are being released that address all five senses, and plenty of prototype items are being tested.

\section{Completeness of sensory information}

Simply addressing each sense isn't enough. An environment must offer complete sensory information to ensure a user remains immersed in the game world. For example, an environment might be visually stimulating, however, if the trees and stream are completely still when they should, in fact, be moving, it may draw a user out of their immersive state. Likewise, creating an environment with solely inanimate objects and no people, when it would be logical for people to be present, may also have the same effect. Simple questions such as "why isn't there anyone else in the village?" may be enough to draw them out of the game world and back to reality.

\section{Cognitively demanding environments}

For a user to remain immersed in a virtual world, it is essential to draw on their mental capacity and cognitive awareness using challenging and mentally stimulating tasks. For example, if reaching the next level of a game does not require any form of mental stimulation, a user may lose interest. However, if the user must draw on their own mental resources to achieve something in the game space, they have become mentally invested in their virtual world. If a user's mental capacity is used up via a cognitively demanding environment, they are less likely to notice things that would draw them out of a state of immersion, because their mind is otherwise occupied.

\section{A strong and interesting narrative, plot, or story}


Perhaps the strongest tool, and one that is used effectively in the video game industry but not yet at all in the architectural industry, is the concept of a narrative or plot. A successful and intriguing story in a virtual world will capture the attention of a user similarly to how a good book will capture a reader and make them unaware of the world around them. The fact that having strong plot in literature is enough to stimulate spatial presence, where the other previous requirements of spatial presence are severely lacking, demonstrates the power of this requirement. It is perhaps the single most powerful tool in ensuring a user becomes fully cognitively immersed in

a virtual environment. It is also the broadest category, as narrative, plot, or story can span such a wide variety of themes and may appeal to certain demographics, whereas others may not be as interested.

\section{Consistency}

In considering the second category, there are also four primary characteristics a game space needs to establish consistency. A consistent environment will ensure a user remains spatially present in a virtual world. Inconsistencies can be jarring and may be enough to pull a user from a state of cognitive immersion back to their own realities. Consistency can be broken down into four main requirements; lack of incongruous visual cues in the game world, consistent behaviour from things in the game world, an unbroken presentation of the game world, and interactivity with items in the game world. The following characteristics outline the basic requirements to achieve a consistent virtual environment that will enforce spatial presence. 


\section{Lack of incongruous visual cues in the game world}

In terms of visuals, technology has advanced so far in that digital graphics can rival real world environments, and even offer enhanced visual experiences beyond what is possible in the real world. Vision is the sense we often rely on most in sensing and appreciating our environments, and in recognizing space. It is easy to become visually immersed in a virtual world, and it is essential to ensure the visual environment is seamless and consistent enough for the user to believe in the fictional space. Incongruous visual cues, such as graphic mistakes or inconsistencies, may draw a user out of an immersive state. These inconsistent visual cues in a virtual world have the same effect that being able to see backstage at a play has on a theatregoer or the effect of a boom microphone being dropped into a scene of a movie. A stronger example would be an advertisement dropping in the middle of the screen in the middle of an engaging battle sequence. The user is reminded of the outside world, and their spatial presence is challenged.

\section{Consistent behaviour from things in the game world}

Similarly to the previous category, it is important for all elements of the game world to remain consistent in their behaviour. If a game is set in an ancient civilization, but a background character begins speaking on a modern cell phone, the user will question the authenticity of the act, and their spatial presence will be challenged. Consistency in objects, people, backgrounds, and other game elements is essential in creating a believable and immersive story line and environment. 


\section{An unbroken presentation of the game world}

An unbroken presentation of the game world means that the virtual environment should remain consistently available and displayed. If the environment disappears to be replaced with a loading screen or some sort of background information display, it jars the cognitive focus of the user, and they lose their state of mental immersion.

\section{Interactivity with items in the game world}

This requirement relates largely to the previous section on mental richness, as it offers a more contextually rich experience of the game world. Consistent interaction with elements in the game world, such as background characters, inanimate objects that offer a particular use or benefit, or even the consumption or food or drink items, offers a sense of consistency between the user and various parts of the virtual environment. A user is able to interact with items similarly to how he or she would in the real world, enhancing their sense of immersion through consistency of action and interaction.

\subsection{Immersive Video Game Case Studies}

The benefit of having a clearly empirically laid out framework for achieving spatial presence lies in our ability to outline the characteristics needed in a game that will result in a fully immersive product. It also allows us to look critically at existing games to discuss their successes and setbacks in achieving spatial presence.

There are, of course, numerous variations and types of video games, and not all of them are considered immersive. Most racing games, for example, are not fully immersive as they do not offer the benefit of connecting with a virtual world in an 
emotional way. They are simply intended for momentary gratification, and when you leave the game world, you are disconnected completely with the virtual space. Role playing games and fully interactive live MMORPGs (Massively Multiplayer Online Role-Playing Games) are considered immersive in that they allow the user to become cognitively present in the game world, ultimately forgetting they are in a virtual space other than that where they physically exist.

A popular game that can be considered immersive is the Assassin's Creed video games. The previously mentioned framework for spatial presence can be utilized to break down the game components and examine what characteristics exist in the game world that results in spatial presence. In looking critically at an existing immersive game, we can better understand the components required for spatial presence, which will ultimately allow us to apply our understanding of said characteristics to a new environment that will promote spatial presence. The expectation is, that through a study of spatial presence of an existing successful game, we can then analyze the results and apply them to a virtual recreation of an architectural historic site, and explore ways to create a cognitively immersive gamelike world that will allow a user to become spatially present, and ultimately able to experience or build their own intangible values surrounding the site.

\subsubsection{Case Study: Assassin's Creed}

The Assassin's Creed video game series is an immensely popular set of video games that explored fictional recreations of historic cities. The user controls an assassin that sets out to defeat the Templars and protect free will in the cities. Each game is set in 
a different city during a different historical period, and the goal is to win the war against the Templars and protect the city's freedom. ${ }^{54}$ As is evident through online forums and gaming communities, it is not uncommon for users to become completely immersed in these games for weeks if not months at a time, and the games are hailed as an exemplary demonstration of virtual immersive environments. This game was selected as an example due to its deep historical connection and successful franchise history. The user embarks on a journey through the game world, accessing new environments, progressing through a narrative story-line, and completing tasks and challenges along the way. The completeness of the game world and the cognitively demanding challenges throughout the story line, in addition to the end goal of winning the game by progressing successfully through the narrative, are what enables these games to be so highly immersive.

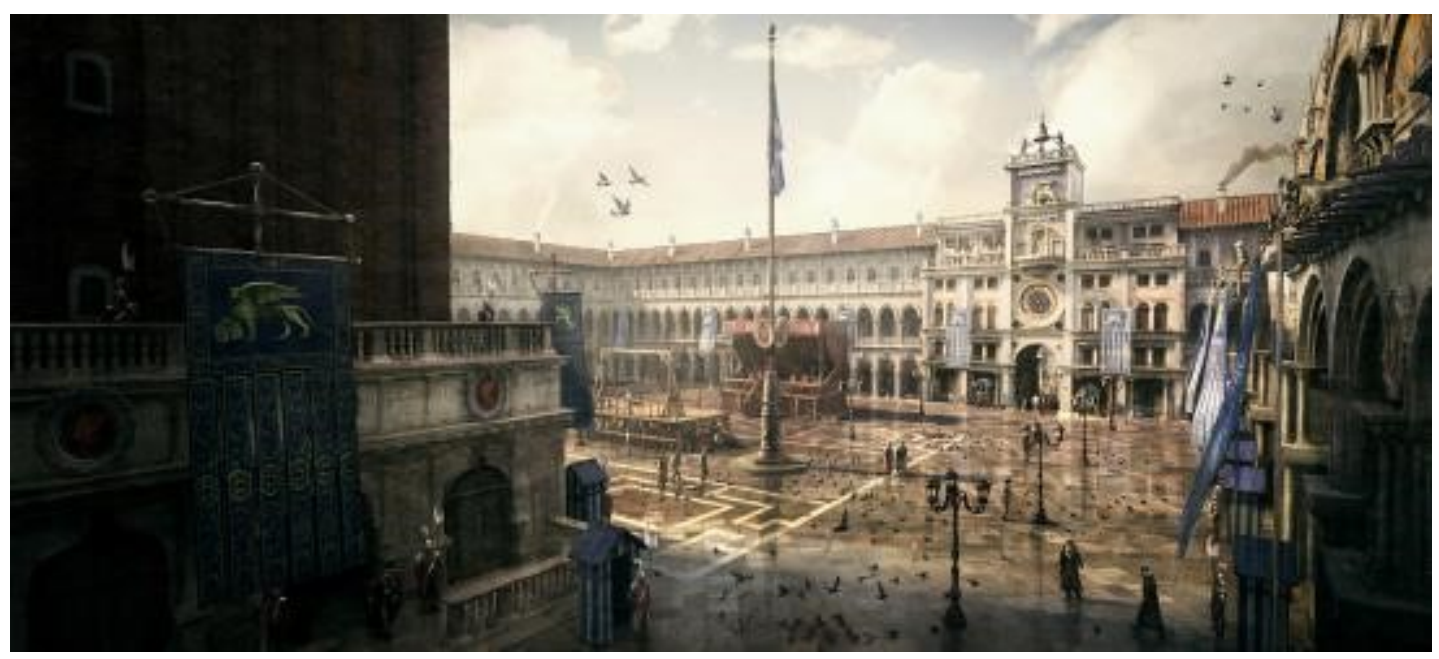

\section{Illustratin 8 Assassin's Creed II, Ubisoft Montreal}

54 “Assassins vs. Templars,” Ubisoft. https://www.ubisoft.com/en-US/game/assassins-creed/ 
Ubisoft, the game developers, ensured the virtual environments and game elements were accurate to the chosen histories within the game. They hired consultants to research the accuracy of their representations. Maria Elisa Navarro, a Ph.D. Student at McGill University at the time, consulted for Assassin's Creed II, a game set in Renaissance Florence. One correction she noted was the inclusion of wrought iron balconies in the game, which would not have existed in that time period, which were removed and replaced with historically-accurate material to ensure accuracy and completeness of the virtual game world. ${ }^{55}$ The beauty of video games, a phenomenon that parallels heritage, is that a user's cultural background impacts their experience of the game or environment. For example, the Middle-Eastern cities, architecture, words, and gestures in Assassin's Creed: Revelations, the fourth instalment of the game, may elicit nostalgic feelings for a user who is from or has visited the Middle-East. Users unfamiliar with the region reported very different immersive experiences of the game, referencing the architecture and environmental layouts in general as it facilitated game play. ${ }^{56}$ Users experience the game worlds in different ways, imposing their own cultural beliefs, experiences, and awareness to the experiences, all of which contribute to the user's ability to become immersed in the game. Through these immersive games, users are able to instil their own cultural

\footnotetext{
${ }^{55}$ Manuel Saga, "What It's Like to be an Architectural Consultant for Assassin's Creed II," Translated by Matthew Valletta, ArchDaily (2015), Accessed February 5, 2017.

56 Magy Seif El-Nasr, Maha Al-Saati, Simon Niedenthal, and David Milam, "Assassin's Creed: A Multi-Cultural Read," Simon Fraser University Journals (2008)
} 
values on the game experiences, build new value systems based on the new experiences, and benefit from the games on a cognitive and emotional level.

The following table depicts my personal analysis of Assassin's Creed based on Dr. Madigan's breakdown of Wirth et al.'s framework for spatial presence.

\begin{tabular}{|c|c|c|c|}
\hline Characteristic & Strong & Average & Weak \\
\hline \multicolumn{4}{|l|}{ Richness: } \\
\hline Multiple channels of sensory information & & & \\
\hline Completeness of sensory information & & & \\
\hline Cognitively demanding environments & & & \\
\hline A strong and interesting narrative, plot, or story & & & \\
\hline Consistency: & & & \\
\hline Lack of incongruous visual cues in the game world & & & \\
\hline Consistent behaviour from things in the game world & & & \\
\hline An unbroken presentation of the game world & & & \\
\hline Interactivity with items in the game world & & & \\
\hline
\end{tabular}

Table 1 Spatial presence characteristic assessment of Assassin's Creed.

\subsubsection{Case Study: World of Warcraft}

World of Warcraft, developed by Blizzard Entertainment in 2004, is an immensely popular Massively Multiplayer Online Role-Playing Game (MMORPG). The game world is immense and, as users level up, their characters interact with computergenerated challenges and other users playing the game live. The level of live interaction and collaboration between users is in part why the game is so appealing to a wide audience. However, it is the consistency, interactive elements and cognitively demanding experiences within the game world that immerse users and 
maintain their interest throughout ongoing subscriptions. ${ }^{57}$

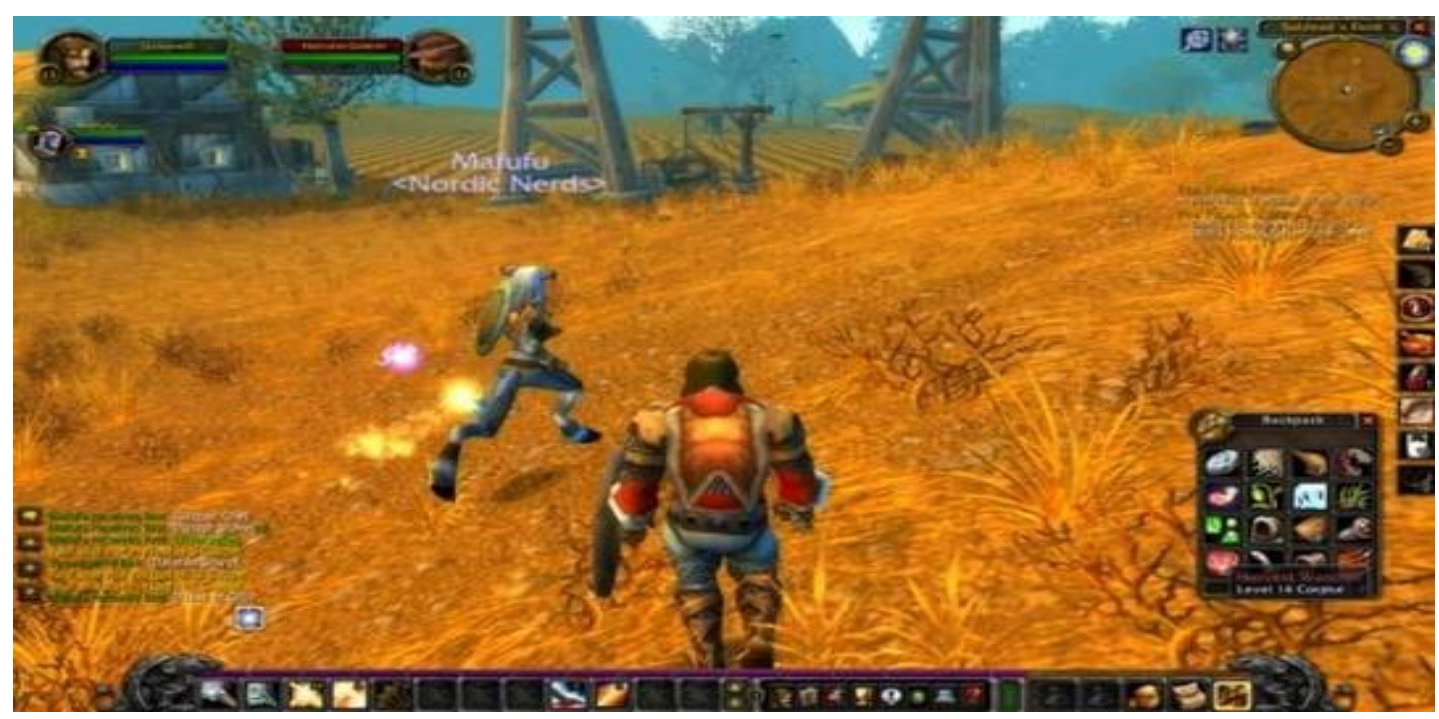

Illustration 9 World of Warcraft gameplay user interface.

Users have been known to subscribe to the game for years at a time, consistently returning to the game world to continue their character advancement and social interactions, remaining committed to the game and their characters. ${ }^{58}$ What is unique about the game as it relates to spatial presence, is that the graphic environments are hyper unrealistic and cartoonish, yet the environments remain highly immersive. This is largely due to the consistency of the game world. As players move through and experience the massive environment, the unique visuals of the fantasy world become known as the game's reality. So, while lacking in visual quality, the high levels of interaction, strong narrative and story sequences, and consistency of the

57 Alex Golub, "Being in the World (of Warcraft): Raiding, Realism, and Knowledge Production in a Massively Multiplayer Online Game," Anthropological Quarterly 83-1 (2010): 17-46.

58 Nicolas Ducheneaut, Nick Yee, Eric Nickell, and Robert J. Moore, "Building an MMO With Mass Appeal,” Sage Journals, V.1-4 (2006) Accessed January 5, 2017. 
environment and experiences create a highly immersive gaming experience that has proven immensely successful over the years. The benefit of such an immersive environment is that the users gain appreciation for the game world; they place value on their experiences and their characters, and the virtual world begins to matter. It is one of the most popular MMORPGs to date, comprising over six million subscribers worldwide ${ }^{59}$ Patrick Webb, a twelve-year committed World of Warcraft player, describes his reasons for remaining with the game in an interview conducted March 1, 2017: "I've invested so much time and emotional energy in the game. I place value on my character and the game world I've dedicated much of the last twelve years of my life participating in." When asked what his reaction would be in the event that the game world, Azeroth, would be destroyed or somehow disappear, he responded, "I would be devastated. I feel connected to Azeroth through the game. It's almost as if it's a real place to me." ${ }^{\circ 0}$ The following table depicts my personal analysis of World of Warcraft based on Dr. Madigan's breakdown of Wirth et al.'s framework for spatial presence.

\footnotetext{
59 Ducheneaut et al. ““'Building an MMO With Mass Appeal.”

60 Patrick Webb interview, March 1, 2017. Ottawa, Ontario.
} 


\begin{tabular}{|c|c|c|c|}
\hline Characteristic & Strong & Average & Weak \\
\hline \multicolumn{4}{|l|}{ Richness: } \\
\hline Multiple channels of sensory information & & & \\
\hline Completeness of sensory information & & & \\
\hline Cognitively demanding environments & & & \\
\hline A strong and interesting narrative, plot, or story & & & \\
\hline Consistency: & & & \\
\hline Lack of incongruous visual cues in the game world & & & \\
\hline $\begin{array}{l}\text { Consistent behaviour from things in the game } \\
\text { world }\end{array}$ & & & \\
\hline An unbroken presentation of the game world & & & \\
\hline Interactivity with items in the game world & & & \\
\hline
\end{tabular}

Table 2 Spatial presence characteristic assessment of World of Warcraft. 


\section{Chapter: Spatial Presence in Virtual Heritage}

Presence, as defined in the previous chapter, is the concept of "being" somewhere spatially different from where you physically exist. As a person is physically unable to be in two places at once, a user must believe "that he is physically in an environment that in actual fact he isn't present in." ${ }^{\prime 61}$ The previous chapter described requirements to achieve such a phenomenon in video games, as outlined by Wirth et al. in their research paper entitled A Process Model for the Formation of Spatial Presence Experiences. Users who are spatially present in a game world are enabled the opportunity to partake in intangible experiences, building emotional relationships with the game world that ultimately result in an empathetic relationship between the user and the virtual environment.

As discussed in past chapters, heritage, by definition, comprises both tangible and intangible values. If we are to truly experience the complete definition of heritage in virtual reality, we must ensure the intangible values are translated into the experience, and not solely the visual representation of the tangible space. Accepting the hypothesis that, through spatial presence, we are able to experience new cultures, build value systems, and, in essence, experience the intangible, it is proposed that by creating virtual heritage environments that promote spatial presence, we will enable

${ }^{61}$ Xavier Retaux, "Presence in the environment: theories, methodologies and applications to video games," PsychNology Journal V 1-3 (2003): 286. 
users the opportunity to experience both tangible and intangible heritage values in virtual reality.

With the understanding that certain characteristics are required for a virtual environment to allow for spatial immersion, we can look more closely at how we create and experience virtual heritage. Virtual reality is a common tool in the heritage industry, but until today, it has been predominately utilized to visually recreate the site's physical attributes into a virtual representation. Historic sites are documented through various methods, and translated, whether through modeling or photographic manipulation, into three-dimensional virtual environments able to be experienced in virtual reality. Technology has gone so far to enable these visual representations to come close to rivalling reality, and some go so far as to exceed the visual experience of what a user may see on-site through enhanced graphic capabilities; for example, a recreation of a lost or damaged site.

There have been a number of international virtual heritage projects that have gone farther than simply virtual images of documented sites. Architectural recreations of lost heritage exist as a way for site users to visualize what was previously there. For example, the virtual reality heritage project in Ename, as previously discussed, has successfully demonstrated how we can use virtual recreations and manipulations to experience a site's history, where we couldn't otherwise experience it in real life. The Centre Block virtual tour, on the other hand, depicts a hyper-realistic visual representation of an historic place as it exists today. However, while projects such as these succeed in depicting the tangible qualities of a site, either existing or recreated 
through historic re-interpretation, they do not go so far as addressing the key intangible values that define the site's heritage.

In analyzing the video game industry and its ability to enable cognitive immersion in virtual worlds, allowing their users to experience values and build empathetic relationships in a game, we can begin to explore new methods of experiencing the same values and build the same empathetic relationships to a virtual recreation of an historic place through similar methods. If we can, by following along with the framework outlined to create spatial presence in a virtual historic environment, we may, in fact, uncover a way for a user to experience the full tangible and intangible definition of cultural heritage. By drawing on the characteristics outlined through spatial presence theory to experience intangible values, and the technologies and methodologies used in the heritage industry today to capture and represent tangible space, we can begin to formulate a new methodology that will give a user a complete experience of cultural heritage in virtual reality.

We may be able to break through the barriers that we have faced thus far in our visual representations of heritage and unlock the ability to experience the intangible in virtual space, as one would in a virtual game world. Such an achievement would allow a user to build value systems and experience intangible values, as they would be in "a psychological state in which virtual (para-authentic or artificial) objects are experienced as actual objects in either sensory or non-sensory ways," 62 thus enabling

${ }^{62}$ Kwan Min Lee, “Presence, Explicated,” Communication Theory 14-1 (2004): 27-50. 
the user to experience true heritage through the act of being spatially immersed in the virtual historic environment. This thesis proposes a methodology that combines the tangible representations as found in the heritage industry and the intangible experiences $\mathrm{s}$ found in the gaming industry, that will allow an accurate representation of cultural heritage through virtual reality. Drawing on lessons learned from past chapters, a framework is proposed that will enable intangible and tangible values and characteristics alike to be incorporated into virtual heritage, accessible to a global audience through virtual reality technologies.

\subsection{Audience Consideration}

We live in an age of technology, and in the past few short years, virtual reality has gone from an advanced technology utilized in professional and scientific environments to being a widely-used technology available in the common home. This opens up enormous possibilities in who can experience cultural heritage through virtual reality. No longer are we limited to specialized equipment only industry professionals can utilize, but these experiences are now available to the public as a whole within their very own living rooms.

Prior to commencing any project proposal, particularly one that is so reliant on its user for success, it is crucial to define a target audience for the product. As the general public now has the opportunity to experience what was once reserved for industry professionals and researchers, this opens up tremendous possibilities in sharing the world of heritage with a broader audience, even one that once perhaps would not have been interested in heritage on their own. Through this new global 
accessibility of virtual reality, the heritage industry may, perhaps, even become a desirable topic for gamers and other non-industry professionals.

The intent with exploring the experience of heritage through virtual reality is to communicate a site's history through virtual methods to a broader audience. As such, architects and conservationists aren't necessarily the target audience for such a product, however, they may still find value in such a tool in terms of experiencing a site in a new way.

The intended audience for the proposed game-like virtual recreation of an historic site would be the general public, more specifically those interested in visiting or learning more about the site and its history. There are two primary audiences that would benefit from such a product or experience, although in two very different ways. Users who visit the site and are interested in exploring it in a new way would benefit from the virtual environment in that they would be given an opportunity to experience the site in a completely new capacity, and the opportunity to learn more about the site's history in a unique way would benefit the user as an enhancement to their pre-existing knowledge or experience of the site. The primary benefit here is that a program such as this will allow the visitors to experience new layers of information that would add to the experience of visiting the real place. Users who are unable to visit the physical site would benefit from the program by it enabling them to experience cultural heritage through virtual reality. The primary benefit here is that they are given the opportunity to experience and build their own values based on the site, and ultimately be given the opportunity to develop empathetic relationships with the virtual heritage in question. In both instances, the user is 
exposed to a new experience of a particular site, with additional layers of information and unique interaction that they otherwise would not be allowed access to through simply visiting a site or reading about it through research.

\subsection{Proposed Framework}

This thesis proposed a five-step methodology in creating virtual heritage that allows a user to experience both tangible and intangible values through the promotion of spatial presence in virtual reality. The three steps include:

1. Define heritage values and character-defining elements.

2. Establish target goals and purpose of virtual heritage experience.

3. Represent tangible space through documentation, representation, or interpretation.

4. Represent intangible values through cognitively immersive experiences.

5. Evaluate.

The following sections will elaborate on each proposed step, offer references to support the basis for each methodology, and offer a list of characteristics necessary to achieve each step successfully.

\subsubsection{Step 1: Define heritage Values and Character-defining Elements}

Methodology: Thoroughly research and understand the site in question and establish an appropriate list of heritage values and character-defining elements that follow the Parks Canada guidelines.

Prior to beginning the representation of cultural heritage in virtual reality, it is prudent that a strong understanding of all tangible elements and intangible values of 
the site are established, and character-defining elements are documented. Parks Canada's Standards and Guidelines defines character-defining elements as: the materials, forms, location, spatial configurations, uses and cultural associations or meanings that contribute to the heritage value of an historic place, which must be retained to preserve its heritage value. ${ }^{63}$ In the event that the site is recognized as an historic place, the character-defining elements may already be established. If the cultural heritage in question is not yet officially recognized, the character-defining elements must be established as the first step of the proposed methodology. This will offer a complete list of tangible elements that will be translated into virtual reproductions, and intangible values that will be addressed through carefully constructed experiences, in the following steps. Once established, the tangible elements and intangible values should be categorized in two separate lists.

\subsubsection{Step 2: Establish target goals and purpose of virtual heritage} experience.

Methodology: Establish a clear set of target goals and outcomes intended by the virtual heritage experience.

In order to be able to accurately measure the success of the virtual experience, it is essential to first establish a set of goals and desired outcomes for the project. As defined in Chapter 3, the intent behind virtual heritage is to share the experience with "a global audience in such a way as to provide formative educational

\footnotetext{
${ }^{63}$ Parks Canada, The Standards and Guidelines for the Conservation of Historic Places in Canada.
} 
experiences through electronic manipulations of time and space." ${ }^{64}$ An educational purpose is inherent in the definition of virtual heritage, and while, in order to capture the full definition of heritage in a virtual environment by incorporating both tangible and intangible elements and values into the experience, the overall outcome should be educational. The user must learn something from the experience, and in most cases, this aspect will surround the history of the site. The virtual heritage must also translate both tangible and intangible values into the experience.

\subsubsection{Step 3: Represent tangible space through documentation, representation, or interpretation.}

Methodology: Recreate the tangible elements of the site in question by either a) photorealistic visual representation based on photographic documentation, or b) artistic recreation based on scholarly interpretation. Ensure the following characteristics are met in the creation of the virtual environment to ensure the virtual reality environment successfully facilitates spatial presence: multiple channels and completeness of sensory information (at the minimum, visual and sound), an unbroken and consistent presentation of the virtual environment, and a lack on incongruous visual cues.

The London Charter acknowledges the need for ensuring computer-based visualization methods are applied with "scholarly rigour, and that the outcomes of research that include computer-based visualization should accurately convey to users

\footnotetext{
${ }^{64}$ Stone and Ojika, "Virtual Heritage: What Next?"
} 
the status of the knowledge that they represent, such as distinctions between evidence and hypothesis, and between different levels of probability." ${ }^{95}$ This suggests that it should be explicitly clear whether the visualization represents an accurately documented existing site or a recreation of a lost site based on artistic representation and interpretation. An accurate and complete visual representation of the tangible space will facilitate immersion in virtual reality. Setting the state through the interpretation of material space is the first step in creating convincing virtual environments. If the virtual heritage in question is intended on representing an existing site, an accurate documentation through photographic methods translated into a virtual model will ensure a believable and accurate representation of reality. Photorealistic environments that mimic the physical characteristics of the actual site are preferable for representations of existing heritage. If the virtual heritage in question is intended on recreating a lost or altered cultural heritage site, artistic license can be implemented, and the resulting virtual environment should accurately depict the fact that the visualization is, in fact, a recreation and not an accurate depiction of a documented site.

The following characteristics are inspired by Wirth's Framework for Spatial Presence as laid out by Dr. Madigan and relate directly to the creation of the crafted virtual reality environment. By ensuring these characteristics are met, the virtual

65 “The London Charter,” Accessed February 6, 2017. http://www.londoncharter.org 
reality environment will set the stage for an immersive experience as it relates to the environment itself.

Multiple channels and completeness of sensory information: As this category relates to the physical characteristics of the site, it is straightforward to address. The sights, sounds, smells, and textures of the site can be recorded and recreated using existing and prototype virtual reality technologies. Sounds and sights can be immediately installed into a head set, and are the most important senses to address in setting the stage for an immersive environment, as the integration of sound is known to enhance the sense of presence. ${ }^{66}$

An unbroken and consistent presentation of the virtual environment: Significantly reliant on the methods utilized to create the environment, a user must be offered an unbroken experience of the virtual space. Movement from one sphere to the next, or however the user is able to move through the environment, should be smooth enough so that the user does not disconnect from their immersive state. If the virtual reality environment is based on a real-world environment rather than a fictional fantasy world, creating consistent behaviour in the virtual world will be crucial in designing a convincing environment to the user. Simple things such as water flowing in the correct direction of a stream, contextually relevant sounds, and interactive experiences that are consistent with true historical events, will allow the experience to be consistent and believable. If the virtual environment is based on an artistic

${ }^{66}$ Serafin, "Sound Design to Enhance Presence in Photorealistic Virtual Reality," 1. 
interpretation of a site, ensure the representation is consistent throughout the environment to ensure the user can grow to believe the surroundings.

Lack on incongruous visual cues: This category is what sets a game-like environment apart from an architectural modelling interface. A consistent visual representation of the environment without the added tools available in typical architectural software is essential in allowing the user the ability to get lost in the game space. This is also primarily where audience plays a major factor in the design of the environment, as the inhabitable virtual space must be designed in such a way for the general public to be able to experience it without the need for specialized software training or modelling abilities. The environment will be stripped of controls apart from those essential to the game-space experience, such as minor navigation buttons or interactive elements. Unlike typical modelling or other architectural or recording software, the user interface is minimal to non-existent to ensure the user is not drawn away from the virtual environment.

\subsubsection{Step 4: Represent intangible values through cognitively immersive} experiences.

Methodology: Incorporate the intangible values of the site into the virtual heritage experience. Ensure the following characteristics are met to ensure a cognitively immersive environment that promotes spatial presence: cognitively demanding environments, a strong and interesting narrative, plot, or story, and interactivity with items in the game world. 
This stage is the most crucial in ensuring a complete experience of cultural heritage, as it relates to the intangible values that relate to the site in question. These are also the values that tend to get ignored in past representations of virtual heritage, yet are the most significant in defining a site's heritage, as these values relate to human experience and cultural values.

Cognitively demanding environments: Virtual heritage should comprise some sort of challenge that requires the user to think critically within the environment and solve puzzles or progress through steps in order to advance. This will enable the user to mentally invest in the experience, increasing opportunity for immersion.

A strong and interesting narrative, plot, or story: Based on the cultural heritage site's history, questions such as who, what, when, where, and how can be addressed and formulated into a story that the user progresses through as part of the virtual reality experience. Crucial in a user's interaction of the intangible values of cultural heritage, a complete narrative experience will provide the opportunity for the history of the site to be told and interacted with.

Interactivity with items in the game world: Fairly self-explanatory, this characteristic contributes to cognitively demanding environments and a strong and interesting narrative, plot, or story. As a user progresses through stages or puzzles as they relate to the story, elements of interaction will enhance the experience and help the user feel like they are participating within the virtual heritage. 


\subsubsection{Step 5: Evaluate}

Methodology: Evaluate the outcome of the virtual heritage project by comparing the user's experience to the desired outcomes established in Step 2.

The final step of the proposed methodology is to evaluate the effectiveness of the virtual heritage project. Have the objectives outlined in Step 2 been met? As virtual heritage is meant to be educational, learning transfer should be evaluated. Learning transfer, as it relates to virtual reality, is defined as when a user learns something in VR that they can use in real life. ${ }^{67} \mathrm{~A}$ user's knowledge and understanding of the site after the experience compares to before the experience will provide insight into the successes of the virtual heritage project. The true test, however, is to determine whether users have developed empathy for the cultural heritage site represented through virtual reality. A user's feeling towards the site, in terms of appreciation, emotional connection, and newly perceived values will enable the researcher the ability to gauge the success of the experience. In the event that the user does not feel connected to the site in any way, the experience likely lacked a strong enough cognitive immersion as it relates to a site's intangible values and history.

\footnotetext{
${ }^{67}$ Bloom, et al., Taxonomy of Educational Objectives, Handbook I: The Cognitive Domain (New
} York: David McKay Co Inc.,1956) 


\section{Chapter: Project Example}

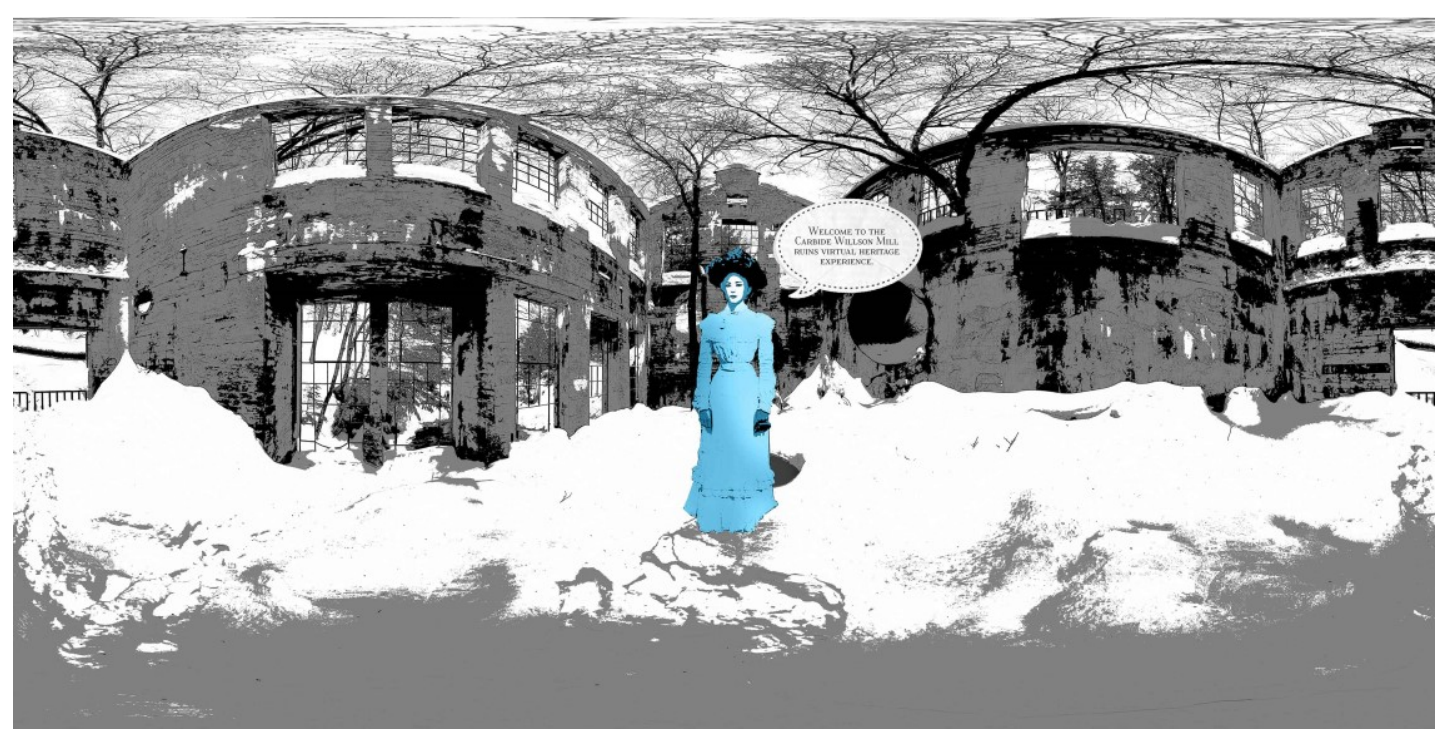

Illustration 10 Carbide Willson Mill Ruins virtual reality experience.

To demonstrate the proposed framework, the following chapter proposes a virtual heritage game world based on the Carbide Willson Mill ruins site in Gatineau Park. Based on the proposed framework, the project will be broken down by each step and characteristic in an effort to demonstrate methodologies that can be applied to the formation of the representation of the site in virtual reality. The aim is to create a virtual heritage experience that promotes spatial presence, thus enabling the user the opportunity to experience both tangible elements and intangible values of the cultural heritage site. 


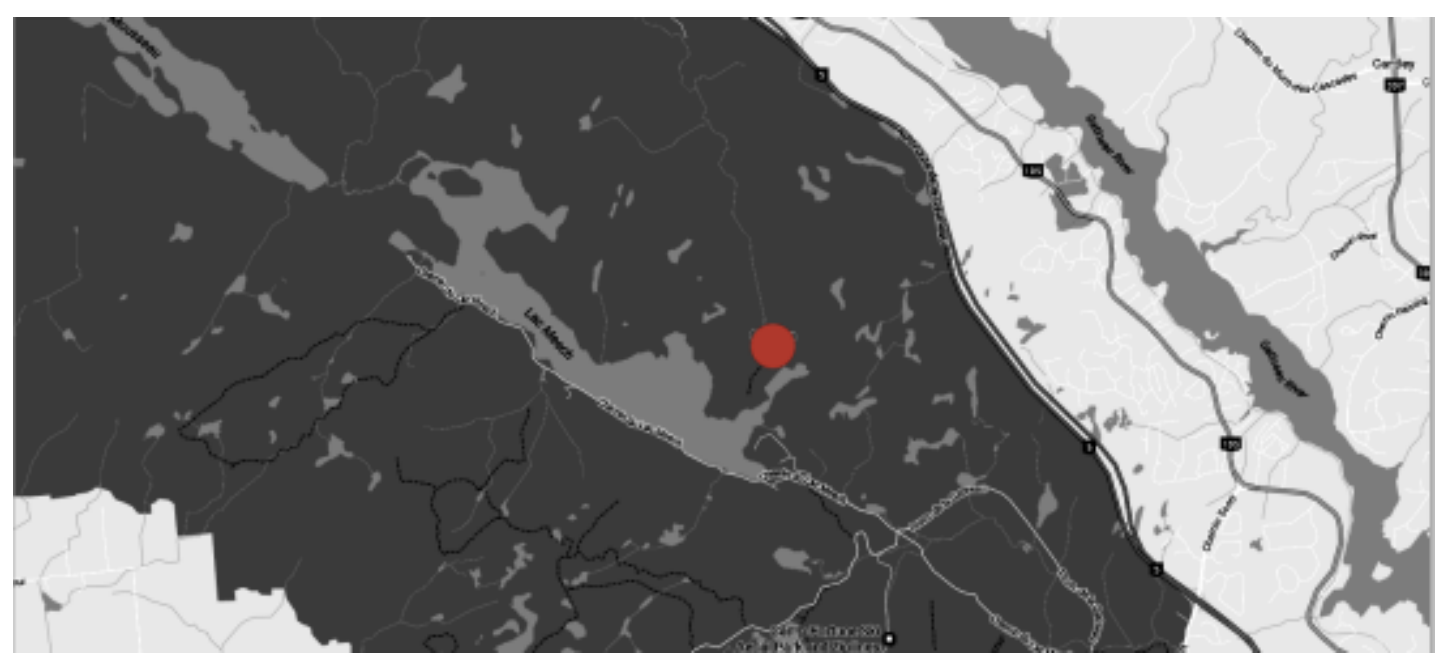

Illustration 11 Location of Carbide Willson Mill ruins, Gatineau Park

\subsection{Site Introduction: Carbide Willson Mill ruins}

The chosen site for the project proposal is the Carbide Willson Mill ruins located in Gatineau Park, Quebec. The site was chosen due to its rich industrial history, unique material fabric, and fascinating narrative and story-telling opportunities.

Thomas Leopold Willson was a Canadian inventor born near Princeton, Ontario, in 1860. Known as the man who turned "water into light," 68 by twenty-one he had patented his own design for the first electric arc lamp. His most notable discovery was a process to create calcium carbide which produces acetylene gas, which was

${ }^{68}$ Jenniver Paton, “Willson, Thomas Leopold," Dictionary of Canadian Biography. V XIV (19111920) 
commonly used to create light. Willson stumbled upon the discovery while attempting to create a more economical process for fabricating aluminum. ${ }^{69}$

In 1907, Willson built a summer home on Meech Lake. Four years later he built an industrial plant at nearby Meech Creek, where he experimented with condensation methods of phosphoric acid. Unfortunately, not long after, Willson ran out of money and lost most of his estate to J.B. Duke, an American tobacco industrialist. ${ }^{70}$ In 1915 , while raising funds for a hydroelectric project in Labrador, Willson died of a heart attack. The project was eventually brought to fruition in 1973, labelled the Churchill Falls project. Today, the remnants of his estate and mill in Gatineau Park are accessible to the public.

A popular tourist destination in Gatineau Park, the mill on Meech Creek was the site of many experiments and the production of fertilizer through his exploration of uses of calcium carbide. A concrete shell of its former self with no windows or roof, the mill is located directly adjacent to the creek and is surrounded by the remnants of other industrial outbuildings. The acid condensation tower succumbed to a fire and was burnt to the ground. All that remains is a circular footprint of what once stood tall on the site. ${ }^{71}$ The dam and generating plant were never maintained, and today,

\footnotetext{
69 “Commercial Process for Producing Calcium Carbide and Acetylene,” Accessed February 2, 2017. https://www.acs.org

70 Michael Klepper and Michael Gunther, The Wealthy 100: From Benjamin Franklin to Bill GatesA Ranking of the Richest Americans, Past and Present (Secaucus, New Jersey: Carol Publishing Group, 1996), 100.

71 “Willson Ruins," Capital Gems, Accessed February 10, 2017.
} 
overgrown vegetation and imposing trees surround the ruins, offering a ghosted glimpse into the site's industrial past.

The site itself is not officially registered as an historic place on the Canadian Register. However, due to its unique fabric and histories and the role the site played in Canada's industrial heritage, the site is a considerable piece of our country's industrial heritage. Despite it being a popular destination for hikers in the summer, there is little information available online about the site and its rich history. A virtual heritage experience will offer a unique look at the mill and render the site accessible to a broader audience.

\subsection{Framework Breakdown}

\section{Define heritage values and character-defining elements.}

The primary heritage values of the Carbide Mill ruins site are the history of the site's owner, Thomas Willson; the role the plant played in the industrial history of the region; and the industrial activities that occurred at the mill, including Willson's manufacturing of fertilizer created from calcium carbide and nitrogen gas.

The character-defining elements include the structure's location within Gatineau Park adjacent to Meech Creek set within a forested area, the extant concrete walls with door and window openings, cylindrical exhaust opening, concrete cylindrical tower base, and concrete remnants of the dam. 


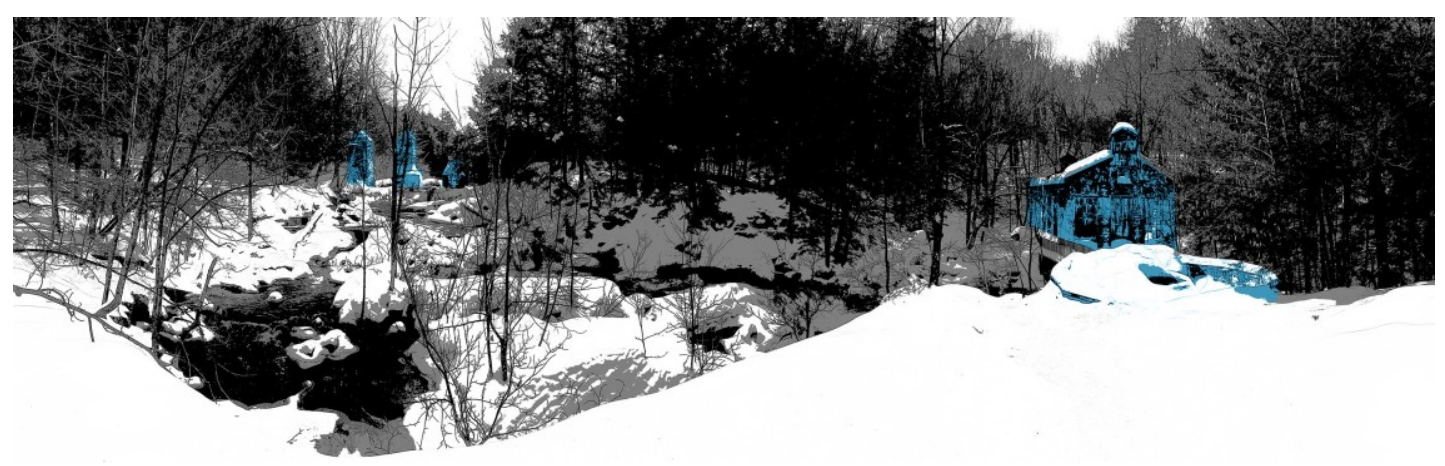

Illustration 11 Highlighted character-defining elements.

\section{Establish target goals and purpose of virtual heritage experience.}

The intent behind the Carbide Willson Mill virtual heritage project is to educate the public on the history and heritage value of the mill site; the experiments and resulting inventions that took place there; and the inventor himself, Thomas Willson. Through an interactive virtual reality experience of the site based on photographic documentation and virtual interpretation or recreation of historical events, a user will gain knowledge and appreciation of the historic site and its significance as part of Canada's industrial history.

\section{Represent tangible space through documentation, representation, or interpretation.}

360 degree photographic spheres were taken on-site and utilized to create a visuallyaccurate representation of the site as it exists today. The spheres were translated into a virtual reality experience and will provide the experiential base for which the following characteristics can be applied. 


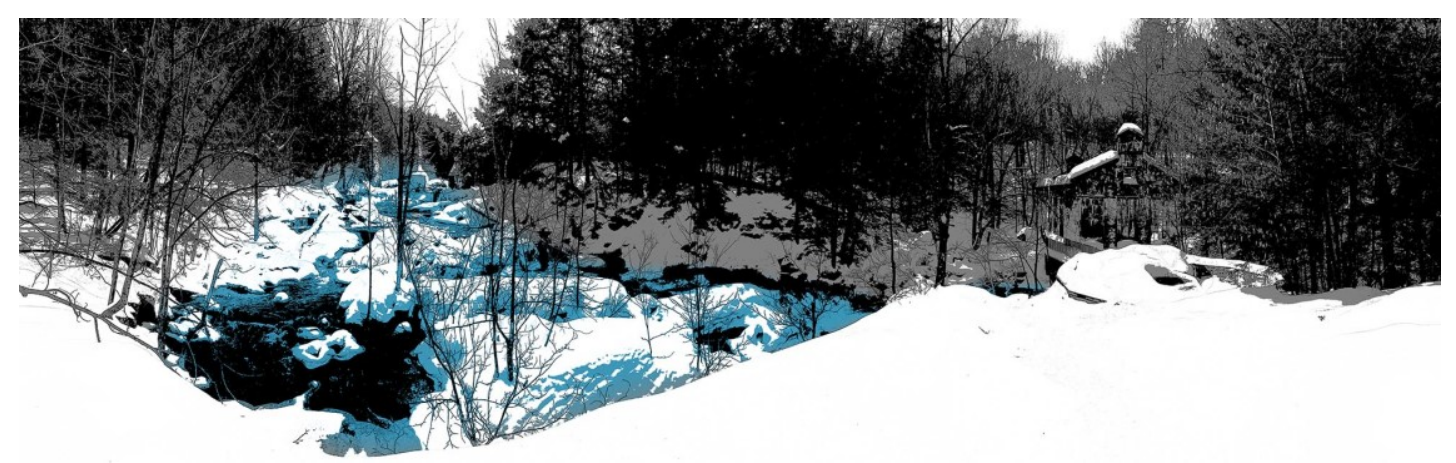

Illustration 12 Sensory recreation of tangible elements. The sound of water from the creek.

Multiple channels and completeness of sensory information: Beyond the visual, exterior sensory information of this particular site includes the scent of the forest, the sound of rustling leaves in the surrounding trees, birdsong, and the soft rushing of water down the nearby stream. For the interior experience, the sounds of an eccentric inventor in his shop can be recreated, including the creaking of machines, the hum of electricity, the flickering of gas lights, and even the mutterings of Willson himself. A fantasy world of sights, sounds, and other senses can be artistically replicated to demonstrate a day in the life of Thomas Willson as he works in his mill.

An unbroken and consistent presentation of the virtual environment, and lack of incongruous visual cues: Through the virtual reality environment, the user will be able to move through an unbroken series of photospheres, replicating a threedimensional visual experience. Minimal user interfacing will exist apart from what is necessary to navigate and interact with objects in the game world. 


\section{Represent intangible values through cognitively immersive experiences.}

A strong and interesting narrative, plot, or story: Perhaps the most intriguing of the characteristics, this is where the site's history comes alive. The Carbide Willson mill was the working site of an eccentric inventor who significantly impacted the local industrial economy, and, not only did his work greatly contribute to Canada's industrial history, but his personal life was as intriguing as his inventions.

While a significant player in Canadian history, he was perhaps not a favoured neighbour at the time. Damming the creek and flooding his neighbors' boat houses did little to improve his popularity. Through an exploration of both his industrial and personal histories, a unique educational narrative will enable the users to get to know the man behind the mill and immerse themselves in his world.

Elements of the historical narrative include the following:

- Angering neighbours by flooding their boathouses as a result of damming the waterways for his experiments.

- Concealing his experiments and discoveries in the heavily wooded area, as he was known to be suspicious of outsiders stealing his secrets.

- Experimenting with new applications for carbide, including his creation of fertilizer derived from nitrogen gas and calcium carbide - the primary manufacturing that took place at the mill. 
- Pride regarding the construction of first phosphorus acid condensation plant in the world - the tower that was eventually destroyed by fire. ${ }^{72}$

- His eventual death in poverty. Despite the fact that the plant was producing fertilizer beyond expectations, Willson ran out of money, and his assets were seized. Today, the site lays in ruin, demonstrative of the later events of his life after building the Meech Lake plant.

Cognitively demanding environments: Through a series of challenges that follow the narrative of the historical storyline, users will be expected to solve puzzles, interact with the environment, and complete tasks that progress the storyline. A series of challenging questions that relate to the site's history are asked upon beginning the game, and the answers are discoverable by interacting with elements in the game world. Challenges will include sourcing the correct materials, interacting with the correct site elements and locations at the correct point in the narrative, and successfully achieving tasks that relate to Willson's inventions, in particular, the production of fertilizer that was the primary purpose of the Meech Creek plant. The game is won when all challenges have been complete.

One primary challenge of the Carbide Willson Mill Ruins Virtual Heritage Experience includes solving puzzles and answering questions posed by an introductory character in the mill. The user is tasked with exploring the site and interacting with various elements, such as the concrete base of the acid

\footnotetext{
72 "Willson Ruins," Capital Gems, Accessed February 10, 2017.
} 
condensation tower, to discover the answers to specific questions through interactive story-telling. Stories that relate to the site's intangible values will shed light on how the site would have been experienced during the tenancy of Thomas Willson. These stories include, but are not limited to, Willson's numerous patents, the fire that occurred at the acid condensation tower, and the flooding of the dam.

Interactivity with items in the game world: In order for the user to feel part of the game world, they must be able to interact with elements within the virtual environment. In its simplest form, voice overlays explaining locations and historical moments that are triggered when the user approaches a unique space or object are effective in promoting interactivity. Recreations of Willson and other characters may populate the game space, and, depending on the technologies utilized, clickable artefacts and interactive objects will enhance the user's experience. As the site is rich in history, allowing the user to interact with historical moments and become part of the story line will ensure a rich, interactive and immersive experience.

Specifically to the Carbide Willson Mill site, interactive items include the nearby dam, architectural features of the ruins, the remnants of the adjacent industrial outbuildings, etc. Layers of artistically represented visual information will be integrated into the game experience, demonstrating to the user the original uses and intentions of particular elements of the site that currently lie in ruin. Interactions will be part of the narrative and address the requirements of the challenges set out as per the cognitively demanding environments. 
Consistent behavior from things in the game world: As the game could offer an experience in modern time, within the site of the ruins, or as a recreation of the historic original, consistency in historical time periods is a significant item to be addressed. If experiencing a recreation of the historic site, items such as cell phones and modern clothing would be out of place. Likewise, if the game represents the modern context of the site, having an historical figure appear in 1800's clothing will result in inconsistent experiences.

\section{Evaluate.}

Following a user's experience of the virtual heritage project, the success of the Carbide Willson Mill virtual heritage experience can be measured by analyzing the user's newfound knowledge and appreciation for the site itself. Has the experience successfully demonstrated the site's unique history in a way that promotes an empathetic relationship with the cultural heritage? The most basic way to answer that is to pose the question "Do you think the site has value?" to the user following their experience of the game. If the user acknowledges the site to have cultural or heritage value beyond the material value of the physical structure, and they acknowledge they have gained an appreciation of the site through their own experience of it, the intention behind the project has likely been realized. In the event a user removes the headset and is not affected in a manner beyond simply acknowledging a visual experience, the project has perhaps not achieved a high enough level of cognitive immersion, and step 3 should be revisited. As the game does not claim to recreate intangible values, rather it offers the opportunity for the user to experience said intangible values in a game world, it is difficult to measure 
the successes of the proposed experience, as intangible experiences are user dependent. As such, ongoing discussions between user and game developers are essential in the analysis and study of such proposed projects.

\subsection{Documentation, Technology, and Methodology}

In order for the above-mentioned characteristics to prove successful, it is essential to create an environment that is visually accurate and stimulating to the user to ensure the virtual environment proves convincing enough to the user. As virtual heritage references an existing place, in the event that the site has not been lost to degradation, ruin, or other sources of loss, it is crucial to ensure the site is appropriately documented and translated into a virtual environment that is both accurate and honest to its material counterpart.

Numerous technologies exist that allow for precise on-site documentation, such as laser scanners and digital cameras, and many of these have been utilized to full potential for various virtual reality projects around the world. For the Carbide Mill site and this project specifically, I explored various methods of digital documentation to draw a conclusion as to which method best suited this site.

The site was recorded through laser scan point cloud data in 2013 through collaboration between the Carleton Immersive Media Studio and the Architectural Institute in London, England. The scan data recorded the structure and surrounding site though a series of point cloud scans, merged together to form a complete model. Utilizing this point cloud data, a mesh can be formed, and an accurate digital 
recreation can be formed. From this data, measurements can be taken, and a model can be created based on the information gathered from the scans.

This was my first approach in creating the virtual environment; however, it proved unsuccessful in that the scan data was not dense enough to create a virtual image that rivalled reality. Due to the complicated site and many trees surrounding the structure, the scan data is overly complicated, inconsistent, and not adequate to create a realistic representation of the site itself for the purpose of this thesis. The scans did, however, provide invaluable data regarding form, scale, and massing of the mill ruins, and provided a method in which accurate measured drawings could be created.

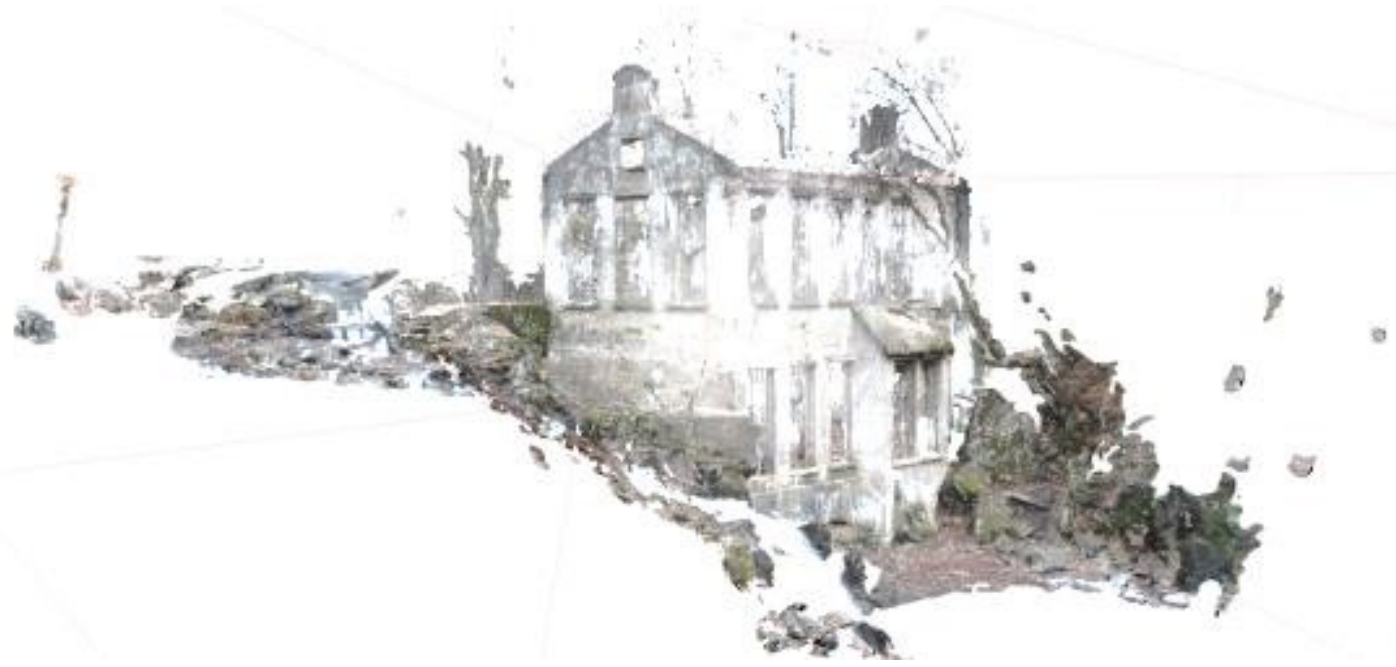

Illustration 13 Pointcloud, Carbide Willson Ruins. Author.

Photogrammetry has proven an exceptionally powerful tool for on-site documentation. Through a series of overlapping photographs, a computer program can measure the distances of a place and create an accurate three-dimensional mesh of the documented area. Photogrammetry is particularly successful when the target 
object has enough uniquely-dispersed details to recognize and pair from each photograph but is simple enough that the program does not confuse elements, resulting in an inaccurate and incomplete mesh.

I documented the site using photographs intended for photogrammetric modelling, however, due to the simple and uniform texture of the structure and the numerous trees infiltrating the target object area, the resultant mesh was still not accurate enough to rival reality. While the results of this test were more desirable than the mesh created from the point cloud, the site proved too difficult for photogrammetry without more specialized equipment or site manipulation.

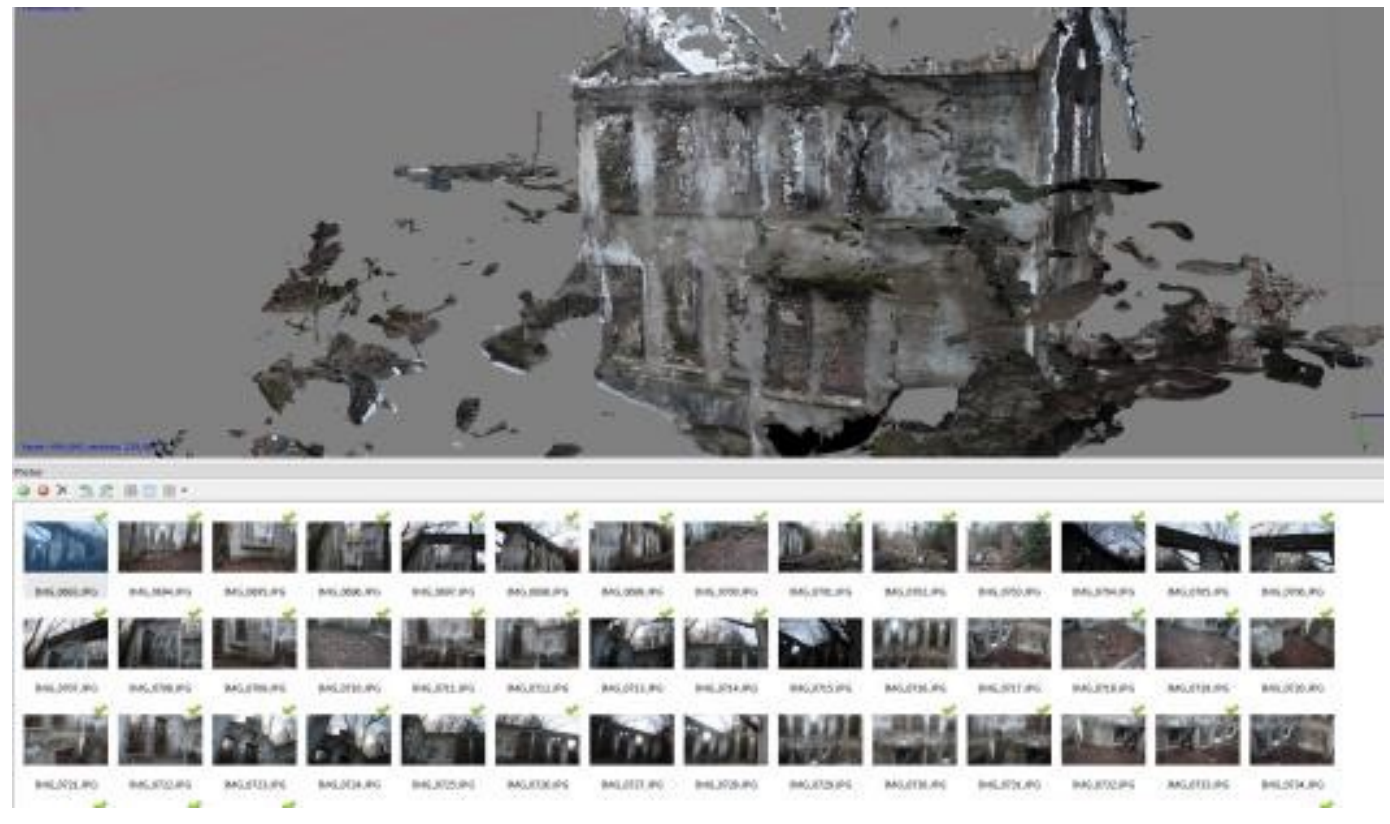

Illustration 14 Photogrammetry, Carbide Willson Ruins. Author.

The third method of documentation for the purpose of a virtual reality model was using a series of continuous photographs to create a three-dimensional photosphere. This method varies from the previous two as it does not rely on a computer to create a model or mesh of the site, rather it focuses on simply the visual environment in 
creating a photographic sphere from the position of the photographer. Through a series of photographic spheres, I was able to document the site from various angles and vantage points. The results were far superior to the previous methods. In fact, the results are so accurate, that it does in fact rival the experience of being on-site, albeit only visually. The drawback to this method, as previously mentioned, is the inability to create a mesh of the target object, but in consideration of what is required in order to experience spatial presence in a virtual environment, the photo spheres are adequate for our purpose. Through linking a series of these photographic spheres, we are able to recreate the experience of walking through the site without being visually reminded through inconsistencies in the environment that you are within a virtual recreation of space rather than in the space itself.

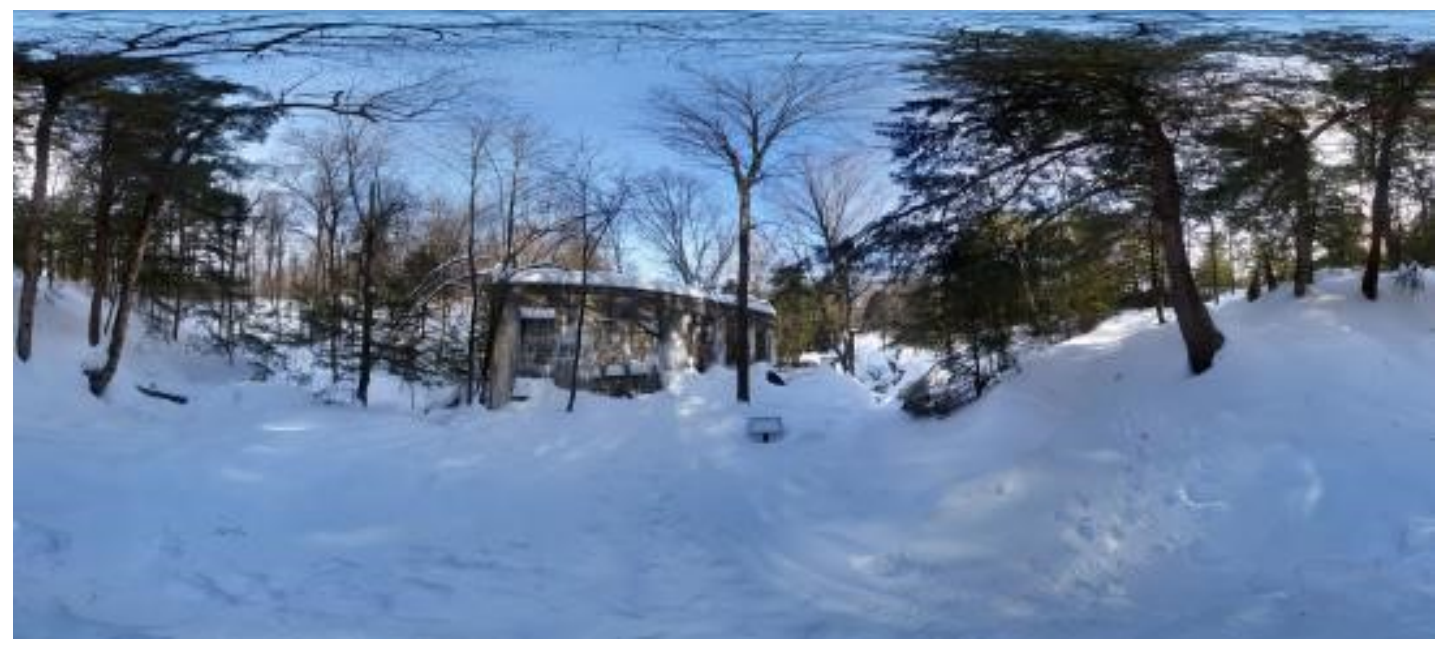

Illustration 15 Photosphere, Carbide Willson Ruins. Author.

The result of my experiment of applying three different methods of documentation has concluded that for the purpose of an experiential virtual tour or game-like environment photographic spheres are superior in their visual consistencies and adequate for our purpose. Interestingly, however, the final method was the only 
approach completely un-reliant on specialized equipment or software. Any visitor can document a site using this method with nothing but a smartphone and a free integrated application. Any user, either a professional in the field or a visitor to the site, can document the site accurately and through simple technologies that they already have on-hand. Not only does this open the field to outsiders, which is an intriguing concept in itself in terms of educational barriers and sharing of knowledge, but implies that a documented game-world could be infinite, growing every time a user visits the site and contributes more data to the project. This crowdsourcing of data has the potential to greatly increase user connection to the project as user have the ability to directly contribute to the world in which they will experience through virtual space.

Most intriguing, however, is that the two primary methods of visual recreation utilized data to recreate model-like forms of the physical characteristics of the site. The photographs and point cloud scan data were processed and used to form a digital recreation of the site. In considering the intent of this thesis and the research findings which suggest it is the experience that is of value, not the material object, it is interesting how the two methods that focused solely on recreating the material elements proved insufficient in creating a believable visual environment.

The photographic spheres, while lacking in the data necessary to create digital models and meshes of the three-dimensional site elements, offered a better experiential opportunity and will allow us to focus on the virtual experience, specifically for the user, and not on the material objects themselves. The use of the photographic spheres strengthens the proposal that through immersive experiences, a 
user can experience intangible values and emotional connections, which are, ultimately, not reliant on the value of the material object itself. As per the modern definition of heritage, these ties are further strengthened.

The proposed game integrates both raw un-manipulated photosphere data and artistically-rendered images in the virtual game experience. The former is utilized as a modern-day virtual tour of the site, offering the user the opportunity to explore the site as it exists today. The latter is utilized in the game itself, offering a consistent visual environment that allows layers of new information to be integrated into the game world in a congruous manner. The resultant game world offers the user the opportunity to experience both accurate modern representation and artistic historic interpretation in a single virtual heritage experience. 


\section{Chapter: Conclusion}

Heritage — as defined as an intangible overview of cultural, historic, and personal value systems that surround any unique historic artefact or place—is a dynamic, ever-changing thing. Cultural heritage allows for an appreciation of an historical site in a way that encompasses far more than simply the monetary or aesthetic value of a material object. The importance we place on heritage is human and complex, and our experiences of said heritage change from user to user. As a result, representations and educational displays of cultural heritage need to address these dynamic values and experiences that are constantly in flux.

By definition, cultural heritage comprises both tangible and intangible elements and values, and as such, if we are to offer a complete experience of heritage in virtual reality, both sets of values must be addressed. The methodology outlined in this thesis proposes the creation of an environment that does not directly communicate the values or histories of an historic site, rather an environment that allows its user to shape their own experiences and value systems in a virtual world in a way that is as dynamic, complex, and unique as the user. If the definition of heritage is userdependent, then so must the environment that claims to represent it. As such, this thesis does not propose a method of digitally recreating intangible heritage, rather it proposes a methodology that creates environments that specifically allow a user the opportunity to create their own intangible experiences within a game world.

Based on an investigation into the video game industry's ability to create virtual environments capable of allowing its users the ability to experience the intangible- 
newly imposed values, belief systems, emotional and empathetic relationships between their own minds and the virtual space in a completely fictional environment - we can conclude that the sheer ability to promote complex intangible experiences through virtual means exists in the technology we have today. Or, at least, through the technology we have today. Drawing from the lessons learned through these various gaming systems and methodologies, and in analysis of the framework proposed to achieve spatial presence in a virtual world, we are offered an opportunity to experience far more in an architectural virtual space than simply the sensory reproduction of material objects, as has been the focus of architectural models and re-creative experiences to date.

Through the application of characteristics drawn from the framework for spatial presence in relation to a particular site, we are offered the opportunity to experience the full, complex and ever-changing intangible definition of architectural and cultural heritage. No longer are we limited to the five senses in our experience of virtual space, but an entire world of possibility has opened in our understanding of virtual experience and historic experiential recreation.

As the experiential methods proposed in this thesis are new to the architectural and heritage industries, it is crucial that research continues to further our understanding of how such methods work, particularly with existing historic sites and monuments. To fully understand the opportunities and limitations offered by the proposed methodologies and framework for achieving spatial presence in a virtual historic environment, we need to continue an ongoing investigation into the technologies, applications, and proposed virtual experiences, which should include comprehensive 
user group studies of both public and professional audiences. As creators of proposed virtual heritage experience, we must ensure the virtual reality experiences are both educational and honest in their depiction, as uninformed users are likely to accept the virtual models as authoritative. ${ }^{73}$ We must ensure the level of accuracy and interpretation are clearly communicated as part of the experience.

The following list of questions requires further exploration and goes beyond the limits of this thesis as it is submitted in 2017.

1. Is there a categorical difference in our experience of a virtual environment that is purely fantasy versus one based on real-world documentation and data?

2. How do we ensure an authentic experience and prevent forcing inauthentic or false experiences?

3. Will an immersive VR experience based on an historic site alter one's perception of the site itself? If so, how?

The results of this proposal suggest an ongoing exploration into the complex and ongoing definition of cultural heritage and the opportunities virtual game-like worlds represent in the future virtual reality experiences. The prospect that we are no longer limited by technology as it relates to psychological and emotional experience is exciting, and the possibilities are endless regarding the experiences we can shape for

${ }^{73}$ Bernard Frischer, "Mission and Recent Projects of the UCLA Cultural Virtual Reality Laboratory," Virtual Retrospect (2003): 65-74. 
future generations and how they experience cultural, architectural, and industrial heritage. 


\section{Bibliography}

American Chemical Society. "Commercial Process for Producing Calcium Carbide and Acetylene," Accessed February 2, 2017.

https://www.acs.org/content/acs/en/education/whatischemistry/landmarks/calciumcarb ideacetylene.html

Anne Frank Stichting. "Anne Frank House, a museum with a story." Accessed March 1, 2017. http://www.annefrank.org/en/Museum/

Anne Frank Stichting. "Diary of Anne Frank on UNESCO documentary heritage list," (2009) Accessed March 1, 2017.

http://www.annefrank.org/en/News/News/2009/UNESCO-documentary-heritage-list

Araoz, Gustavo. "Protecting Heritage Places under the New Heritage Paradigm \& Defining its Tolerance for Change: A challenge for ICOMOS.” (2009): 4.

Bloom, B.S. (Ed.). Engelhart, M.D., Furst, E.J., Hill, W.H., Krathwohl, D.R. Taxonomy of Educational Objectives, Handbook I: The Cognitive Domain. New York: David McKay Co Inc.,1956

Brown, Mark. "British Museum exhibits viewable online thanks to Google partnership." The Guardian, November 12, 2016. Accessed February 5, 2017. https://www.theguardian.com

Burdea, Grigore C. \& Coiffet, Philippe. Virtual Reality Technology, $2^{\text {nd }}$ Edition. New Jersey: Wiley-IEEE Press, 2003.

Capital Gems. "Willson Ruins.” Accessed February 10, 2017. http://www.capitalgems.ca/willson-ruins.html

Carleton Immersive Media Studio. ““'Senate Tour.” Accessed March 14, 2017. http://tour-ext.sencanada.ca/tour/index.html

Chu, S. \& Downes, J. “Odour-evoked autobiographical memories,” Chemical Senses 25 (2000): 111-116. https://chemse.oxfordjournals.org/content/25/1/111.full

Denard, Hugh. "A New Introduction to The London Charter," Accessed March 1, 2017. http://www.londoncharter.org/fileadmin/templates/main/docs/ch6_denard.pdf

Ducheneaut, N., Yee, N., Nickell, E., \& Moore, R.J. "Building an MMO With Mass Appeal,” Sage Journals, V.1-4 (2006) Accessed January 5, 2017. 
Fontaine, G. "The experience of a sense of presence in intercultural and international encounters." Presence: Teleoperators and Virtual Environments 1-4 (1992): 482-490. http://www.mitpressjournals.org/doi/abs/10.1162/pres.1992.1.4.482?journalCode=pres \#.WNpo9m_yuCg

Frischer, B. "Mission and Recent Projects of the UCLA Cultural Virtual Reality Laboratory," Virtual Retrospect (2003): 65-74.

Golub, A. "Being in the World (of Warcraft): Raiding, Realism, and Knowledge Production in a Massively Multiplayer Online Game," Anthropological Quarterly V. 83-1, Institute for Ethnographic Research (2010): 17-46.

Google. "Google Cultural Institute," Accessed February 5, 2017. https://www.google.com/culturalinstitute/about/partners

Government of Canada. "The Canadian Heritage Information Network." Accessed February 13, 2017. http://www.rcip-chin.gc.ca/index-eng.jsp

Granic, I; Lobel, A; Engels, R. C. M. E. "The Benefits of Playing Videogames.” American Psychologist, Vol 69-1 (2014): 66-78.

Griffiths, M. "The educational Benefits of video games," Education and Health Vol. 20 No.3 (2002): 47-51. Accessed January 3, 2017.

Ingham, Lucy. "VR Feedback Glove to Bring Back Sense of Touch to Virtual Reality," Factor (2015) Accessed February 15, 2017. http://factor-tech.com/gaming/17538-vrfeedback-glove-to-bring-sense-of-touch-to-virtual-reality

ISPR. The Concept of Presence: Explication Statement," International Society for Presence Research (2000), Accessed February 20, 2017. https://ispr.info

Jingushicho. "Ise Jingu, Rituals and Ceremonies." Accessed February 10, 2017, http://www.isejingu.or.jp/en/ritual/index.html

Jokilehto, Jukka. "Definition of Cultural Heritage, References to Documents in History." ICCROM Working Group 'Heritage and Society' (1990): 13-45.

Jones, M. T. "The Impact of Cultural Transmission through Bishoujo Games." Psychology Journal 3, no. 3 (2005): 292-311. http://www.psychnology.org/file/pnj3(3)/psychology_journal_3_3_jones.pdf

Kirshenblatt-Gimblett, Barbara. “Theorizing Heritage.” Ethnomusicology, Vol. 39, No. 3. (1995): 367-380. 
Klepper M., \& Gunther, M. The Wealthy 100: From Benjamin Franklin to Bill Gates-A Ranking of the Richest Americans, Past and Present. SNew Jersey: Carol Publishing Group, 1996.

Larson, Lincoln R. \& Poudyal, Neelam C. "Developing sustainable tourism through adaptive resource management: a case study of Machu Picchu, Peru." Journal of Sustainable Tourism 20-7 (2012): 917-938. Accessed February 5, 2017. http://www.tandfonline.com/doi/abs/10.1080/09669582.2012.667217

Lee, K.M. "Presence, Explicated.” Communication Theory 14-1 (2004): 27-50. Accessed February 2, 2017. http://onlinelibrary.wiley.com/doi/10.1111/j.14682885.2004.tb00302.x/abstract

Madigan, Jamie. "The Psychology of Immersion in Video Games." The Psychology of Video Games (2010). http://www.psychologyofgames.com/2010/07/the-psychologyof-immersion-in-video-games/\#foot_text_514_2

Mera, Miguel. "Towards 3-D Sound: Spatial Presence and the Space Vacuum," in The Palgrave Handbook of Sound Design and Music in Screen Media (Palgrave Macmillan UK: 2016): 94.

Millar, Heather. "Can Virtual Reality Emerge As a Tool for Conservation?" YaleEnvironment360, June 27, 2016, Accessed February 15, 2017. http://e360.yale.edu/features/can_virtual_reality_emerge_as_a_tool_for_conservation

Minsky, M. “Telepresence.” OMNI Magazine (1980). Accessed February 2, 2017. http://web.media.mit.edu/ minsky/papers/Telepresence.html

Parks Canada. "Parks Canada's Departmental Performance Report 2013-14." Accessed February 2, 2017. http://www.pc.gc.ca/eng/docs/pc/rpts/rmr-dpr/index.aspx.

Parks Canada. "The Canadian Register.” Accessed February 11, 2017. http://www.historicplaces.ca/en/pages/register-repertoire.aspx

Parks Canada. The Standards and Guidelines for the Conservation of Historic Places in Canada.(2010)

Paton, J. "Willson, Thomas Leopold." in Dictionary of Canadian Biography, vol. 14, University of Toronto/Université Laval, 2003. Accessed February 1, 2017, http://www.biographi.ca/en/bio/willson_thomas_leopold_14E.html. 
Pletincks, D., Callebaut, D., Killebrew, A.E., Silberman, N.A. "Virtual-Reality Heritage Presentation at Ename." IEEE MultiMedia V7-2 (2000): 45-48. http://dl.acm.org/citation.cfm?id=614970

Pujol, Laia \& Champion, Erik. "Evaluating Presence in Cultural Heritage Projects." International Journal of Heritage Studies 18-1 (2012): 83-102.

Retaux, X. "Presence in the environment: theories, methodologies and applications to video games.” PsychNology Journal V 1-3 (2003): 283-309.

Roehl, D.B. "Virtual Archeology. Bring New Life to Ancient Worlds." Innovation 28 (1997): 35 .

Saga, M. "What It's Like to be an Architectural Consultant for Assassin's Creed II," Translated by Matthew Valletta, ArchDaily (2015), Accessed February 5, 2017. http://www.archdaily.com/774210/maria-elisa-navarro-the-architectural-consultantfor-assassins-creed-ii

Seif El-Nasr, M., Al-Saati, M., Niedenthal, S., \& Milam, D. “Assassin's Creed: A MultiCultural Read," Simon Fraser University Journals (2008) http://journals.sfu.ca/loading/index.php/loading/article/view/51

Serafin, Stefania \& Serafin, Giovanni. "Sound Design to Enhance Presence in Photorealistic Virtual Reality." International Conference on Auditory Display, ICAD 04. Sydney, Australia, 2004.

Steuer, Jonathan. "Defining Virtual Reality: Dimensions Determining Telepresence," Social Responses to Communication Technologies, Stanford University (1993) http://www.cybertherapy.info/pages/telepresence.pdf

Stone R., Ojika T. “Virtual Heritage: What Next?” IEEE Multimedia 7(2) (2000): 73-74.

The British Museum. "The British Museum with Google.” Accessed February 5, 2017. http://www.britishmuseum.org/with_google.aspx

The British Museum. "The British Museum.” Accessed February 5, 2017. https://www.britishmuseum.org/about_us/management/about_us.aspx

The London Charter for the Computer-based Visualisation of Cultural Heritage. (2009) http://www.londoncharter.org/

Ubisoft. “Assassins vs. Templars.” Assassin's Creed. https://www.ubisoft.com/enUS/game/assassins-creed/ 
UNESCO. "Historic Sanctuary of Machu Picchu." Accessed March 1, 2017. http://whc.unesco.org/en/soc/1094

University of Reading. "Virtual Reality Experience Allows You to Walk Around and Even Smell this Roman Town." Accessed March 1, 2017. https://www.reading.ac.uk/news-and-events/releases/PR703427.aspx

VR-iPhone. "FEELREAL: The Virtual Reality Mask," 2015. Accessed January 10, 2017. https://www.vr-iphone.com/2015/05/feelreal-the-virtual-reality-mask/

Wirth, Werner et al. "A Process Model of the Formation of Spatial Presence Experiences," Media Psychology 9 (2007): 493-525.

Wissmath, B, Weibel, D., \& Groner, R. "Dubbing or Subtitling? Effects on Spatial Presence, Transportation, Flow, and Enjoyment." Journal of Media Psychology 21-3 (2009): 114-125. 


\section{APPENDIX}

The following images are the raw photographic spheres (virtual tour) and artistically

rendered spheres (game) utilized in the creation of the virtual reality environment as part of the Carbide Willson Mill ruins virtual heritage proposal.

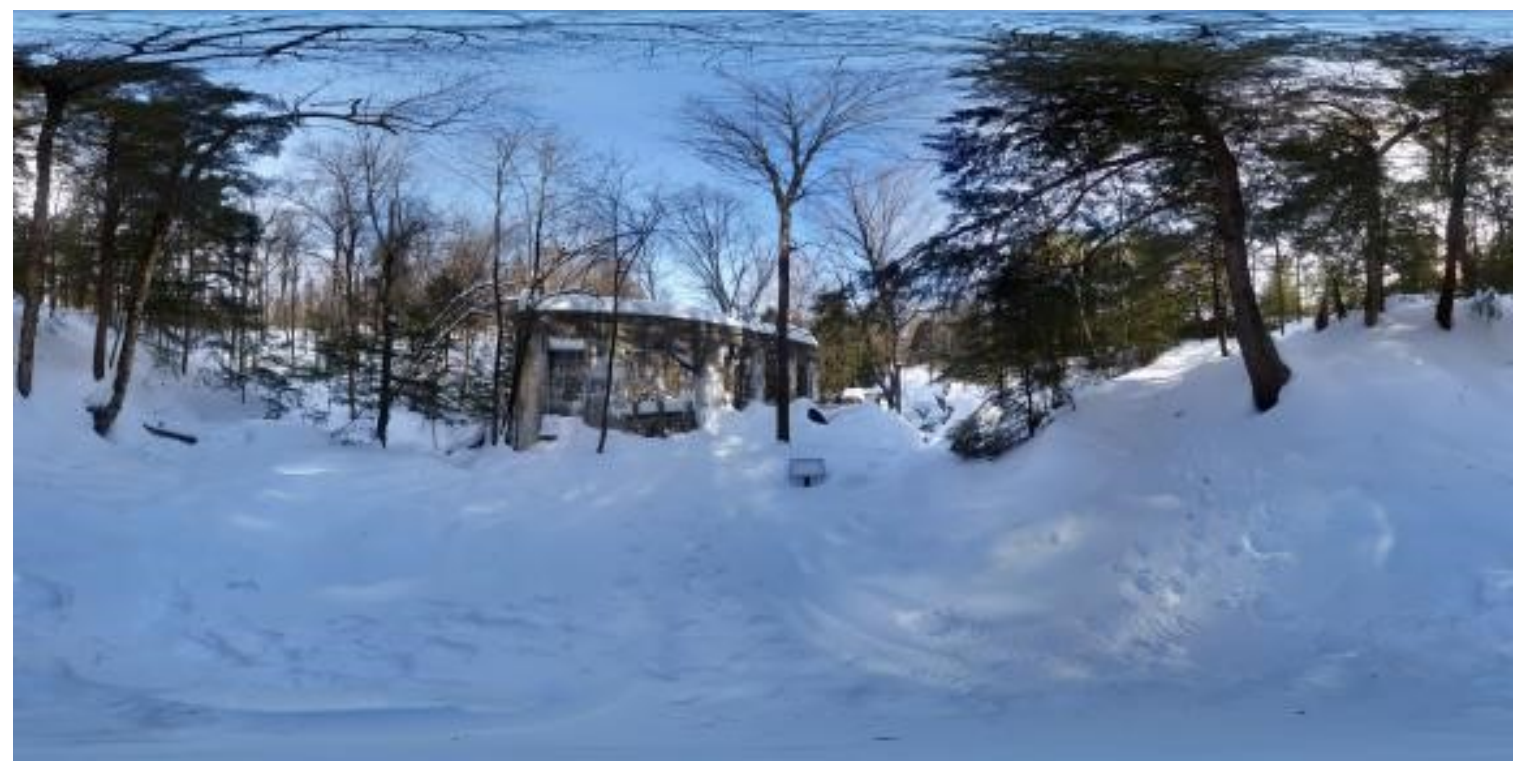

360 Photosphere 1. Author.

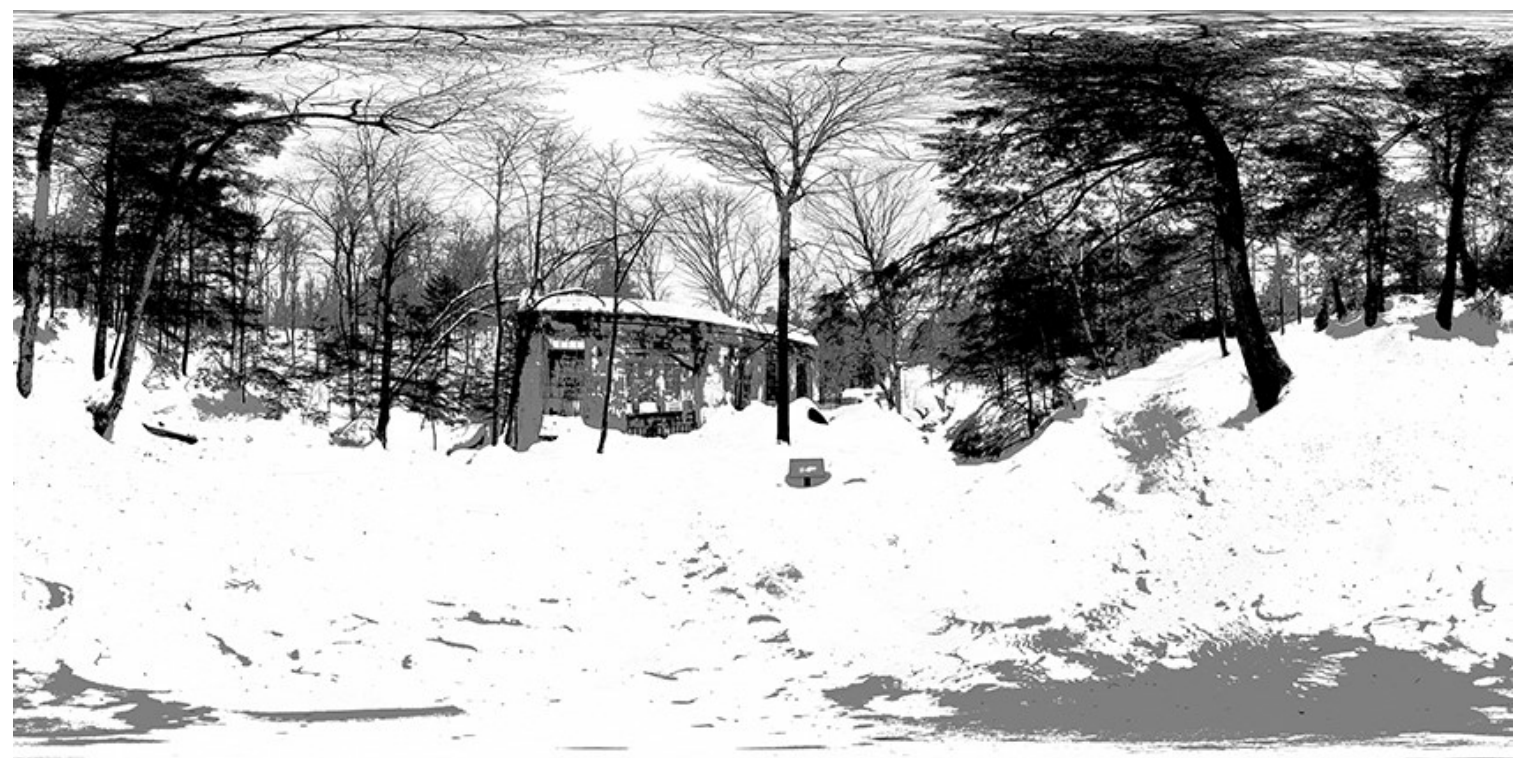

360 Edited Photosphere 1. Author. 


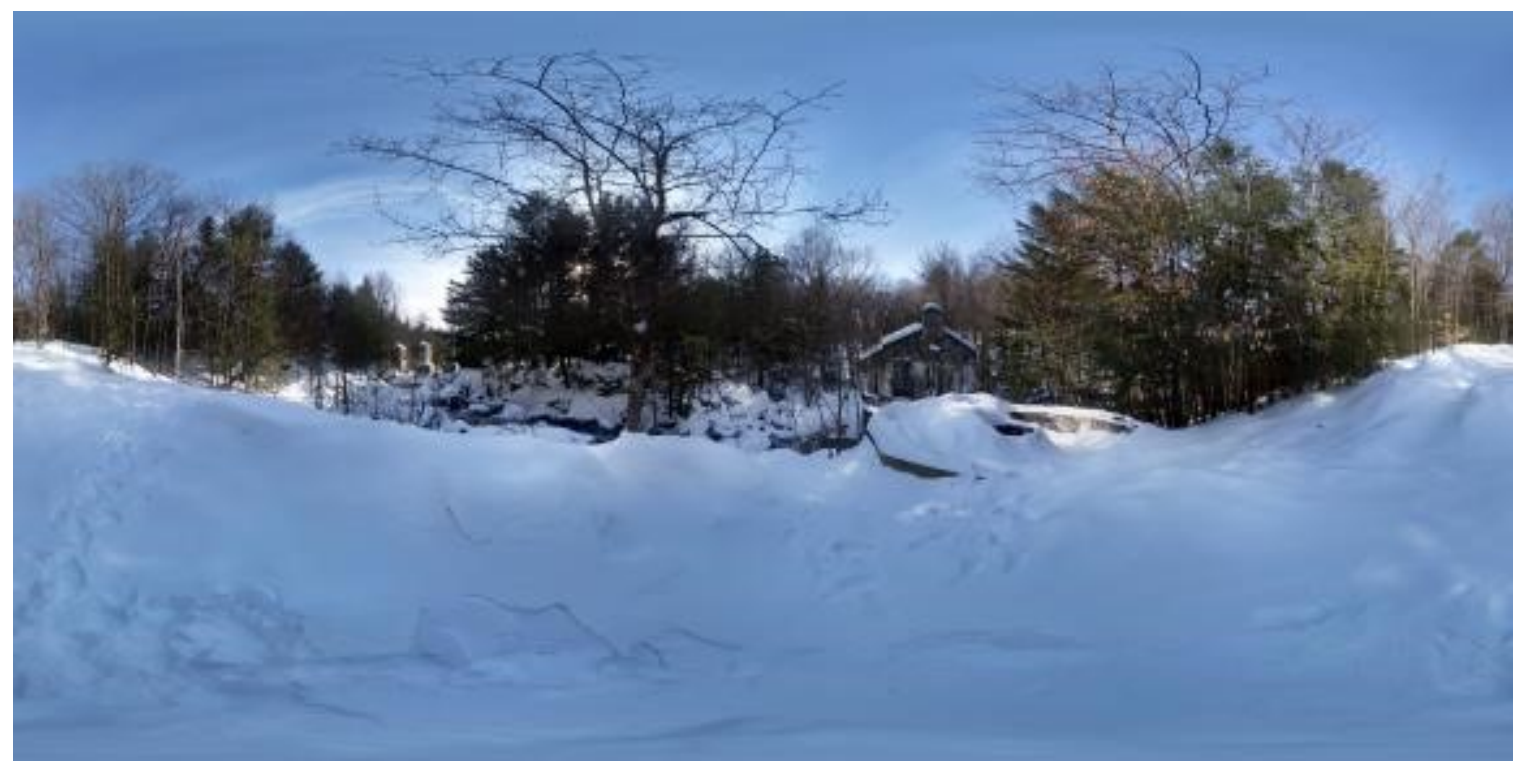

360 Photosphere 2. Author.

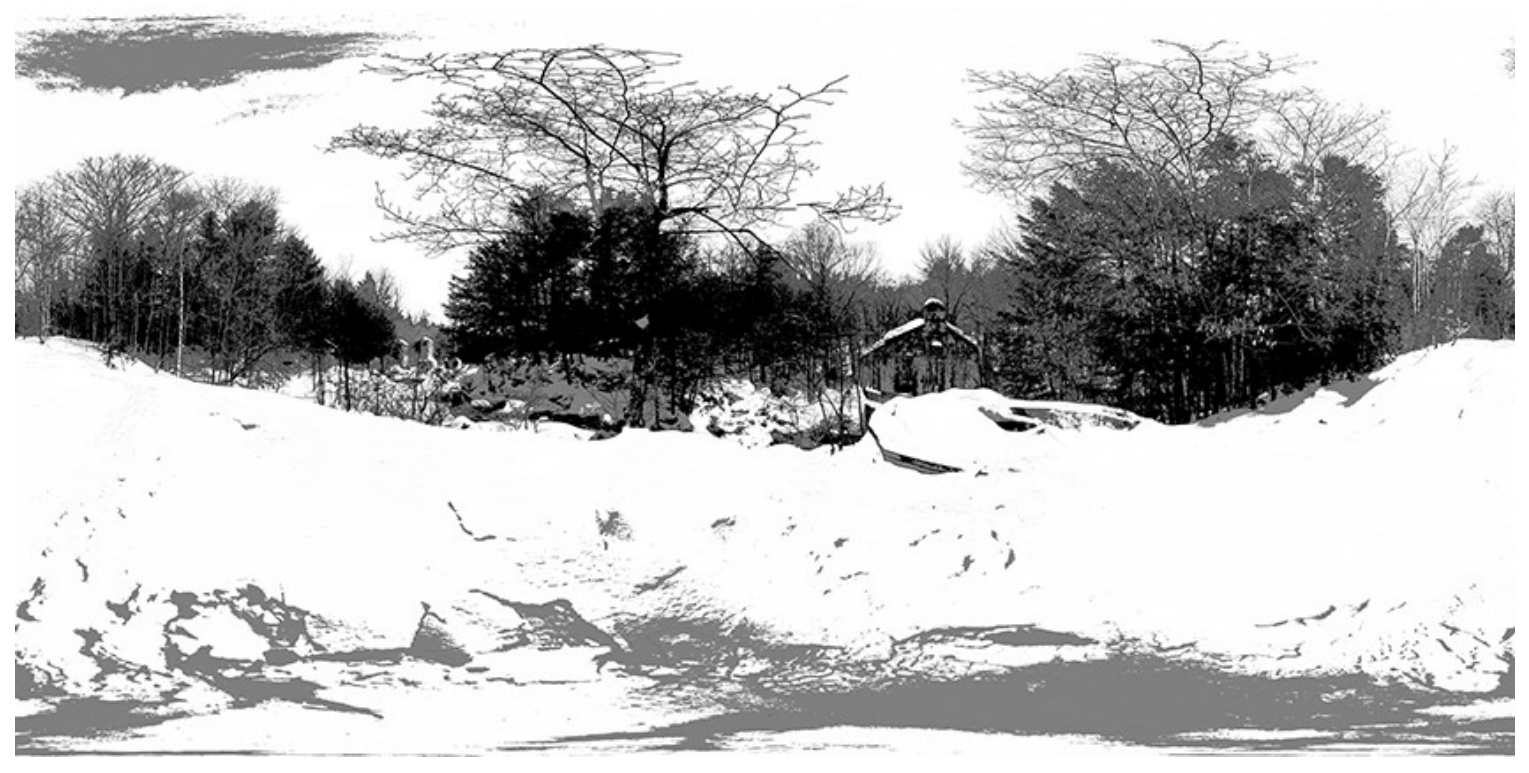

360 Edited Photosphere 2. Author. 


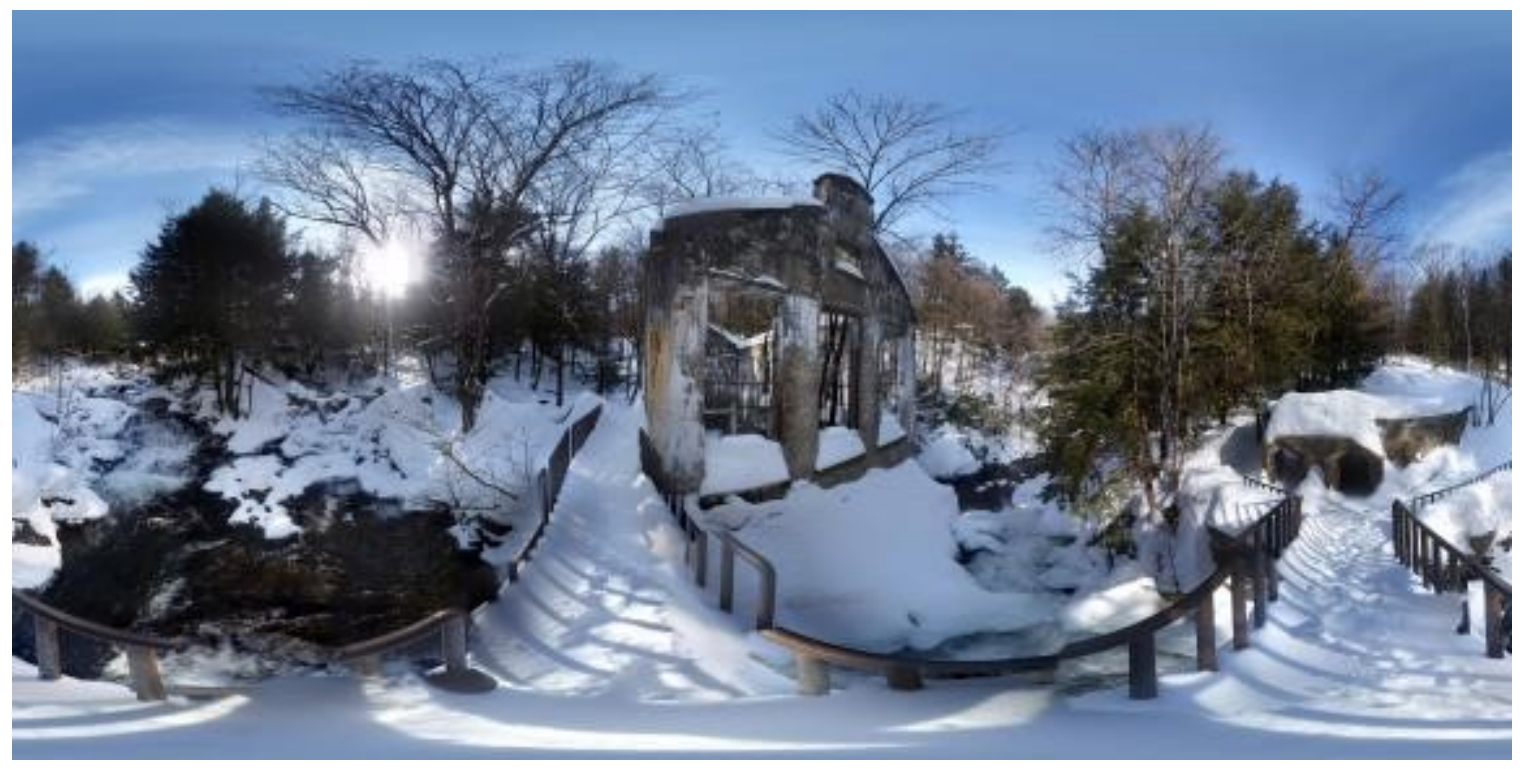

360 Photosphere 3. Author.

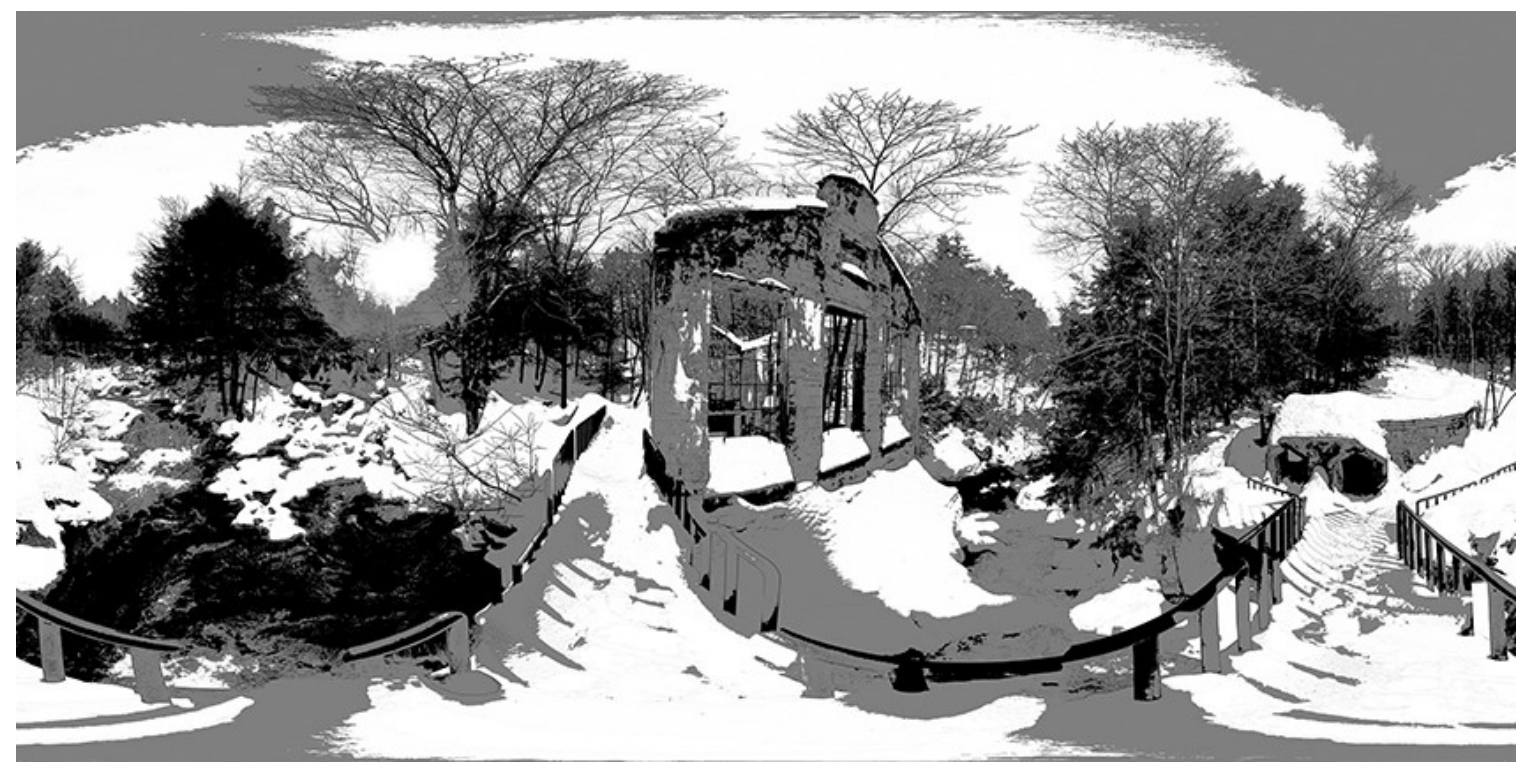

360 Edited Photosphere 3. Author. 


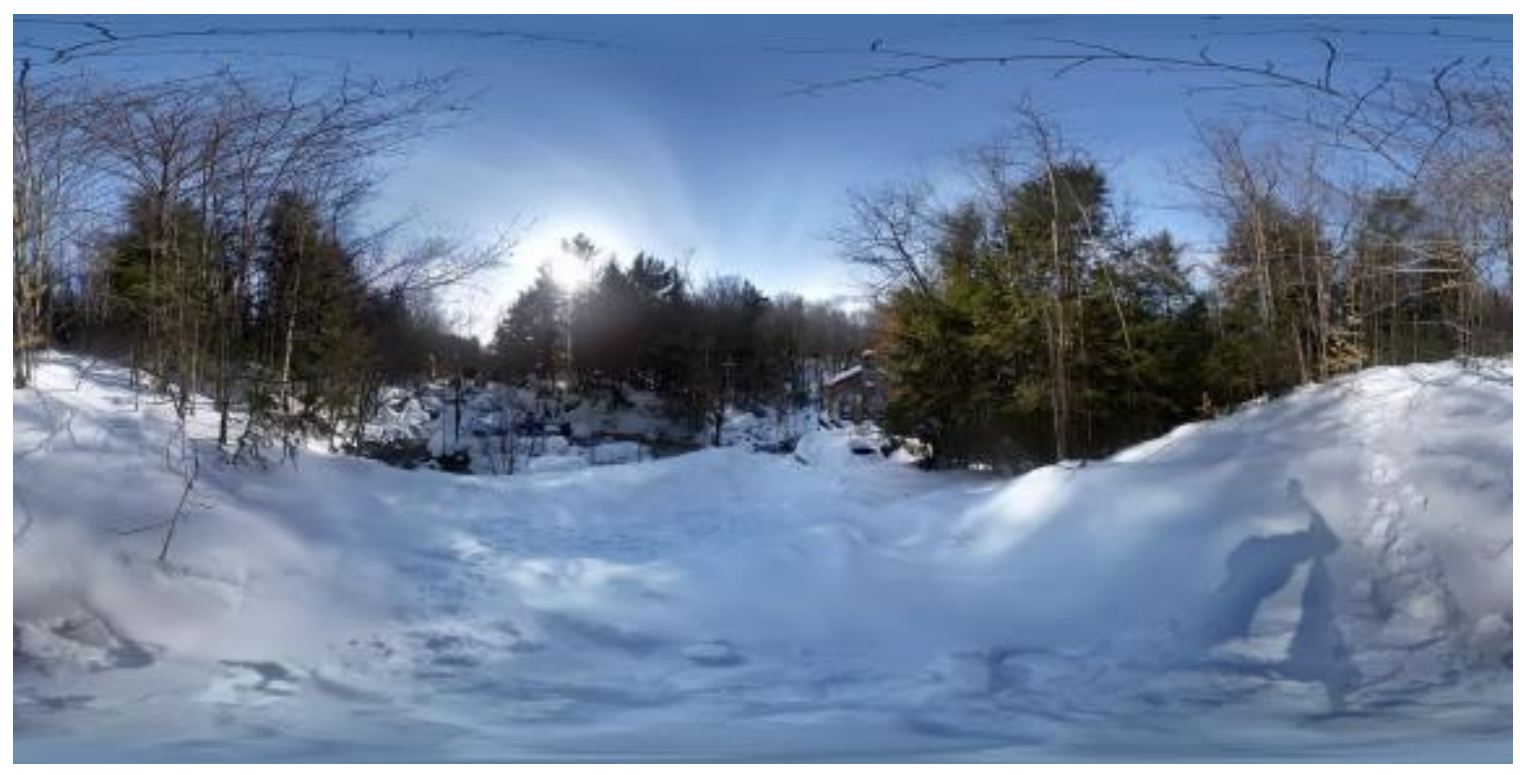

360 Photosphere 4. Author.

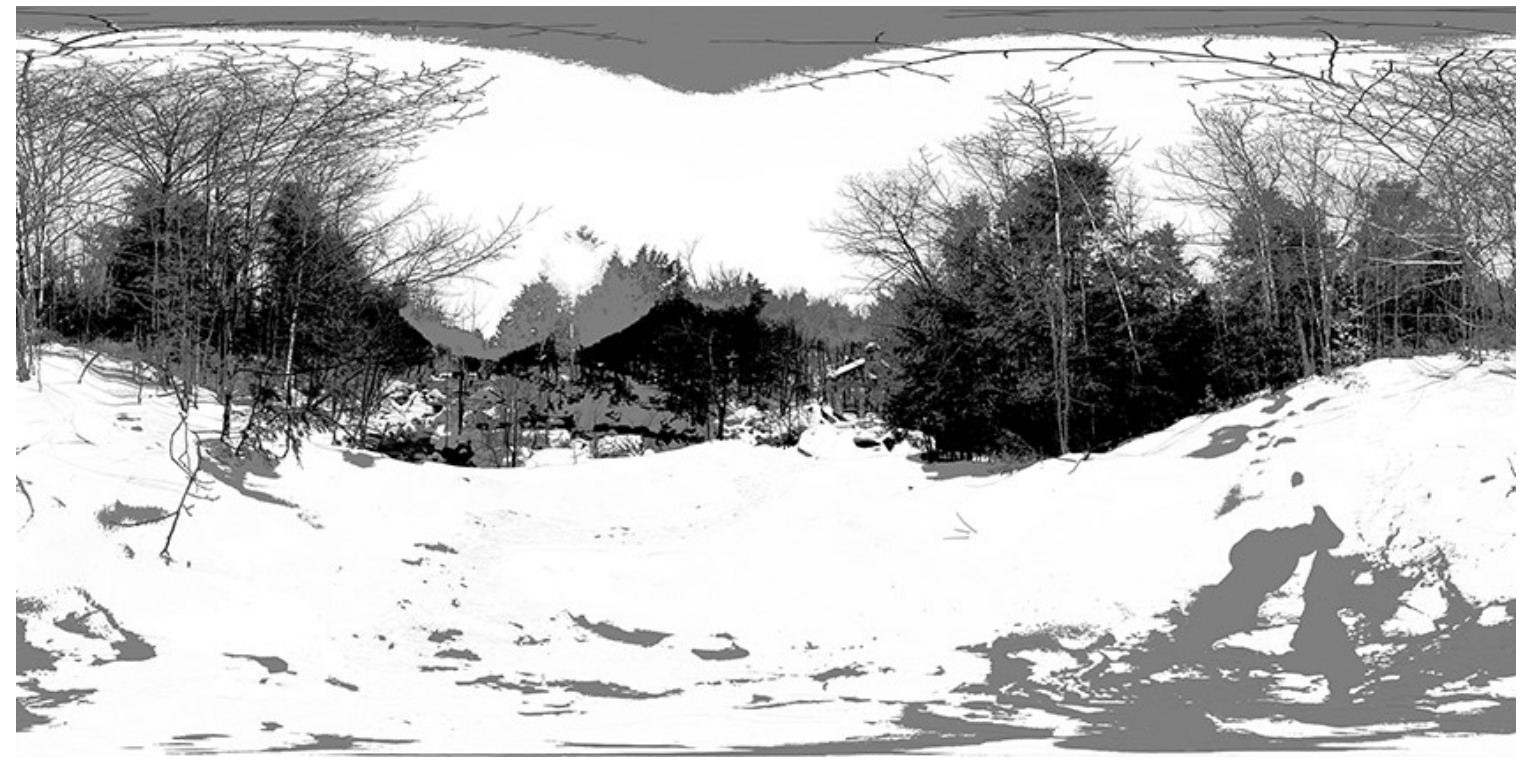

360 Edited Photosphere 4. Author. 


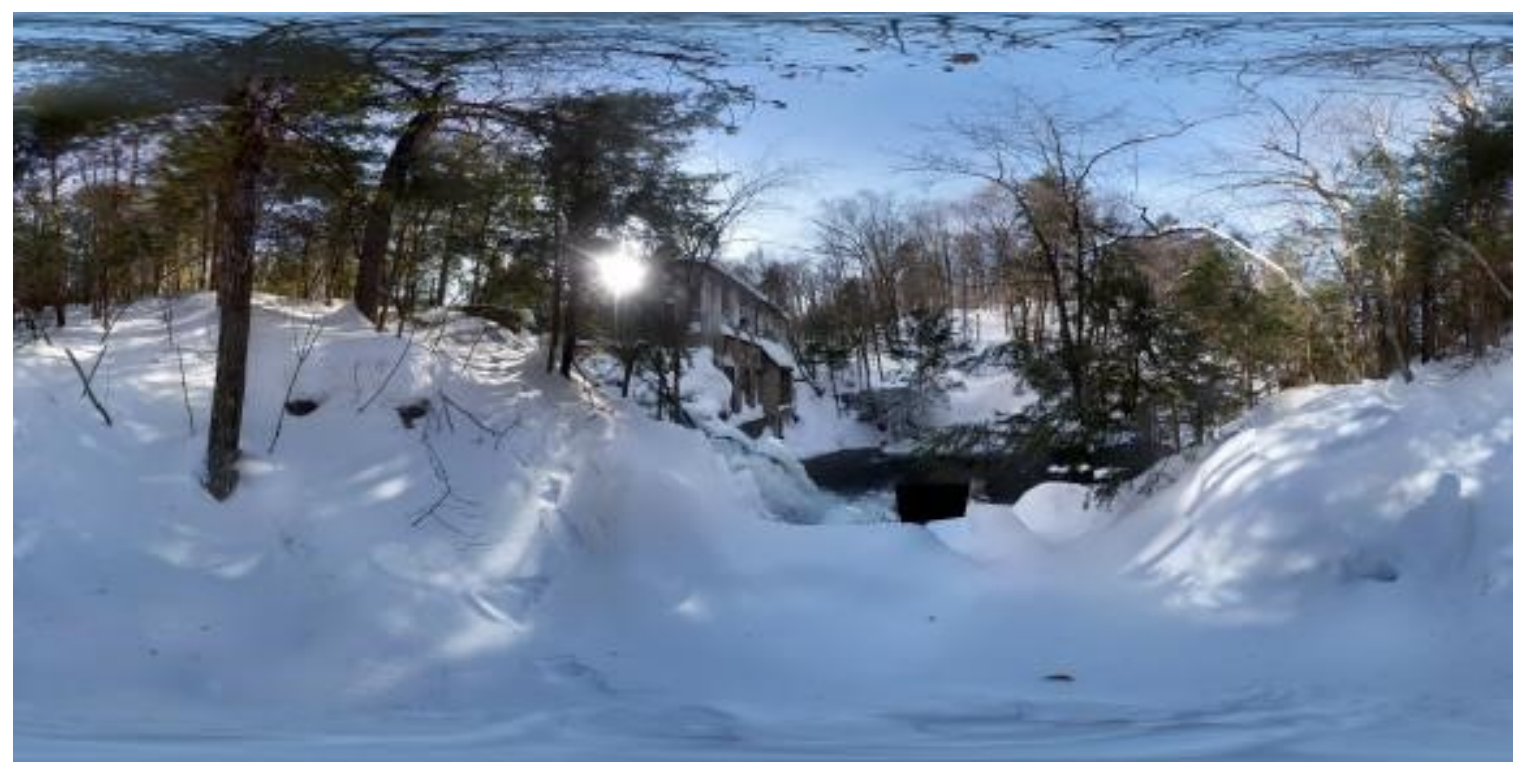

360 Photosphere 5. Author.

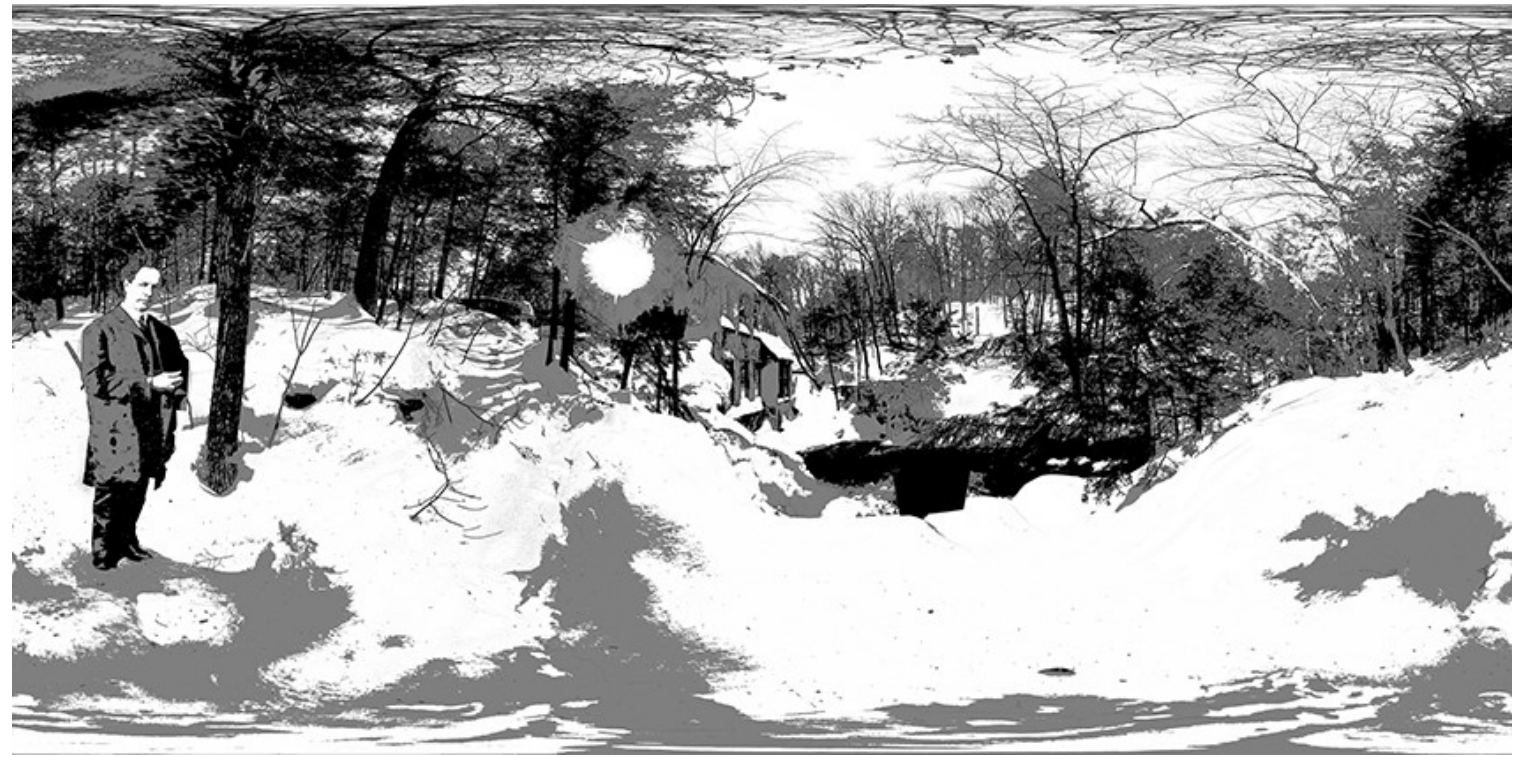

360 Edited Photosphere 5. Author. 


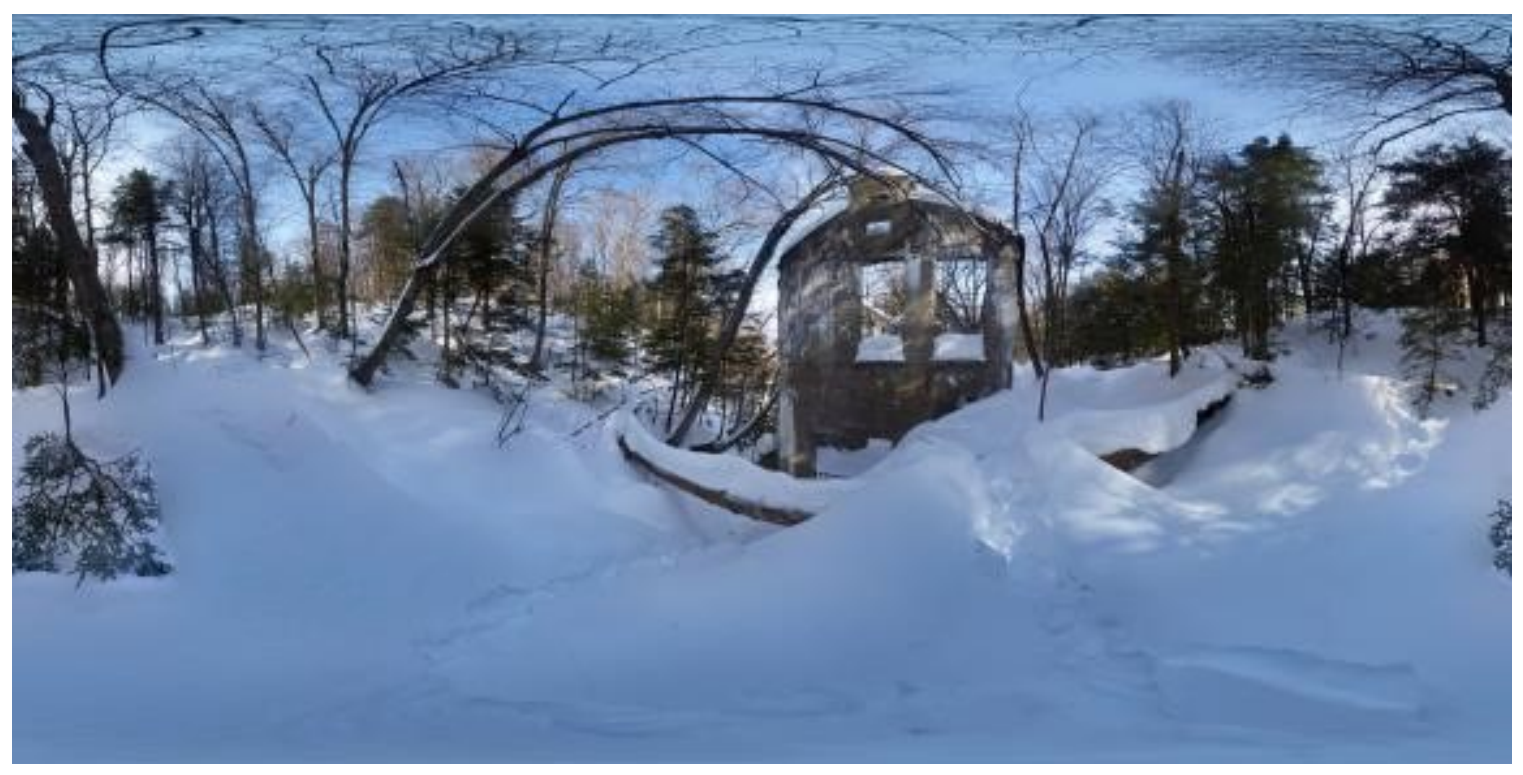

360 Photosphere 6. Author.

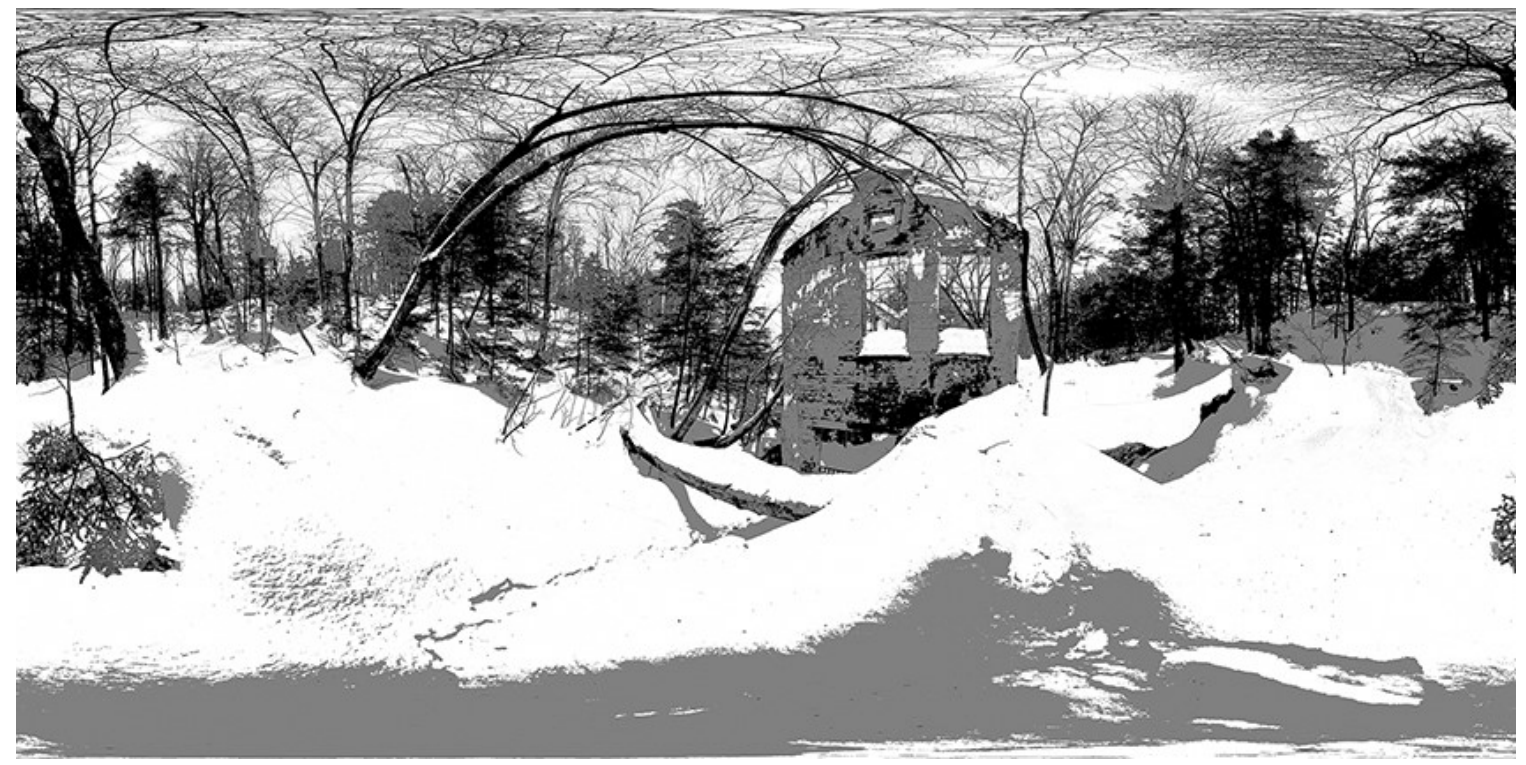

360 Edited Photosphere 6. Author. 


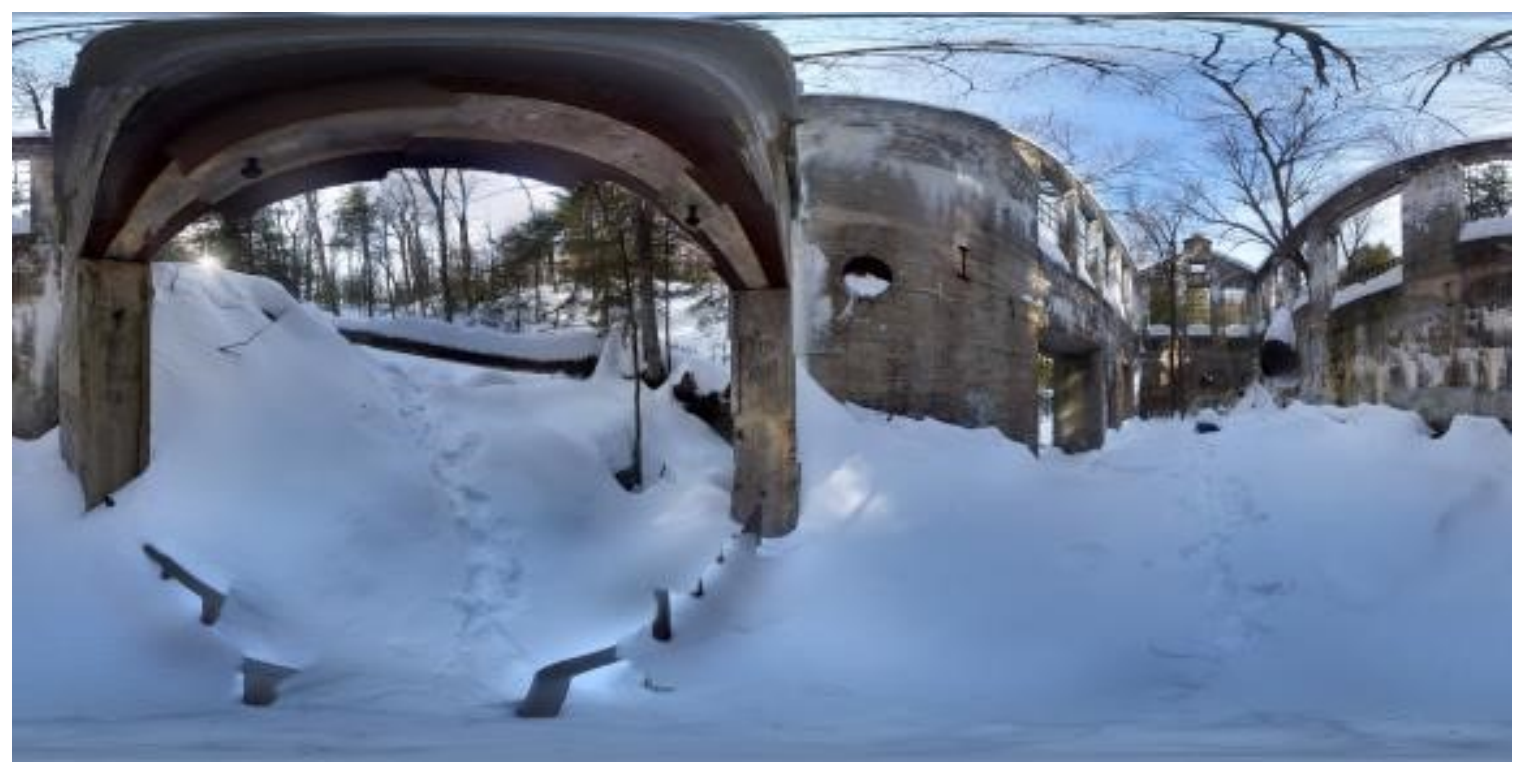

360 Photosphere 7. Author.

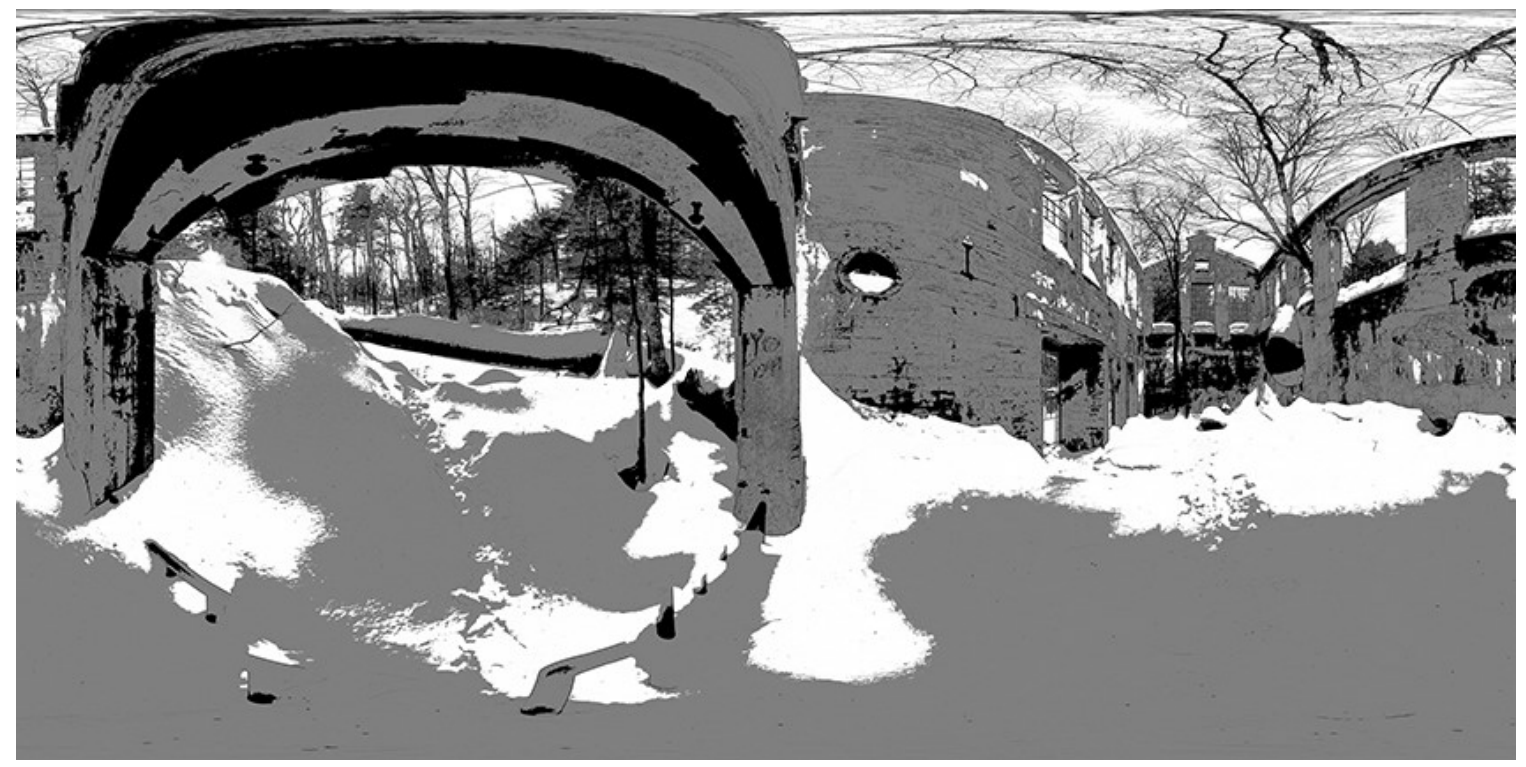

360 Edited Photosphere 7. Author. 


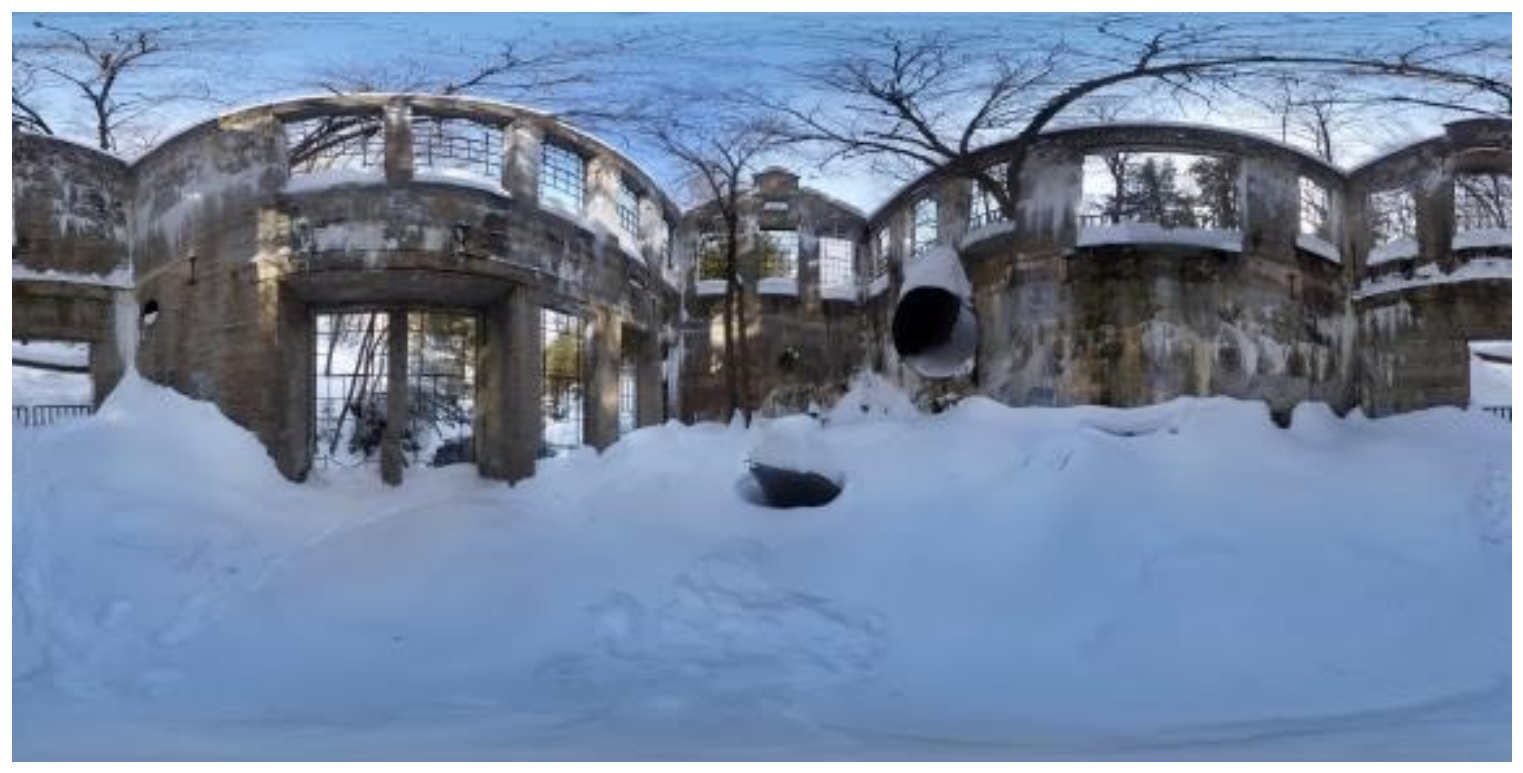

360 Photosphere 8. Author.

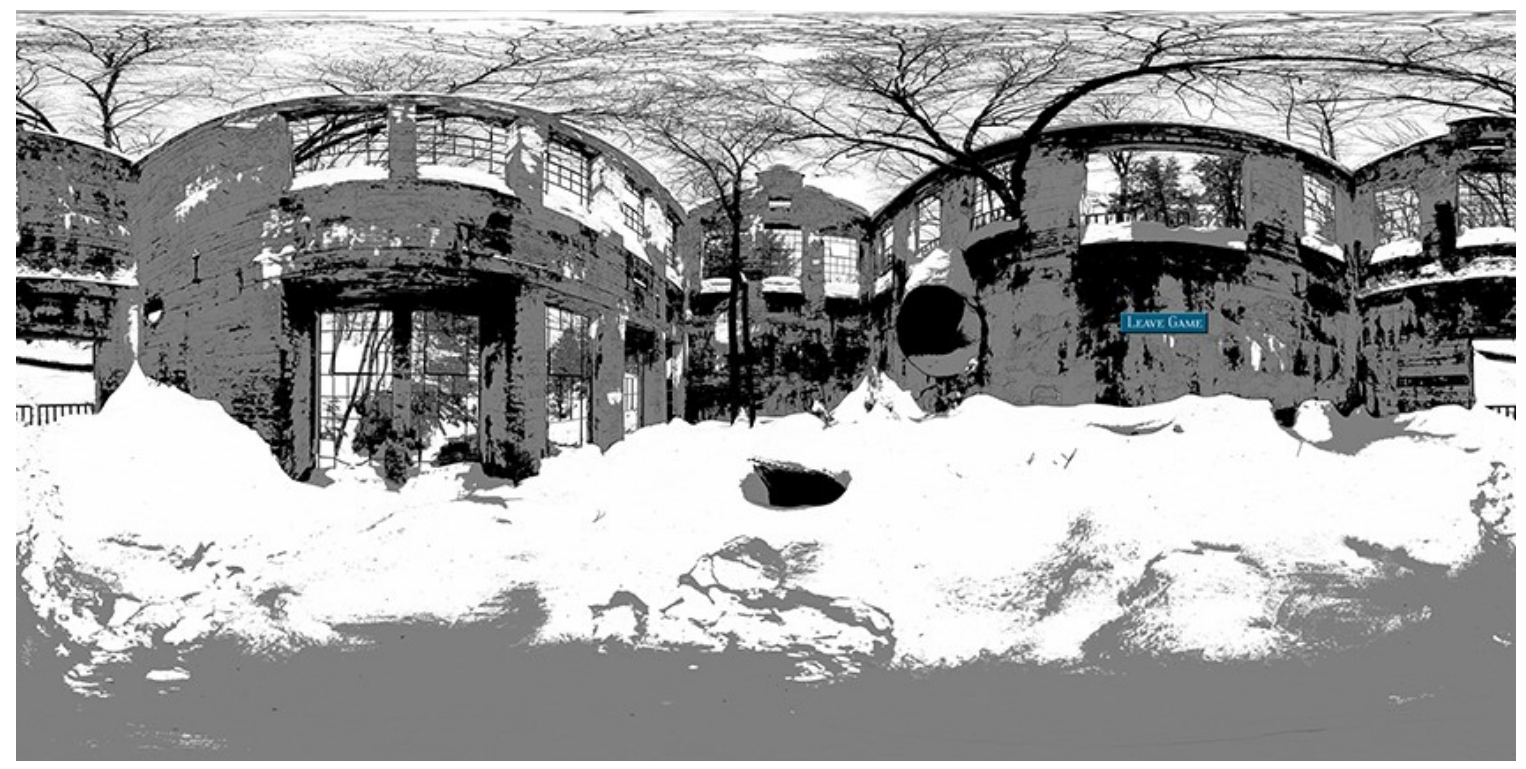

360 Edited Photosphere 8. Author. 


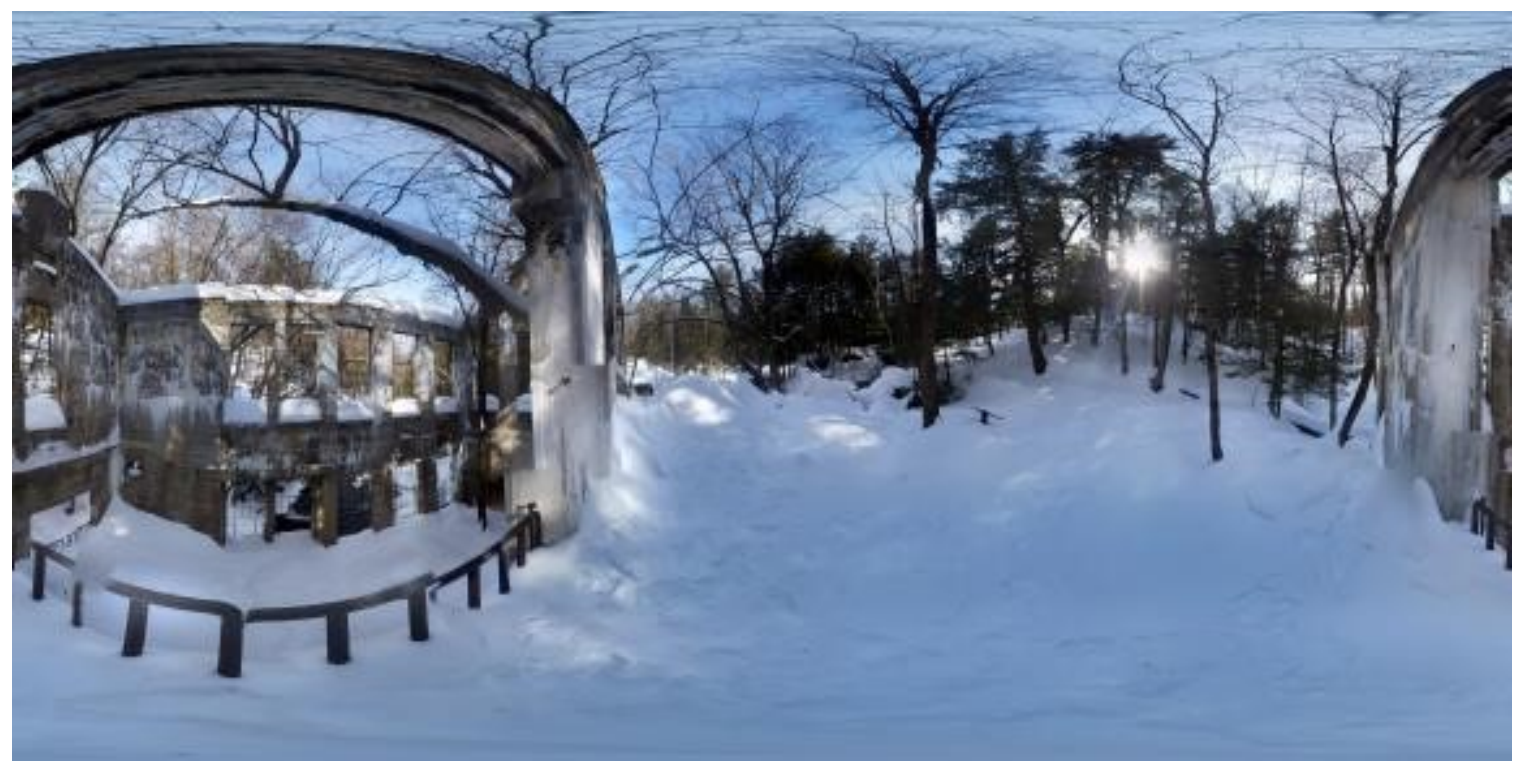

360 Photosphere 9. Author.

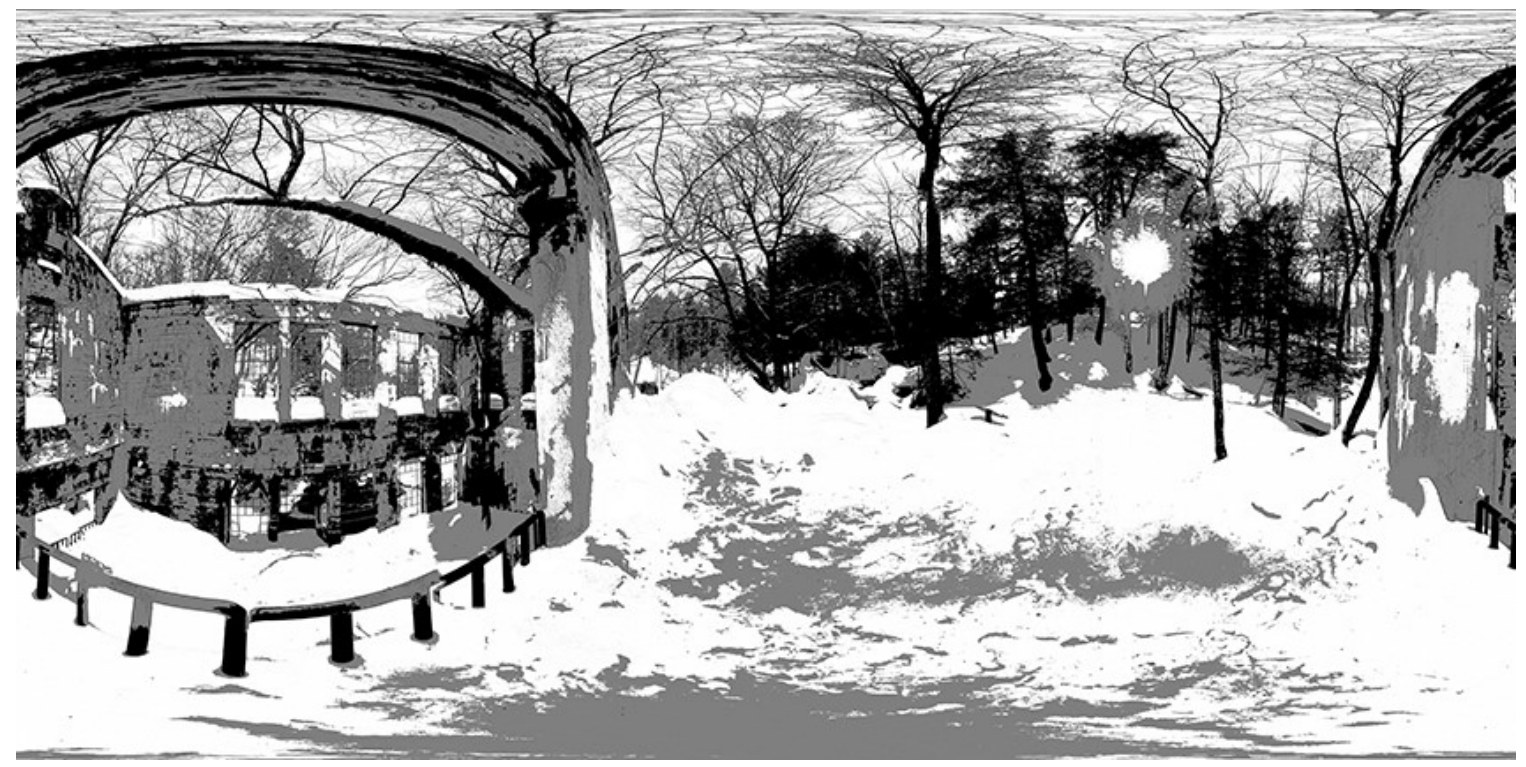

360 Edited Photosphere 9. Author. 